



\section{Chemical and Physical Hazards in the Egg Production Chain in the Netherlands}

H.J. van der Fels-Klerx ${ }^{1}$, E.D. van Asselt ${ }^{1}$, M. Pikkemaat ${ }^{1}$, R. Hoogenboom ${ }^{1}$, S.P.J. van Leeuwen ${ }^{1}$, P. van Horne ${ }^{2}$, P.E. Boon ${ }^{3}$, L. Razenberg ${ }^{3}$, M. Mengelers ${ }^{3}$, F. Leenstra ${ }^{4}$

1 RIKILT Wageningen University \& Research

2 Wageningen Economic Research

3 Rijksinstituut voor Volksgezondheid en Milieu (RIVM)

4 Livestock Research

This research was funded by the Netherlands Food and Consumer Product Safety Authority (NVWA).

RIKILT Wageningen University \& Research

Wageningen, January 2017

RIKILT report 2016.005 
Van der Fels-Klerx, H.J., E.D. van Asselt, M. Pikkemaat, R. Hoogenboom, S.P.J. van Leeuwen, P. van Horne, P.E. Boon, L. Razenberg, M. Mengelers, F. Leenstra, 2017. Chemical and Physical Hazards in the Egg Production Chain in the Netherlands. Wageningen, RIKILT Wageningen University \& Research, RIKILT report 2016.005. 58 pp.; 10 fig.; 10 tab.; 154 ref.

Project number: $1257340801+1247321601$

Project title: gevaaranalyse pluimvee eierketen

Project leader: H.J. van der Fels- Klerx

This report can be downloaded for free at http://dx.doi.org/10.18174/387371 or at www.wur.eu/rikilt (under RIKILT publications).

(C) 2017 RIKILT Wageningen University \& Research

The client is allowed to publish or distribute the full report to third parties. Without prior written permission from RIKILT it is not allowed to:

a) publish parts of this report;

b) use this report or title of this report in conducting legal procedures, for advertising, acquisition or other commercial purposes;

c) use the name of RIKILT other than as author of this report.

P.O. Box 230, 6700 AA Wageningen, The Netherlands, T +31(0)317 4802 56, E info.RIKILT@wur.nl, www.wur.eu/rikilt. RIKILT is part of Wageningen University \& Research.

This report from RIKILT has been produced with the utmost care. However, RIKILT does not accept liability for any claims based on the contents of this report.

RIKILT report 2016.005

Distribution list:

- Jos Cornelese (NVWA)

- Marca Schrap (NVWA)

- Dick Sijm (NVWA)

- Gerard Visser (NVWA) 


\section{Contents}

$\begin{array}{ll}\text { Summary } & 5\end{array}$

$\begin{array}{llr}1 & \text { Introduction } & 7\end{array}$

$2 \quad$ Material and methods $\quad 8$

$\begin{array}{lll}2.1 & \text { Literature study } & 8\end{array}$

2.2 Monitoring data $\quad 8$

$3 \quad$ The egg production chain $\quad 9$

3.1 Chain structure in the Netherlands $\quad 9$

3.1.1 Hatchery and rearing 9

3.1.2 Layer farms 9

$\begin{array}{ll}3.1 .3 \text { Egg production by laying hens } & 10\end{array}$

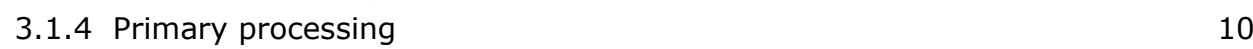

3.1.5 Further processing of egg products 10

3.2 Production figures $\quad 12$

3.2.1 Farms and companies $\quad 12$

3.2.2 Egg and egg products 12

$4 \quad$ Chemical and physical hazards 13

4.1 Chemical hazards $\quad 13$

4.1.1 Layer farms $\quad 13$

4.1.2 Primary processing $\quad 32$

$\begin{array}{ll}4.1 .3 \text { Egg processing } & 33\end{array}$

4.2 Physical hazards $\quad 34$

4.3 Most relevant chemical and physical hazards $\quad 34$

$5 \quad$ Human health implications $\quad 36$

5.1 Toxicity of dioxins $\quad 36$

5.1.1 Acute/short-term toxicity 36

5.1.2 Chronic toxicity and health based guidance values 36

$\begin{array}{lll}5.2 & \text { Exposure to dioxins } & 37\end{array}$

$\begin{array}{lll}5.3 & \text { Burden of disease } & 38\end{array}$

$\begin{array}{llr}6 & \text { Prevention and control } & 39\end{array}$

6.1 Entire egg production chain $\quad 39$

$\begin{array}{lll}6.2 & \text { Layer farms } & 39\end{array}$

$\begin{array}{lll}6.3 & \text { Processing } & 40\end{array}$

$7 \quad$ Trends and forecasts $\quad 41$

$\begin{array}{lll}7.1 & \text { Animal husbandry systems } & 41\end{array}$

$\begin{array}{lll}7.2 & \text { Feed management and import } & 42\end{array}$

$\begin{array}{lll}7.3 & \text { Egg consumption } & 43\end{array}$

7.4 Export and import of eggs and egg products $\quad 44$

7.4.1 Export of egg and egg products $\quad 44$

7.4.2 Import of egg and egg products $\quad 46$

$\begin{array}{llr}8 & \text { Conclusion } & 47\end{array}$

$\begin{array}{ll}\text { References } & 48\end{array}$

$\begin{array}{ll}\text { Annex } 1 & 56\end{array}$ 



\section{Summary}

This study aimed to identify the most relevant chemical and physical hazards for human health in the egg production chain in the Netherlands. This study was conducted on the request of the Netherlands Food and Consumer Product Safety Authority (NVWA). The presence of chemical and physical hazards at different stages in this chain was evaluated as well as potential health effects for consumers related to the major hazards. Furthermore, prevention and control measures to reduce the presence of contaminants at different stages in the egg production chain were identified, as well as future developments related to the egg production chain. Information was collected from scientific literature, national and international reports, governmental surveys, and national datasets. Since consumption of eggs from other poultry species (e.g., duck, quail) is very low in the Netherlands, only chicken eggs were considered.

Results showed that the presence of dioxins and dioxin-like PCBs in imported feed materials and in both locally produced and imported eggs and egg products, is the major chemical hazard, although an exposure assessment performed in 2014 showed that egg (products) contributed less than $5 \%$ to the overall intake of dioxins and dioxin-like PCBs via food for the average consumer in the Netherlands. Eggs from free-range and organic systems may contain higher concentrations of these compounds compared to eggs from cage and barn systems, although the current strict self-control and resulting measures have led to reduced levels in the former systems. Another relevant chemical hazard is the presence of veterinary drug residues in imported (from outside EU) eggs and egg products as well as the presence of veterinary drugs in eggs produced in the Netherlands. The latter group may result from the Cascade regulation and/or the production or use of medicated feed (coccidiostats). The main physical hazard is the presence of egg shell fragments in egg products; these shell fragments may be introduced during the egg breaking process at the egg processing industry.

Measures to prevent and/or reduce the presence of chemical and physical hazards (egg shell fragments) in eggs and egg products are related to generally accepted good agricultural practices, good hygienic practices, good veterinary practices, good processing practices, and adoption of quality management systems, as well as ensuring high and up-to-date awareness and knowledge of food safety of actors within the egg production chain. In addition, the collection and exchange of relevant, high quality data from one stage of the chain to the next one is a prerequisite for quality assurance within the chain and as such is part of the IKB EI-system.

In recent years, the number of layer farms is decreasing and the number of laying hens kept per farm is increasing. Consumption data in the Netherlands show an increasing demand for eggs from freerange and organic systems. As a result of the ban on conventional battery cages in the European Union, the proportion of farms with a cage system has decreased significantly in the past few years (enriched cages are still allowed), whereas the number of farms with organic and free-range systems has increased during this period.

From the results of the current study, it is recommended to monitor feed materials, egg and egg products for the presence of chemical contaminants, in particular dioxins and dioxin-like PCBs The presence of dioxins and dioxin like-PCBs in eggs from the various housing systems should be investigated in more detail. Furthermore, imported eggs should be tested on the presence of veterinary drug residues, and nationally produced eggs should be tested on the broad range of veterinary drugs regulated for poultry in general. 


\section{Introduction}

Laying hens can ingest contaminants from the environment, via water and feed, or via veterinary drug treatment, and those contaminants can be transferred to the eggs. Eggs contain a high percentage of fat and have the potential to accumulate, for instance, persistent organic pollutants (POPs) such as polychlorinated biphenyls (PCBs) and dioxins. Such substances can pose a potential threat to human health. Also, in later phases of the egg production chain, possible contamination of eggs and egg byproducts may occur.

The European Commission (EC) has established the General Food Law (Regulation (EC) No 178/2002), which stipulates the delivery of safe and traceable foods. To achieve a high level of public health protection, the EC has set maximum levels for certain contaminants with the aim to reduce their presence in foodstuffs to levels that are safe for human health (Regulation (EC) No 1881/2006). In the Netherlands, the Netherlands Food and Consumer Product Safety Authority (NVWA) checks feed and food products for the presence of possible hazards for human and animal health. As it is not possible to inspect all food and feed products placed on the Dutch market, the NVWA needs to prioritize its activities.

The main objective of this study was to identify chemical and physical hazards in the egg production chain in the Netherlands, as well as their potential adverse effects on human health. This study was performed on the request of the NVWA. Results can be used to identify the main risks and to effectively apply risk-based monitoring strategies. The consumption of eggs from duck, turkey, pheasant, quail, goose, and guinea fowl is very low in the Netherlands. Therefore, the main focus was on eggs from chickens (i.e. eggs from laying hens, layer and broiler parent stocks).

The main study objective is broken down into the following research topics:

- Identification of potential chemical and physical hazards that might occur in the egg production chain (performed by the RIKILT authors);

- Identification of potential pathways of introduction of chemical and physical hazards (identified in 1) in the egg production chain (performed by the RIKILT authors);

- Potential adverse effects of the most important chemical and physical hazards to human health (performed by the RIVM authors);

- Recommendations for interventions to reduce the presence of chemical and physical hazards in the egg production chain (performed by the RIKILT authors);

- Identifying future developments for the egg production chain until the year 2025 that might affect the presence of chemical and physical hazards (performed by the Wageningen Economic Research and RIKILT authors). 


\section{Material and methods}

The necessary information for this study was collected from scientific literature, reports from national and international institutes, and available national and international datasets.

\section{$2.1 \quad$ Literature study}

Information from scientific literature was collected from different sources, including Scopus, Google and Google Scholar, using the following key words: chemical and/or physical -contaminants, -hazards, -pollutants in egg and egg products. Furthermore, reports from international institutions and organizations such as the European Commission (EC), the European Food Safety Authority (EFSA), the US Food and Drug Administration (FDA), the World Health Organization (WHO), and the Food and Agriculture Organization (FAO) were used to retrieve relevant data and information.

\subsection{Monitoring data}

Data from RASFF (Rapid Alert System for Feed and Food), and the Dutch KAP database were used. The KAP database is part of the Quality Program for Agricultural Products, which involves intensive cooperation between the government and agribusiness in the Netherlands on exchange of monitoring results for presence of chemical contaminants in feed and food, and their ingredients. Monitoring results were retrieved from KAP for the period 01-01-2005 to 31-12-2014, covering results from chemical analyses of samples of eggs, egg yolk and mayonnaise. Data originated mainly from NVWA and RIKILT.

Data subtracted from RASFF covered notifications and alerts for chemical and physical hazards in eggs and egg products in the period 01-01-2002 to 31-12-2014 (Annex 1). Data included: year of notification, notification type and type of contaminated product, type of the hazard, hazard level, and the origin and distribution of the hazard. It should be stressed that not all incidents are reported in RASFF, but only those that are relevant for other member states.

Three databases containing information on incidentally occurring chemical hazards in the food production chain within the Netherlands were also evaluated. These databases are: a) notifications reported in the Notification Support System of the NVWA (MeldingenOndersteuningsSysteem, MOS); b) notifications on food collected by the National Poisons Information Centre (Nationaal Vergiftigingen Informatie Centrum, NVIC), and c) risk assessments performed by the RIVM/RIKILT Front Office for Food and Product Safety, hereafter referred to as Front Office. Information collected from MOS and NVIC has been summarized on a quarterly basis from 2010 up to and including 2012, as part of a trend analyses project (RIVM, 2010-2012). For the current study, all available information in the trend analysis project was screened for chemical and physical hazards occurring in eggs and egg products. Information collected from the Front Office has been summarized on a yearly basis from 2006 until 2014 (Front Office, 2010-2014). For the current study, the available information was screened for chemical hazards occurring in eggs and egg products from 2010 up to and including 2014. 


\section{The egg production chain}

\subsection{Chain structure in the Netherlands}

\subsubsection{Hatchery and rearing}

Parent hens lay eggs intended to be hatched as layer hens. These eggs are hatched at the hatcheries. After hatching, day-old chicks are delivered to the rearing farms to be raised as pullets till the age of about 17 weeks. The pullets are then moved to the layer farms and kept there for their useable lifetime (Figure 1).

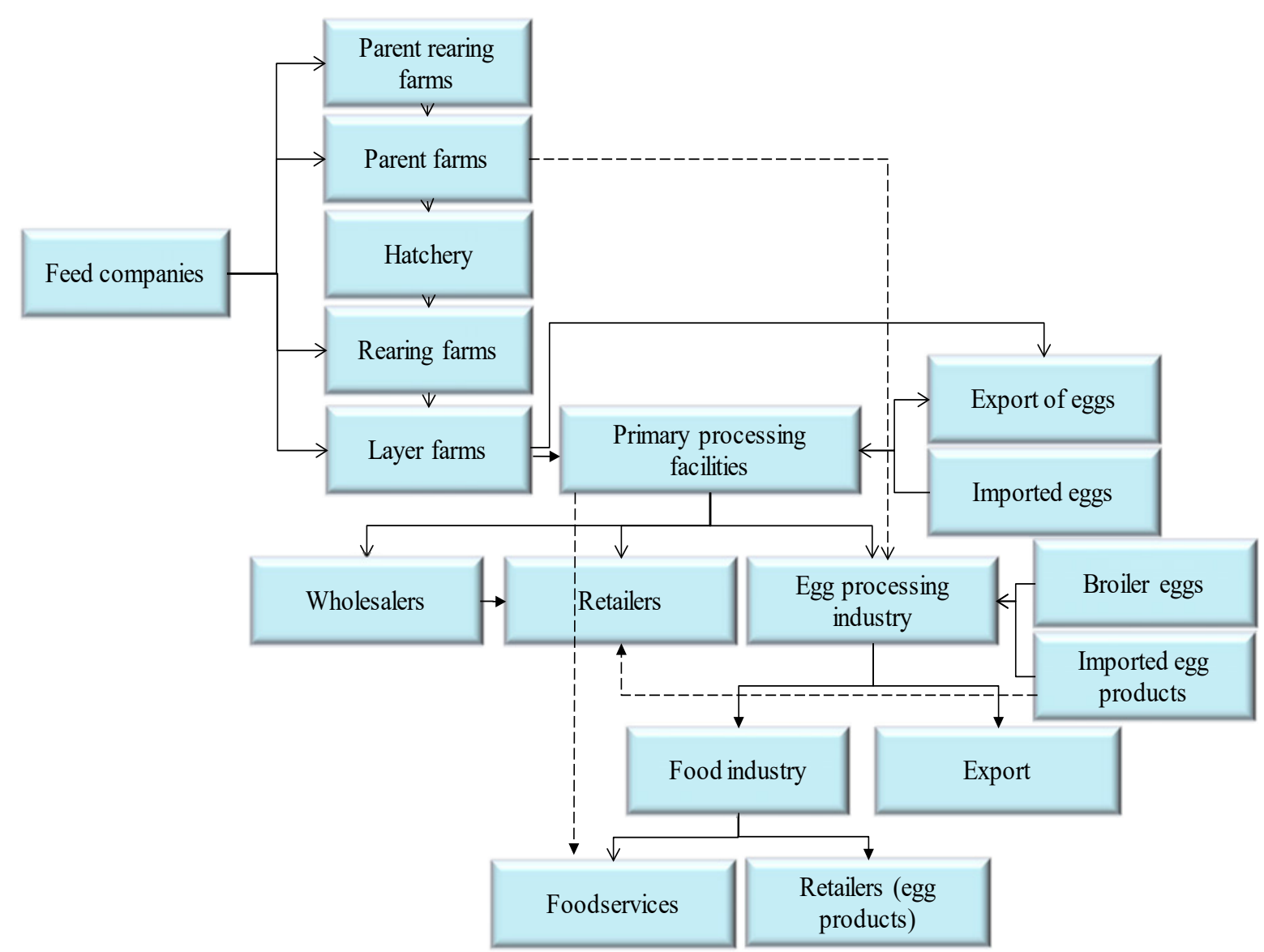

Figure 1 Schematic description of the egg production chain in the Netherlands.

\subsubsection{Layer farms}

The layer farms are responsible for the management of the hens and the production of eggs. Laying hens are kept in different housing systems for commercial egg production in the Netherlands, including cages or non-cages, such as barns, organic and free-range systems. Cage husbandry means that hens are continuously housed in cages within a shed. As off 2012, the conventional cage has been banned in the European Union, and only enriched cages with a minimum space of $750 \mathrm{~cm}^{2}$ per laying hen or alternative housing systems, such as barn, free-range and organic systems are allowed (Directive 1999/74/EC). In the Netherlands, a further ban is implied for enriched cages from 2021 onwards, when colony cage type systems (equipped with nest boxes, perches and dustbathing facilities) are the only type of housing systems allowed in the Netherlands (Legkippenbesluit, 2004). 
In barn systems, hens are kept in houses that may have multiple tiers (aviaries) with nest boxes and perches. Birds are free to roam in the shed. The floor is generally covered with litter and/or other material such as slats or wire mesh. In the latter case, part of the floor area should be covered with litter. There is a maximum of 9 hens per $\mathrm{m}^{2}$ usable area. In free-range husbandry, birds are housed in sheds identical to the barn systems, but birds have access to an outdoor range, a pasture of at least $4 \mathrm{~m}^{2}$ per hen (EC, 1999). Organic systems are a specific form of free-range systems, according to the requirements of organic production (EC, 2008a). In the barn area, no more than 6 hens per $\mathrm{m}^{2}$ are kept. Furthermore, beak treatment is not allowed and the hens have access to a pasture like freerange hens. Besides, the hens receive feed according to organic standards (Leenstra et al., 2014).

\subsubsection{Egg production by laying hens}

The formation of an egg in the (laying) hen occurs within the hen's ovary and oviduct. Maturation of the yolk in the ovary takes around 10 days of exponential growth, so the ovary has several follicles in different development stages at any time. The largest follicle is the one to be ovulated and to produce an egg. The egg white, or albumen, is formed in and secreted by the oviduct. Formation of the proteins takes 1-2 days, while the actual deposition of egg white around the yolk occurs during 2-3 hours after ovulation. Normally, the ovary produces one egg every 24 hours (light/dark cycle). An egg consists of the yolk (30-33\%), albumen (about 60\%) and the shell (9-12\%). The shell consists of about $95 \%$ calcium carbonate and about $5 \%$ organic material. It is formed when the egg has entered the uterus. Calcium, phosphorus and Vitamin $D_{3}$ are essential for a good quality of the egg shell.

\subsubsection{Primary processing}

After the eggs have been produced, they enter the primary processing stage. This stage refers to the sorting, candling, grading and packaging of the eggs. Sorting and candling is done to maintain consistent quality and size of eggs as well as to minimize the number of cracked and/or dirty eggs sent for sale. The eggs are graded into different quality categories. The highest quality eggs receive a grade $A$, whereas grade $B$ is assigned to eggs that have lesser interior quality. These $B$ eggs are usually used to make liquid, frozen, and dried egg products. Primary processing can occur either on the farm at which the eggs are produced or at a centralized processing facility. At the primary processing stage, eggs are packed and transported to the wholesalers/retailers or directly to the foodservices. Off-graded eggs are transported to the egg processing industry.

\subsubsection{Further processing of egg products}

Eggs (including rejected eggs from layer hens, layer and broiler parent stocks) can be further processed for the food service and/or manufacturing industries (Figure 2). At this stage, liquid whole egg or egg white and yolk are collected by crushing the egg (if necessary) by separating the yolk and egg white (albumen), and removing the shell particles by centrifugation and/or filtration. Thus, an egg is separated into its following components: albumen, yolk and shell. Afterwards, different processing procedures are undertaken (as required) to create refrigerated liquid egg products, frozen egg products, dried egg products, and non-food by-products. For example, whole egg, egg white and egg yolk can be dried to form egg powder: whole egg powder, egg white powder or egg albumen powder, and egg yolk powder. The refrigerated liquid egg products, frozen egg products and the dried egg products can be used by the food industry as ingredients to produce food products such as cake, biscuit, pasta, mayonnaise, and ice-cream for retail and foodservices users. Hazards related to the latter process are not included in this study. Figure 2 presents a schematic illustration of egg processing. 


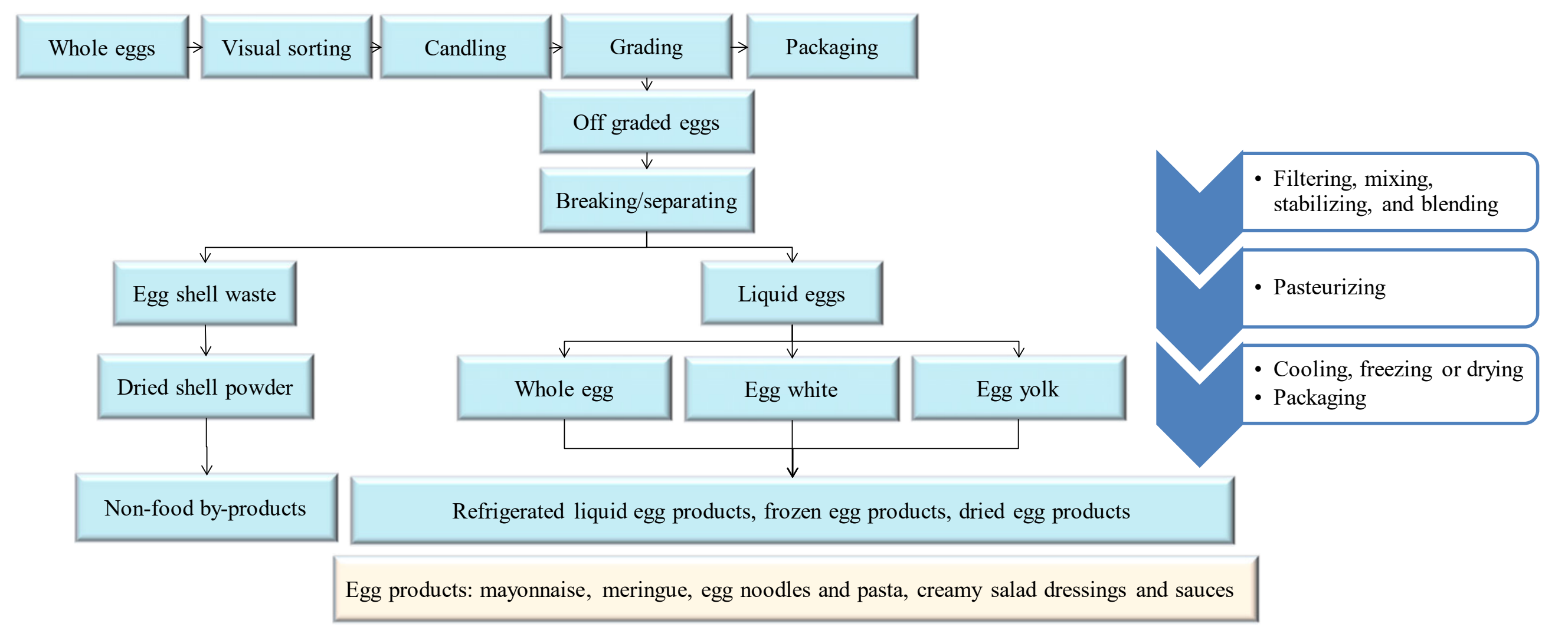

Figure 2 Schematic presentation of egg processing, as performed in the egg processing industry in the Netherlands. 


\subsection{Production figures}

\subsubsection{Farms and companies}

Table 1 presents an overview of the numbers and capacities of the firms involved in the Dutch egg production chain.

Table 1 Quantification of the firms involved in the Dutch egg production chain ${ }^{1}$.

\begin{tabular}{llll} 
& & & Capacity \\
\cline { 2 - 3 } & Number & Hens/chicks & Eggs/year \\
Parent rearing farms & $30-40$ & 0.5 million & 125 million \\
\hline Parent farms & $50-60$ & 1 million & 110 million $^{2}$ \\
\hline Hatcheries & 8 & $35-40$ million & 10 billion $^{2}$ \\
\hline Layer rearing farms & $250-300$ & 11.8 million & 100 million $^{3}$ \\
\hline Layer farms & 930 & 34.8 million & \\
\hline Primary processing facilities & 78 & & \\
\hline Egg processing industries & 17 & & \\
\hline 1 & Data from PPE (2013), LEI/CBS (2014) and Hoste (2014). & \\
2 & & & \\
3 &
\end{tabular}

In the Netherlands, there are eight hatcheries with a total annual capacity of 110 million hatching eggs, of which 100 million eggs are hatched for the Dutch market. About 9 million hatching eggs are hatched for the export market. In 2013, there were about 930 layer farms with a total capacity of 34.8 million hens. Table 2 shows the types and number of layer farms in the Netherlands according to housing system.

Table 2 Classification of the layer farms in the Netherlands in 2013 per housing system ${ }^{1}$.

\begin{tabular}{llll} 
Housing system & Number of farms & Number of hens $(\mathrm{m} \mid \mathrm{n})$. & Percentage of total hens (\%) \\
\hline Cage & 100 & 5.1 & 16 \\
\hline Barn & 530 & 20.1 & 64 \\
\hline Free-range & 190 & 4.8 & 15 \\
\hline
\end{tabular}

1 Based on data from PPE (2013) and LEI/CBS (2014).

\subsubsection{Egg and egg products}

In the Netherlands, a total of around 10 billion eggs were produced in 2012 (PPE, 2013). Furthermore, 2.5 million eggs were imported into the Netherlands in 2012 ( 2 million as table eggs and 0.5 million as egg products). Of the 3200 million eggs consumed in the Netherlands in 2012, 2100 million were sold at the supermarket as table eggs, about 500 million were used by the food service industries and about 600 million eggs were used by the egg processing industry for food production. In addition, 9365 million eggs were exported (6565 million as table eggs and 2800 million as egg products) in 2012. Eggs are exported directly from the layer farms and from the primary processing stage. Egg products are exported from the egg processing industry. Additionally, eggs from the parent farms and the breeder (broiler eggs) farms (about $0.3 \%$ of the total broiler egg production) enter the egg processing industry (Figure 1 ).

Limited information is available on the production of eggs from other poultry species. There is one quail farm in the Netherlands, which started in 2014. Eggs of quail are imported, mainly from France, to be sold to wholesalers and supermarkets. Ducks are not raised for egg production in the Netherlands and there is no import of duck eggs. 


\section{$4 \quad$ Chemical and physical hazards}

\subsection{Chemical hazards}

A variety of chemicals may enter the egg production chain and potentially affect human health, although fewer people will be affected by chemical hazards in eggs compared with microbiological hazards (USDA, 1997). Chemical hazards can be intentionally introduced during the egg production process, or unintentionally enter the egg production chain. The major source of chemical contamination of eggs is through exposure of laying hens to chemicals at the layer farm (Beran and Baum, 1997). Contamination at this stage may be the result of contaminated feed, feeding on contaminated soil, cleaning and sanitizing agents, shed fumigation while birds are present, pesticide use in sheds, insecticide sprays while birds are present and the use of veterinary drugs to treat hens. Chemicals may also enter the egg production chain further along the chain, e.g., by use of food additives and processing aids or via migration from packaging material of eggs and egg products. In the following sections, chemical contamination of eggs and egg products in the Netherlands is addressed in detail, per stage of the chain.

\subsubsection{Layer farms}

Primary production activities can significantly influence the safety of eggs and egg products. Inappropriate management, e.g. lack of good agricultural and veterinary practices, and inadequate hygiene by personnel and of equipment, has the potential to result in introducing chemical hazards into a laying hen flock. As a result, exposure of laying hens to chemicals may occur through feed, water, veterinary treatment, air, soil and/or housing materials. The housing systems can play a role in exposure of hens to chemical contaminants at the layer farms. For example, as a result of their direct contact to the outdoor environment and through the ingestion of soil or organisms in the soil, hens from free-range and organic systems have a greater potential for exposure to several chemical contaminants as compared to hens from barn or cage systems (Schoeters and Hoogenboom, 2006). As another example, the higher stocking density of cage flocks might result in increased infection rates of pathogens resulting in a higher need for medication compared to free-range and organic flocks (EFSA, 2005).

\subsubsection{Dioxins and dioxin-like PCBs}

Dioxins (Polychlorinated dibenzo-p-dioxins and dibenzofurans, PCDD/Fs) can occur as unwanted byproducts in chemical processes such as the synthesis of certain chlorinated pesticides and PCBs but also during the burning of waste. They have also been detected in certain types of clays, some of which were applied in animal feed, probably due to natural formation. Polychlorinated biphenyls (PCBs) cover a group of compounds that can be divided into two groups; "dioxin-like PCBs" (dl-PCBs, those compounds having toxicological properties similar to dioxins) and "non-dioxin-like PCBs" (ndlPCBs). Both dl-PCBs as well as ndl-PCBs, are usually found in feed and food (EFSA CONTAM, 2005).

Dioxins and dl-PCBs are persistent and have the potential to bio-magnify, bio-accumulate and persist in the food chain contributing to their negative effects on human health (EFSA, 2012a; WHO, 2014). According to the Regulation (EC) No 1881/2006, the maximum level for the sum of PCDD/Fs (WHO PCDD/F-TEQ) in eggs in the EU is $2.5 \mathrm{pg} / \mathrm{g}$ egg fat and $5 \mathrm{pg} / \mathrm{g}$ egg fat for the sum of PCDD/Fs and DLPCBs, respectively (WHO-TEF 2005 PCDD/ F-PCB-TEQ) (EC, 2011). There is also a maximum level for the sum of $6 \mathrm{ndl-PCBs}$ of $40 \mathrm{ng} / \mathrm{g}$ fat.

Dioxins and dl-PCBs can enter the egg production chain when hens consume contaminated feed or soil. In 1999, high levels of PCDD/Fs (32 pg I-TEQ (International Toxic Equivalents) PCDD/F/g fat) were found in eggs from Belgium used for breeding (Schoeters and Hoogenboom, 2006). Further analysis revealed also a high level of ndl-PCBs ( $46 \mu \mathrm{g}$ ndl-PCB $/ \mathrm{g}$ fat). The cause was traced to animal feed that was prepared with fat containing PCB-oil (WHO, 2014). This incident resulted in strict 
measures to reduce the overall exposure of consumers in the EU, including increased monitoring. In the Netherlands this resulted in the discovery of an elevated dioxin level in an egg sample from a small farm with free-ranging hens in 2001 (Traag et al., 2002). It was shown that the problem was more general and studies were performed to study the issue and to provide potential solutions (Kijlstra et al., 2007).

Eggs from free-range and organic layer farms more often have elevated levels of dioxins compared with eggs from other housing systems. A literature review revealed that higher concentrations were found in eggs from organic farms in the Netherlands and other EU countries compared with eggs from conventional cage systems (DeVries et al., 2006). Kijlstra et al. (2004) for example found dioxin levels in free-range and organic systems in the Netherlands ranging from 0.4 to $8.1 \mathrm{pg} \mathrm{TEQ} / \mathrm{g}$ fat and for battery systems between 1 and $2 \mathrm{pg}$ TEQ/g fat. In another European survey, elevated levels were reported in eggs from free-range hens in both urban (industrial areas) and rural areas where soil dioxin levels were considered to be low (Schoeters and Hoogenboom, 2006). In a study held in Belgium, mean concentrations of seven marker PCBs (ndl-PCBs plus dl-PCB 118), dioxins and dl-PCBs in eggs from private owners were, respectively, $58.7 \mathrm{ng} / \mathrm{g}$ fat, $10.2 \mathrm{pg}$ TEQ/g fat and $2.1 \mathrm{pg}$ TEQ/g fat. In eggs from commercial free-range farms, these mean concentrations were respectively $3.3 \mathrm{ng} / \mathrm{g}$ fat, $1.4 \mathrm{pg} \mathrm{TEQ} / \mathrm{g}$ fat and $0.8 \mathrm{pg}$ TEQ/g fat (Van Overmeire et al., 2006). A Dutch study showed comparable results: home produced eggs had relatively high levels of dioxins and dl-PCBs with a median level of $4.6 \mathrm{pg} \mathrm{TEQ} / \mathrm{g}$ fat and a maximum of $18.9 \mathrm{pg} / \mathrm{g}$ fat for the sum of dioxins and dl-PCBs. The average level $(6.1 \mathrm{pg} T E Q / \mathrm{g}$ fat) was around ten times higher than the average level as determined in the national monitoring program. A number of samples also showed elevated levels of ndl-PCBs with a median of $13 \mathrm{ng} / \mathrm{g}$ and a maximum of $80 \mathrm{ng} / \mathrm{g}$ fat (Hoogenboom et al., 2016).

According to a survey by the European Commission on PCDD/F levels in eggs sampled between 19871999, eight countries reported levels in cage eggs that were usually far below the EC maximum level (MLs) for PCDD/F in eggs (3 pg TEQ/g fat- WHO-TEF $_{1998}$ ), whereas almost $10 \%$ of eggs produced in alternative systems exceeded this limit. Median concentrations of PCDD/F, in $\mathrm{pg} T E Q / g$ fat, were 0.85 and 0.38 in eggs from, respectively, free-range and cage systems. For dl-PCBs, these values were 0.34 and $0.29 \mathrm{pg}$ TEQ/g fat (Schoeters and Hoogenboom, 2006).

High levels of approximately $120 \mathrm{pg}$ PCDD/F-TEQ/g fat were found in eggs from free-range hens sampled nearby an old municipal solid-waste incinerator in France (Pirard et al., 2005), showing that there may also be specific hot spots.

The consumption, by laying hens, of feed or soil with even moderate levels of dioxins results in increased levels in eggs, as demonstrated in an experimental study. A linear dose-concentration relationship was found between the dioxin levels in feed and eggs. Feed containing $0.4 \mathrm{ng}$ TEQ PCCD/F per $\mathrm{kg}$ resulted in egg levels just above the then existing EU limit of $3 \mathrm{pg}$ TEQ/g egg fat. Furthermore, exposure to dioxins through contaminated soil, mixed at $10 \%$ into the feed, resulted in a similar carryover as from feed (Hoogenboom et al. 2006). Another study estimated that soil contaminated with dioxins at the level of $0.38 \mathrm{pg} T E Q / \mathrm{g}$ soil resulted in egg contamination with dioxins at the level of $1 \mathrm{pg}$ TEQ/g fat (Harnly et al., 2000).

Eggs from hens of larger (free-range) flock sizes had lower dioxin levels (below $3 \mathrm{pg} / \mathrm{g}$ of fat) than eggs from a smaller flock size (having dioxin levels above $3 \mathrm{pg} / \mathrm{g}$ of fat) (Kijlstra et al., 2007). This is probably related to the amount of time spent by the hens at the contaminated area, i.e. the larger the flock size, the higher the tendency to remain inside.

EFSA (2012a) retrieved a total of 1154 sample results from 26 countries for dioxins and dl-PCBs in eggs and egg products from different housing systems that were analysed between 2000-2010. Based on lower bound (LB) values, these data showed a mean concentration of dioxins and dl-PCBs of $1.54 \mathrm{pg} \mathrm{TEQ}{ }_{W H O 05} / \mathrm{g}$, with a median of 0.51 , a $95^{\text {th }}$ percentile of 5.12 and a $99^{\text {th }}$ percentile of 11.95 . Based on upper bound (UB) values, these levels were, respectively $1.62,0.61,5.16$ and 11.96 . LB and UB refer to assigning the non-detected congeners a zero value or the reported limit of quantification, respectively. The percentage of samples of eggs and egg products with dioxins and dl-PCBs levels higher than the maximum limit of $\mathbf{2 . 5}$ for PCDD/Fs (sum of PCDDs and PCDFs compounds expressed in pg TEQwHO05/g) was 5.1\% (95\% confidence interval: 3.8-6.4). Regarding the maximum limit of 5.0 for 
dioxins and dl-PCBs (sum of PCDDs, PCDFs, and dl-PCBs, expressed in pg TEQwho05/g), this percentage was $4.7 \%$ (95\% confidence interval: 3.5-5.9) (EFSA 2012a).

Over the years 2008 to 2014, RIKILT analysed 352 egg samples in the national monitoring program for the presence of dioxins and dl-PCBs. Only 1 sample contained dioxins above the ML and dioxins+dl-PCBs above the ML. One sample contained dioxins above the action limit, but below the ML and two samples contained dioxins + dl-PCBs above the action limit, but below the ML.

Table 3 presents the alert and information notifications of RASFF related to dioxins in eggs and egg products between the years 2002 and 2014 showing that dioxins are still found at levels above the ML in eggs and egg products from some EU countries including the Netherlands.

Table 3 Alert and information notifications of dioxins and DL-PCBs, reported as chemical hazards in on the RASFF system, between 2002-2014.

\begin{tabular}{|c|c|c|c|c|}
\hline Date & $\begin{array}{l}\text { Notification } \\
\text { type }\end{array}$ & Notified by & Countries concerned* & Subject \\
\hline $24-5-2004$ & information & Belgium & Belgium (D/O) & $\begin{array}{l}\text { polychlorobifenyls }(1.065 ; 0.886 ;<0.070 \\
\mathrm{ng} / \mathrm{kg} \text { fat }) \text { in free-range eggs from } \\
\text { Belgium }\end{array}$ \\
\hline $30-6-2008$ & information & Germany & Germany, Spain, Switzerland (O) & $\begin{array}{l}\text { dioxins }(1.23 ; 1.13 \mathrm{pg} \text { WHO TEQ/g) and } \\
\text { dioxin-like polychlorobifenyls }(7.68 ; 7.71 \\
\text { pg WHO TEQ/g) in egg products from } \\
\text { Switzerland }\end{array}$ \\
\hline $28-4-2010$ & alert & Netherlands & $\begin{array}{l}\text { Belgium (D), France, Germany } \\
\text { (D), Netherlands (D/O), Ukraine } \\
\text { (O) }\end{array}$ & $\begin{array}{l}\text { dioxins }(1.35 ; 0.68 ; 0.69-2.8 ; 1.2 ; 3.8 ; \\
2.2 ; 1.3 \mathrm{pg} \text { WHO TEQ/g) in feed for laying } \\
\text { hens from the Netherlands, with raw } \\
\text { material from Ukraine }\end{array}$ \\
\hline $15-12-2010$ & alert & France & $\begin{array}{l}\text { Belgium (D), Commission Services, } \\
\text { France (D/O) }\end{array}$ & $\begin{array}{l}\text { dioxins and dioxin-like polychlorobifenyls } \\
\text { (sum }=8.12 \mathrm{pg} \text { WHO TEQ/g) in eggs from } \\
\text { France }\end{array}$ \\
\hline $15-8-2011$ & alert & Netherlands & $\begin{array}{l}\text { Belgium (D), Luxembourg (D), } \\
\text { Netherlands (D/O) }\end{array}$ & $\begin{array}{l}\text { dioxins ( } 2.07 \mathrm{pg} \text { WHO TEQ/g) and dioxin- } \\
\text { like polychlorobifenyls (sum: } 12.31 \mathrm{pg} \\
\text { WHO TEQ/g) in eggs (organic production) } \\
\text { from the Netherlands }\end{array}$ \\
\hline $7-5-2012$ & $\begin{array}{l}\text { information } \\
\text { for attention }\end{array}$ & Germany & $\begin{array}{l}\text { Commission Services, Germany } \\
(D / O), \text { Netherlands (D) }\end{array}$ & $\begin{array}{l}\text { polychlorobifenyls (non dioxin like in fat: } \\
82.3 \mu \mathrm{g} / \mathrm{kg}-\mathrm{ppb} \text { ) in organic eggs from } \\
\text { Germany }\end{array}$ \\
\hline $19-6-2012$ & $\begin{array}{l}\text { information } \\
\text { for attention }\end{array}$ & Germany & Germany (D/O) & $\begin{array}{l}\text { dioxins ( } 19.5 \mathrm{ng} / \mathrm{kg}-\mathrm{ppt} \text { ) in organic eggs } \\
\text { from Germany }\end{array}$ \\
\hline $29-8-2012$ & alert & Germany & Germany (D/O), Luxembourg (D) & $\begin{array}{l}\text { dioxins ( } 8.15 \mathrm{pg} \text { WHO TEQ/g) in organic } \\
\text { eggs from Germany }\end{array}$ \\
\hline 6-11-2012 & $\begin{array}{l}\text { information } \\
\text { for attention }\end{array}$ & Germany & Germany (D/O), Netherlands (D) & $\begin{array}{l}\text { non-dioxin-like polychlorobifenyls (upper- } \\
\text { bound: } 120 \mu \mathrm{g} / \mathrm{kg} \text { - ppb) in organic eggs } \\
\text { from Germany }\end{array}$ \\
\hline $28-8-2013$ & $\begin{array}{l}\text { information } \\
\text { for attention }\end{array}$ & Germany & Germany (D), Netherlands (O) & $\begin{array}{l}\text { dioxins ( } 3.4 \mathrm{pg} \text { WHO TEQ/g) in organic } \\
\text { eggs from the Netherlands }\end{array}$ \\
\hline $30-8-2013$ & $\begin{array}{l}\text { information } \\
\text { for follow-up }\end{array}$ & Germany & Germany (D/O), Netherlands (D) & $\begin{array}{l}\text { dioxins ( } 8.8 \mathrm{pg} \text { WHO TEQ/g) in organic } \\
\text { eggs from Germany }\end{array}$ \\
\hline
\end{tabular}

* D: Distribution; O: Origin. 
Examination of notifications by the Front Office showed that during the period 2010-2014, three risk assessments were performed related to chemical hazards occurring in eggs or egg products after an incident. The hazards in question were always dioxins:

- Risk assessment of dioxins in hen's eggs, April 2010.

- Risk assessment of dioxins in eggs from free-range hens in Harlingen, October 2013.

- Risk assessment of dioxins in eggs of private chicken owners (private eggs), October 2014.

In 2011, several notifications were reported to the NVWA related to the occurrence of dioxins. This was due to the fact that a German biofuel company had delivered fats intended to be used for deinking, contaminated with dioxins, to a trader who sold it to companies that manufacture animal feed (see also RASSF notifications in Table 3). Fortunately, imported contaminated feed and products of animal origin (including eggs) were intercepted in the Netherlands and contaminated edible products did not reach the Dutch consumer and exporting countries.

It should be mentioned that the egg producers have introduced strict self-control for organically produced eggs. Eggs from each new flock of hens have to be checked after a few weeks at the new farm. Depending on the results, further tests can be omitted or follow-up checks and - if relevant measures have to be applied. This system especially applies for eggs being exported to Germany (following the "KAT" quality control system). As a result of this full control, a number of farms were identified with dioxin or PCB problems, the latter being caused by use of contaminated building debris or asbestos roof plates coated with a PCB-containing paint. In general, the levels in free-range eggs appear to have decreased since the introduction of this self-control program (Hoogeboom, 2015, personal communication).

\subsubsection{Polybrominated diphenyl ethers}

Polybrominated diphenyl ethers (PBDEs) are a class of brominated flame retardants that are widely distributed in the environment and likewise in biota, and in food and feed (EFSA, 2011b). However, limited data are available for the possible contamination of eggs with these compounds. In a study in Canada, egg yolk from eggs from hens housed in free-range systems showed higher concentrations of PBDEs than egg yolk collected from eggs from hens housed in conventional systems (Rawn et al. 2011). The transmission of PBDEs to eggs was confirmed in an experimental study where laying hens were fed a diet containing $3.4 \mathrm{mg} \mathrm{PBDEs} / \mathrm{kg}$ feed (Pirard and De Pauw, 2007). PBDE levels in eggs increased during the five weeks exposure period, reaching $24 \mu \mathrm{g} / \mathrm{g}$ fat, and then decreased to $3 \mu \mathrm{g} / \mathrm{g}$ fat at the end of the trial at about 12 weeks.

According to EFSA, eight congeners are considered of primary interest in the food chain: BDE-28, -47 , $-99,-100,-153,-154,-183$ and -209 . For eggs and egg products, the concentration (mean UB) of the PBDE congeners ranged between $0.07 \mathrm{ng} / \mathrm{g}$ fat for BDE-183 and $3.98 \mathrm{ng} / \mathrm{g}$ fat for BDE-209 (EFSA, 2011b). RIKILT analysed 145 egg samples for the presence of PBDEs in the years 2009 to 2015. The most frequently encountered PBDEs were BDE-99 ( $90 \%$ of the samples ranging from 14 to $802 \mathrm{pg} / \mathrm{g}$ fat), BDE-153 ( $81 \%$ of the samples ranging from 10 to $308 \mathrm{pg} / \mathrm{g}$ fat) and BDE-100 (71\% of the samples ranging from 10 to $234 \mathrm{pg} / \mathrm{g}$ fat). Other PBDEs encountered were BDE-47 (48\%), BDE-66 (1\%), BDE-71 (8\%), BDE-85 (1\%), BDE-119 (9\%), BDE-138 (1\%), BDE-154 (29\%), BDE-183 (23\%) and BDE-209 (39\%). For these Dutch monitoring data, there is no information on potential differences between the various housing systems.

A rather peculiar case was the presence of flame retardants in a widely used feed ingredient for chickens, being choline chloride (Traag et al., 2009). Apart from PBDEs also various other flame retardants were present, including 2,4,6-tribromophenol, a likely precursor for brominated dioxins. Given the dilution in feed production, the levels were unlikely to present a risk, but the incident pointed out the possibility that production of feed grade ingredients is performed on the same production lines as industrial chemicals.

The EFSA CONTAM panel calculated MOEs and concluded that for BDE-47, -153 and -209 the MOE was unlikely to raise a health concern. However, the MOEs for BDE-99 for young children (1-3 years) were 1.4 and 0.7 for average and high exposure, respectively. These MOEs indicate a potential health concern for dietary exposure to BDE-99 (EFSA, 2011b). The low MOEs are primarily caused by the 
long half-life of BDE-99 (1442 days). Young children have a lower MOE compared to adults due to the relative high intake compared to their body weight. Furthermore the CONTAM Panel indicated that one sample in the category "Food for infants and small children" had a high concentration of BDE-99, which could have resulted in an overestimation of the exposure of young children (EFSA, 2011b). Recently, RIVM updated the intake assessment of PBDEs in the Netherlands. Results show that eggs have a low contribution ( $<5 \%$ ) to the total PBDE intake (Boon et al., 2016).

\subsubsection{Heavy metals}

Heavy metals can potentially contaminate the egg production chain through their presence in the environment (e.g. soil, water) or through contamination during processing. The soil may be contaminated by application of fertilizers on agricultural fields and/or industrial contaminations. Laying hens may ingest metals with their feed or soil in case they have access to the external environment.

Heavy metals tend to accumulate in the liver and kidney of livestock, but not much specific information is available for transfer of these compounds to eggs. MacLachlan (2011) showed that cadmium transfer from feed to kidney was 17 times higher, and to liver 100 times higher than to eggs. Kan and Meijer (2007) indicated that transfer of cadmium to eggs is very low or absent. Lead accumulates in liver, kidney and bone, whereas the behaviour of arsenic and mercury depend on their chemical structure. Alkylmercury compounds tend to accumulate in skeletal muscles and brain, whereas aryl compounds and inorganic mercury salts accumulate in liver and kidneys. Inorganic arsenic is converted into methylated metabolites, which are rapidly excreted compared to other organic arsenic compounds (Kan \& Meijer, 2007). Thus, in general, carry-over of heavy metals to eggs is low in comparison to other tissues such as liver and kidney. As a result, the relative contribution of eggs and egg products to the dietary exposure to heavy metals is low. The overall mean cadmium exposure is low, ranging between 0 and $0.22 \%$ (EFSA, 2012b) and the consumption of eggs seems to have only a minor contribution on the total exposure to arsenic via food (EFSA CONTAM, 2009).

The EC has set MLs for heavy metals in several foodstuffs, but not for eggs (EC, 2006). In the following section, information on the presence of arsenic, cadmium, lead, and mercury in eggs and egg-products is summarized. These heavy metals were addressed, because these are the ones that are to some extent regulated in the EU. The RASFF database does not contain any notifications with heavy metals. The KAP database contains only 1 sample of mayonnaise that was tested for the presence of arsenic, cadmium, lead and mercury. Levels were below the LOD.

\section{Arsenic}

Arsenic is a natural component of the earth's crust and is widely distributed throughout the environment in the air, water and land (WHO, 2012a). Arsenic compounds are used in the manufacture of a variety of products and may enter our environment directly from industrial effluents. For instance, arsenic is used, to a limited extent, in pesticides and feed additives (WHO, 2012a). Arsenic is highly toxic in its inorganic form. Sources of contamination of the egg production chain could be through drinking water, feed (contaminated water for crop irrigation) and medications. Based on literature and data submitted from several countries worldwide, the range of total arsenic concentrations in eggs and egg products was reported to be 3-40 $\mu \mathrm{g} / \mathrm{kg}$ (JECFA, 2011). In a study from Belgium, mean concentrations of arsenic in eggs from private owners and commercial free-range farms were, respectively, 16 and $13 \mu \mathrm{g} / \mathrm{kg}$ (Van Overmeire, 2006). In another study from Belgium, the mean fresh weight concentration of arsenic in eggs from free-range hens from private chicken owners was $<8.0 \mu \mathrm{g} / \mathrm{kg}$ (Waegeneers et al., 2009). The mean estimated concentration (middle bound (MB) values) of arsenic in 1768 samples of eggs and egg products from different EU countries was $5.4 \mathrm{\mu g} / \mathrm{kg}$ (EFSA, 2014b). In the EU, there are no MLs for arsenic in food products, except for rice and rice products (ranging $0.1-0.3 \mathrm{mg} / \mathrm{kg}$ ). MLs set in other countries for foodstuffs other than eggs vary from 10 up to $100 \mu \mathrm{g} / \mathrm{kg}$ (CODEX, 1995). Thus, the above mentioned concentrations are within this range.

Exposure to arsenic is mainly via the diet. "The estimated national dietary exposures to inorganic arsenic for average (0.13-0.56 $\mathrm{\mu g} / \mathrm{kg}$ bw per day) and high level adult consumers $(0.37-1.22 \mu \mathrm{g} / \mathrm{kg}$ bw per day) in Europe are within the range of the BMDL01 values (0.3-8 $\mu \mathrm{g} / \mathrm{kg}$ bw per day) for lung and bladder cancer and for dermal lesions. Therefore there is little or no MOE and the possibility of a 
risk to some consumers cannot be excluded" (EFSA CONTAM, 2009). For the Netherlands, the exposure for adults 19-30 years and for children between 2-6 years was estimated by EFSA in 2014. The long-term median exposure to arsenic from food was estimated to be $0.25 \mu \mathrm{g} / \mathrm{kg}$ bw per day for adults $19-30$ years and $0.56 \mu \mathrm{g} / \mathrm{kg}$ bw per day for children 2-6 years of age. For individual persons with a high intake of products containing inorganic arsenic, the long-term exposure was estimated to be $0.41 \mu \mathrm{g} / \mathrm{kg}$ bw per day for adults $19-30$ years and $0.89 \mu \mathrm{g} / \mathrm{kg}$ bw per day for children (P95) (EFSA, $2014 \mathrm{~b}$ ). Products contributing to the arsenic exposure in the Netherlands are mainly milk and dairy products and grain-based products (excluding rice-based products). These products do not contain high levels of arsenic, but contribute mainly due to a high consumption (EFSA, 2014b).

\section{Lead}

Lead occurs in the environment in the inorganic form. Lead can potentially contaminate eggs and egg products through environmental contamination. The concentration of lead in eggs from the Finnish market was $1000 \mu \mathrm{g} / \mathrm{kg}$ (Tahvonen and Kumpulainen, 1995). In a study from Belgium, the mean concentrations of lead in eggs from private owners and commercial farms (both organic and conventional) were, respectively, 68.6 and $8.9 \mu \mathrm{g} / \mathrm{kg}$ (Van Overmeire, 2006). Also in another study in Belgium, mean fresh weight concentrations of lead in eggs from private chicken owners in the autumn of 2006 and the spring of 2007 were, respectively, 116 and $74 \mu \mathrm{g} / \mathrm{kg}$ (Waegeneers et al., 2009). In the latter study, average lead concentrations were found to be higher than reported from other countries. The concentrations of lead correlated to levels found in the soil, indicating that soil is an important source of lead contamination for eggs. Based on the analysis of 1259 samples of eggs and egg products from different EU countries, the mean middle bound lead concentration was $12 \mu \mathrm{g} / \mathrm{kg}$ (EFSA, 2012c). A maximum concentration of $205 \mu \mathrm{g} / \mathrm{kg}$ lead was found in dried whole egg, and a mean concentration of $13 \mu \mathrm{g} / \mathrm{kg}$ was found in egg yolk (EFSA, 2012c). MLs for lead in foodstuffs other than eggs range between 0.02 and $1.5 \mathrm{mg} / \mathrm{kg}$ wet product (EC, 2006).

Mean lifetime dietary exposure to lead was estimated by EFSA in 2012 to be $0.68 \mu \mathrm{g} / \mathrm{kg}$ bw per day in the overall European population based on middle bound mean lead occurrence. Exposure was highest for toddlers and other children with 1.32 and $1.03 \mu \mathrm{g} / \mathrm{kg}$ bw per day, respectively. A study specific for young children in the Netherlands showed that median lead intake via food ranged from $0.53 \mu \mathrm{g} / \mathrm{kg}$ bw per week in 6-year olds to $0.76 \mu \mathrm{g} / \mathrm{kg}$ bw per week in 2-year olds (Boon et al., 2012). The EFSA established that bread and rolls contributes most to the intake $(8.5 \%)$ followed by tea $(6.2 \%)$, tap water $(6.1 \%)$, potatoes and potato products $(4.9 \%)$, fermented milk products $(4.2 \%)$ and beer and beer-like beverages ( $4.1 \%)$. The relative contribution of eggs and egg products to total dietary lead exposure in the European population was low, between 0.3 and $0.5 \%$ depending on the age group (EFSA, 2012c).

\section{Cadmium}

Cadmium is a heavy metal found as an environmental contaminant, both through natural occurrence and from industrial and agricultural sources. Cadmium is released into the environment by wastewater and waste incineration, and contamination of agricultural soils can occur by the use of fertilizers, air deposition and cadmium-containing sewage sludge (EFSA, 2009b).

The mean concentrations of cadmium in eggs from private owners and commercial farms in Belgium were, respectively, 0.5 and $0.3 \mu \mathrm{g} / \mathrm{kg}$ (Van Overmeire, 2006). In another study, the mean fresh weight concentrations of cadmium in eggs from private chicken owners in the autumn of 2006 and the spring of 2007 were 0.5 and $<0.5 \mu \mathrm{g} / \mathrm{kg}$, respectively (Waegeneers et al., 2009). The mean concentration of cadmium in eggs and egg products from different EU countries was $1.27 \mu \mathrm{g} / \mathrm{kg}$ when based on LB and $5.39 \mu \mathrm{g} / \mathrm{kg}$ when based on UB values (EFSA, 2012d). These levels are below the MLs for cadmium in foodstuffs other than eggs ranging from 0.01 to $3 \mathrm{mg} / \mathrm{kg}$ (EC, 2014).

In 2012, EFSA estimated average middle bound lifetime cadmium dietary exposure for the European population as a whole at $2.04 \mu \mathrm{g} / \mathrm{kg}$ bw per week. "It was highest in toddlers with an average of $4.85 \mu \mathrm{g} / \mathrm{kg}$ bw per week and lowest in the elderly population group at $1.56 \mu \mathrm{g} / \mathrm{kg}$ bw per week. Potential 95th percentile middle bound lifetime exposure, with the assumption that the same individuals retained high exposure throughout life, was estimated at $3.66 \mu \mathrm{g} / \mathrm{kg}$ bw per week with a high of $8.19 \mu \mathrm{g} / \mathrm{kg}$ bw per week for toddlers and a low of $2.82 \mu \mathrm{g} / \mathrm{kg}$ bw per week for the elderly. This 
confirmed that children on average and adults at the 95th percentile dietary exposure could exceed health-based guidance values" (EFSA, 2012d). A study in the Netherlands confirmed this as the median intake in 2- to 6-year olds ranged from $2.8 \mu \mathrm{g} / \mathrm{kg}$ bw per week in 6-year olds to $3.9 \mu \mathrm{g} / \mathrm{kg}$ bw per week in 2-year olds. The high (95th percentile) exposure ranged from 4.1 to $5.7 \mu \mathrm{g} / \mathrm{kg} \mathrm{bw}$ per week, respectively. Corresponding levels for adults aged 19 to 69 ranged from 1.3 to $1.6 \mu \mathrm{g} / \mathrm{kg} \mathrm{bw}$ per week and 2.1 to $2,6 \mu \mathrm{g} / \mathrm{kg}$ bw per week, respectively. The intake levels of children aged 3 to 18 were between those of 2-year olds and 19- to 69-year olds. The average life-long exposure to cadmium in the Netherlands was estimated to equal $1.7 \mu \mathrm{g} / \mathrm{kg}$ bw per week. All exposure levels reported were based on the medium bound (MB) scenario, in which samples with a cadmium concentration below the LOD or LOQ were assumed to contain the contaminant at a level equal to $1 / 2$ LOD or $1 / 2$ LOQ (Sprong \& Boon, 2015). The relative contribution of eggs and egg products to the overall mean cadmium exposure in the European study was low, ranging between 0 and $0.22 \%$ (EFSA, 2012d).

\section{Mercury}

Mercury is a metal that is released into the environment from both natural and anthropogenic sources (SCOOP, 2004). Mercury has been shown to accumulate in eggs when organomercury compounds are present in the feed. Reports on human dietary exposure to mercury showed that mercury is relatively widely distributed in food products, but at very low levels, and primarily in the less toxic inorganic form. The most toxic form of mercury, methylmercury, is found at significant levels only in fish and seafood (SCOOP, 2004; EFSA, 2012e). The mean concentrations of mercury in eggs from private owners and commercial farms in Belgium were, respectively, 2.1 and $0.5 \mu \mathrm{g} / \mathrm{kg}$ (Van Overmeire, 2006). The mean fresh weight concentrations of mercury in eggs from private chicken owners in Belgium in autumn 2006 and spring 2007 were, respectively, 3.2 and $4.4 \mu \mathrm{g} / \mathrm{kg}$ (Waegeneers et al., 2009). SCOOP reported mean concentrations of mercury in eggs and egg products in food (in $\mu \mathrm{g} / \mathrm{kg}$ ) of 1.4 for Denmark, 5 for Germany, and 1 for the U.K. (SCOOP, 2004). The MLs for mercury in foodstuffs other than eggs range between 0.5 and $1 \mathrm{mg} / \mathrm{kg}$ (EC, 2006).

In 2012, EFSA CONTAM Panel estimated the intake of methylmercury in Europe based on fish products, as these are the main contributors of methylmerucy exposure. In the Netherlands, the exposure to methylmercury in children of 2-15 years old was estimated in 2015. The mean intake was estimated to be $0.2 \mu \mathrm{g} / \mathrm{kg}$ bw per day. For individuals with a high consumption of fish and/or shellfish, the exposure (P95) was estimated to be $0.5 \mu \mathrm{g} / \mathrm{kg}$ bw per day for children aged 2-6 years and $0.6 \mu \mathrm{g} / \mathrm{kg}$ bw per day for children aged 7-15 years. The mean exposure to methylmercury in persons aged 16-69 years was $0.1 \mu \mathrm{g} / \mathrm{kg}$ bw per day, and for the high consumers $0.5 \mu \mathrm{g} / \mathrm{kg}$ bw per day (Front Office Food And Consumer Product Safety, 2015). EFSA also conducted a study on the dietary exposure to inorganic mercury in Europe. The estimated exposure to inorganic mercury in Europe from the diet alone does not exceed the TWI. For the Netherlands, EFSA CONTAM panel estimated the mean dietary exposure to inorganic mercury (MB) to be $1.16 \mu \mathrm{g} / \mathrm{kg}$ bw per week in toddlers, $0.97 \mu \mathrm{g} / \mathrm{kg}$ bw per week in other children and $0.42 \mu \mathrm{g} / \mathrm{kg}$ bw per week adults aged 19-30 years. The exposure (MB) of high consumers was estimated to be $2.24 \mu \mathrm{g} / \mathrm{kg}$ bw per week in toddlers, $1.83 \mu \mathrm{g} / \mathrm{kg}$ bw per week in other children and $0.78 \mu \mathrm{g} / \mathrm{kg}$ bw per week adults aged 19-30 years. The products contributing most to the exposure to inorganic mercury have not been reported per country. In general for Europe, the exposure to inorganic mercury is mainly by fish and other seafood. Two other large contributors are composite food in children and non-alcoholic beverages in adults. Further, vegetables and vegetable products, fruit and vegetable juices, grains and grain-based products, milk and dairy products and meat and meat products also contribute to the exposure to inorganic mercury. The contribution of eggs and egg products to total inorganic mercury is low, ranging from $0-1.1 \%$ over all age categories (EFSA, 2012e).

\subsubsection{Veterinary drugs and medicinal feed additives}

In Europe, the use of veterinary drugs in animal production is strictly regulated to ensure their safe and efficient use. In the egg production chain, veterinary drugs are used for therapeutic reasons to treat disease and infections. When veterinary drugs are administered to laying hens, most of these drugs will result into detectable residues in eggs laid days to weeks after the cessation of the treatment (Goetting, 2011). Therefore, if a veterinary medicinal product is used, the farmer needs to respect the particular withdrawal period in order to assure that residues in marketable eggs are below 
the respective Maximum Residue Limits (MRLs) (Directive 2001/82/EC) set by Regulation (EU) No $37 / 2010$ (EC, 2010). An overview of the veterinary pharmaceutical substances with an MRL in eggs is given in Table 4. While the safety evaluation and subsequent establishing of MRLs for a new veterinary pharmaceutical (inclusion in EC/37/2010) is an EU coordinated procedure, the actual registration of specific veterinary products is a national concern. Besides some antibiotics, Table 4 also includes coccidiostats; substances intended to kill or inhibit protozoa. To prevent clinical or sub-clinical coccidiosis, feed consumed by broilers is supplemented with anti-coccidial drugs, mostly polyether ionophores. The majority of these coccidiostats are applied as feed additive, to which a different legal framework applies (EC/1831/2003). Although some preparations are approved for rearing of layers, they are not registered for use in laying hens (see: EU register of feed additives pursuant to Regulation (EC) No 1831/2003, edition 223 released 14-12-2015). In 2009, MRLs in, amongst others, eggs were set anticipating the unavoidable carry-over of these compounds in feed production for nontarget animal species (Regulation (EC) No 124/2009) due to cross-contamination of feed batches (EC, 2009) (Table 4). Lasalocid is the only coccidiostat having an MRL in egg ensuing Regulation (EU) No $37 / 2010$ but so far no veterinary product registration for laying hens has been filed. Three additional coccidiostats (monensin, diclazuril and toltrazuril) are included in EC/37/2010 with MRLs established in poultry tissues, but these are excluded for use in laying hens.

Finally, MRLs of several agents against parasites are included in Regulation (EU) No 37/2010 (Table 4). Fenbendazole and flubendazole are benzimidazole anthelmintics used to treat nematode and trematode infections. Piperazin is also an anthelmintic, while phoxim is used for the control of mites, lice and other ectoparasites.

For laying hens (and other, minor poultry species) a very limited number of veterinary medicinal products are available. Therefore, the Veterinary Medicinal Products Directive 2001/82/EC allows the prescription of veterinary products other than the authorised under a provision known as the Cascade (EC 2001) in case there is no suitable veterinary drug authorized. When Cascade prescription is applied, a withdrawal time for eggs of at least 7 days should be taken into account. However, this seven 7 days withdrawal period is usually not substantiated by pharmacokinetic and residue depletion data and may be too short for some veterinary drugs as indicated in the following sections.

Within the EU (and many other parts of the world), several substances are explicitly prohibited for the use in food producing species. These banned compounds are presented in Regulation (EU) No 37/2010 and include chloramphenicol and nitrofurans. The EC has established a harmonised minimum required performance reporting limit (MRPL) for the detection of residues of nitrofuran (metabolites) at $1 \mu \mathrm{g} / \mathrm{kg}$ and $0.3 \mu \mathrm{g} / \mathrm{kg}$ for chloramphenicol residues (Decision 2002/657/EC). 
Table 4 Overview of the pharmacologically active substances having an MRL in egg (ensuing Regulation (EU) No 37/2010 or Regulation (EC) No 124/2009).

\begin{tabular}{|c|c|c|}
\hline Group & Compound & MRL ( $\mu g / k g)$ \\
\hline \multicolumn{3}{|l|}{ Antibiotics } \\
\hline \multirow[t]{2}{*}{ Tetracyclines } & Chlortetracycline & 200 \\
\hline & Tetracycline & 200 \\
\hline \multirow{4}{*}{$\begin{array}{l}\text { Macrolides (incl. lincosamides \& } \\
\text { pleuromutilins) }\end{array}$} & Erythromycin & 150 \\
\hline & Tiamulin & 1000 \\
\hline & Tylosin & 200 \\
\hline & Tylvalosin & 200 \\
\hline Penicillins & Phenoxymethylpenicillin & 25 \\
\hline \multirow[t]{9}{*}{ Ionophores } & Lasalocid & 150 \\
\hline & Narasin & 2 \\
\hline & Salinomycin & 3 \\
\hline & Semduramicin & 2 \\
\hline & Maduramicin & 12 \\
\hline & Robenidine & 25 \\
\hline & Decoquinate & 20 \\
\hline & Halofuginone & 6 \\
\hline & Nicarbazin & 300 \\
\hline Benzimidazoles & Piperazin & 2000 \\
\hline
\end{tabular}

\section{Transfer to eggs}

A laying hen can produce one egg approximately each 24 hours. Drugs entering the bloodstream will distribute through the body, and thus also occur in the ovary and oviduct of the laying hen.

Compounds may preferentially deposit in the yolk or albumen, depending on the physicochemical properties of the residue. Drug levels in yolk will accumulate during its maturation in the ovary. Consequently, after exposure for 8-10 days residue levels in yolk will generally reach a constant level. Residues in egg white generally are a reflection of drug plasma levels and will usually reach a platform after 2-3 days. Residue depletion from egg white and yolk correlates with the egg formation process. Drugs that clear rapidly from the body will usually also disappear from egg white in about 2-3 days after termination of exposure, and clearance of the yolk generally takes about 10 days. However, if the exposure levels are very high, or the drug clearance is slow, residue depletion from the laying hen, and thus the eggs produced, may take much longer, even up to 70 days after the last administration (Kan, 2003).

\section{Monitoring data for VMPs}

Within the EU, food of animal origin is monitored for the presence of residues and contaminants ensuing council directive 96/23/EC, which issues member states to implement National Monitoring Plans (NMP), and lays down minimal sampling levels and frequencies. With respect to residues of pharmacologically active compounds, according to Directive 96/23/EC (EC 1996) eggs have to be monitored for categories A6 (prohibited compounds, Table 2 Regulation (EU) No 37/2010), B1 (Antibacterial substances, including sulphonomides, quinolones) and B2b (anticoccidials, including nitroimidazoles).

In the Netherlands, 8420 egg samples were analysed for the presence of veterinary drug residues in the period 2005-2014, yielding no formal MRL violations. However, a sample containing enrofloxacin 
was found in 2008, and a sample containing doxycycline was encountered in 2009 (NVWA Pers. Comm.). These compounds may have been applied through "Cascade prescription", as they should not be used in laying hens (have no MRL in egg established). These incidents do nevertheless stress the importance of keeping a wide enough scope with respect to residue screening and not limit monitoring to the registered compounds. In this context, the use of effect-based assays (screening methods relying on antimicrobial activity) as currently applied for NMP screening, is considered to be an adequate approach. Other compounds reported in the KAP database in the period considered were lasalocid (11 samples), coccidiostatics (11 samples mainly nicarbazin) and 1 sample containing salinomycin.

Results of NMPs are reported yearly in a Commission Staff Working Paper on the implementation of national residue monitoring plans in the Member States. Analysis of the results between 2007-2013 is summarized in Table 5 and shows incidental reporting by the EU Member States of the following antibiotic groups: tetracyclines, quinolones and sulfonamides. It should be noted that the majority of the reported non-compliant results comprises compounds without an MRL for eggs. The overview shows a (relatively) frequent occurrence of ionophores and other coccidiostats. For this category, it should be taken into account that after 2009, MRLs (related to unavoidable carry-over) have been set (Regulation (EC) No 124/2009). In 2015, the Dutch NMP only yielded samples containing sub-MRL concentrations of coccidiostats: 5 egg samples containing nicarbazin ( $<1 / 10 * M R L)$, two cases of narasin, and one case of lasalocid also far below the MRL (NVWA, pers. comm).

With respect to the banned substances (category A6), Table 5 shows no violations have been reported since 2008.

Table $5 \quad$ Non-compliant results (Directive 96/23/EC monitoring) reported for egg between 20072013 (targeted \& suspect sampling) within the EU (Residues of Veterinary Medicinal Products).

\begin{tabular}{|c|c|c|c|c|c|c|c|c|c|}
\hline Category & Compound & 2007 & 2008 & 2009 & 2010 & 2011 & 2012 & 2013 & Total \\
\hline \multirow[t]{8}{*}{ B1 } & Antibacterials & & 3 & & & & & & 3 \\
\hline & Doxycycline* & & & & 4 & 1 & 2 & & 7 \\
\hline & Enrofloxacin* & 1 & 1 & & 13 & 2 & 1 & 4 & 22 \\
\hline & Ciprofloxacin** & 1 & 1 & & & & & 1 & 3 \\
\hline & Sulfadiazine* & 1 & 2 & & 1 & & & 3 & 7 \\
\hline & Sulfadimethoxine* & & & 1 & 1 & & & & 2 \\
\hline & Sulfamonomethoxine* & & & & & & & 1 & 1 \\
\hline & Sulfadimidine* & & & & & & 2 & & 2 \\
\hline \multirow{8}{*}{$\mathrm{B} 2 \mathrm{~b}$} & Lasalocid & 5 & 10 & 13 & 2 & 4 & 3 & 14 & 51 \\
\hline & Maduramicin & 1 & 4 & 12 & 3 & 11 & 1 & & 32 \\
\hline & Monensin* & & 1 & 1 & & 2 & & & 4 \\
\hline & Narasin & 1 & & 2 & & 2 & 3 & 2 & 10 \\
\hline & Nicarbazin(incl. DNC) & 36 & 38 & 9 & 3 & & 1 & & 87 \\
\hline & Robenidine & 8 & 3 & 1 & & & 2 & & 14 \\
\hline & Salinomycin & 13 & 4 & 6 & 1 & 3 & 1 & 2 & 30 \\
\hline & Semduramicin & 1 & 4 & 1 & & 1 & & & 7 \\
\hline A6 & Metronidazole & & 1 & & & & & & 1 \\
\hline
\end{tabular}

Additional data are obtained from the RASFF alert and information notifications of veterinary drug residues in eggs and egg products over the period 2002-2015 (Tables 6a-c). 
Table 6a Alert and information notifications of VMP residues belonging to class B1 compounds, reported as chemical hazards in the RASFF system, between 2002-2015.

\begin{tabular}{|c|c|c|c|}
\hline Date & Notified by & Notification type & Subject \\
\hline 25-3-2015 & Belgium & alert & $\begin{array}{l}\text { trimethoprim, sulfonamide, enrofloxacin and toltrazuril ( } 9 \text {; } \\
89 \mu \mathrm{g} / \mathrm{kg}-\mathrm{ppb} \text { ) unauthorised in organic whole-egg-powder from the } \\
\text { Netherlands, with raw material from Belgium, Germany and Denmark }\end{array}$ \\
\hline $20-3-2015$ & Germany & alert & $\begin{array}{l}\text { enrofloxacin }(49 ; 38 \mu \mathrm{g} / \mathrm{kg}-\mathrm{ppb}) \text { unauthorised in organic whole-egg- } \\
\text { powder from the Netherlands, with raw material from Germany, Belgium } \\
\text { and Denmark }\end{array}$ \\
\hline $8-9-2010$ & Poland & information & enrofloxacin $(2426.6 \mu \mathrm{g} / \mathrm{kg}-\mathrm{ppb})$ unauthorised in eggs from Poland \\
\hline 2-12-2009 & France & information & $\begin{array}{l}\text { unauthorised substance tylosin }(7.3 \mathrm{mg} / \mathrm{kg}-\mathrm{ppm}) \text { in whole fresh liquid } \\
\text { eggs from Spain }\end{array}$ \\
\hline $28-3-2008$ & Belgium & alert & $\begin{array}{l}\text { tilmicosin }(>400 \mu \mathrm{g} / \mathrm{kg}-\mathrm{ppb}) \text { unauthorised in egg powder from } \\
\text { Argentina }\end{array}$ \\
\hline $23-4-2004$ & Spain & information & $\begin{array}{l}\text { macrolides (presence) unauthorised in egg white powder -dried } \\
\text { albumen }\end{array}$ \\
\hline 27-8-2003 & Austria & information & difloxacin $(113 \mu \mathrm{g} / \mathrm{kg}-\mathrm{ppb})$ unauthorised in hen eggs \\
\hline $21-3-2003$ & $\begin{array}{l}\text { United } \\
\text { Kingdom }\end{array}$ & alert & $\begin{array}{l}\text { unauthorised substance sulphadimethoxine }(320 \mu \mathrm{g} / \mathrm{kg}-\mathrm{ppb}) \text { in Quail } \\
\text { eggs }\end{array}$ \\
\hline
\end{tabular}


Table $6 \boldsymbol{b} \quad$ Alert and information notifications of coccidiostats (class B2b compounds), reported as chemical hazards in the RASFF system, between 2002-2015.

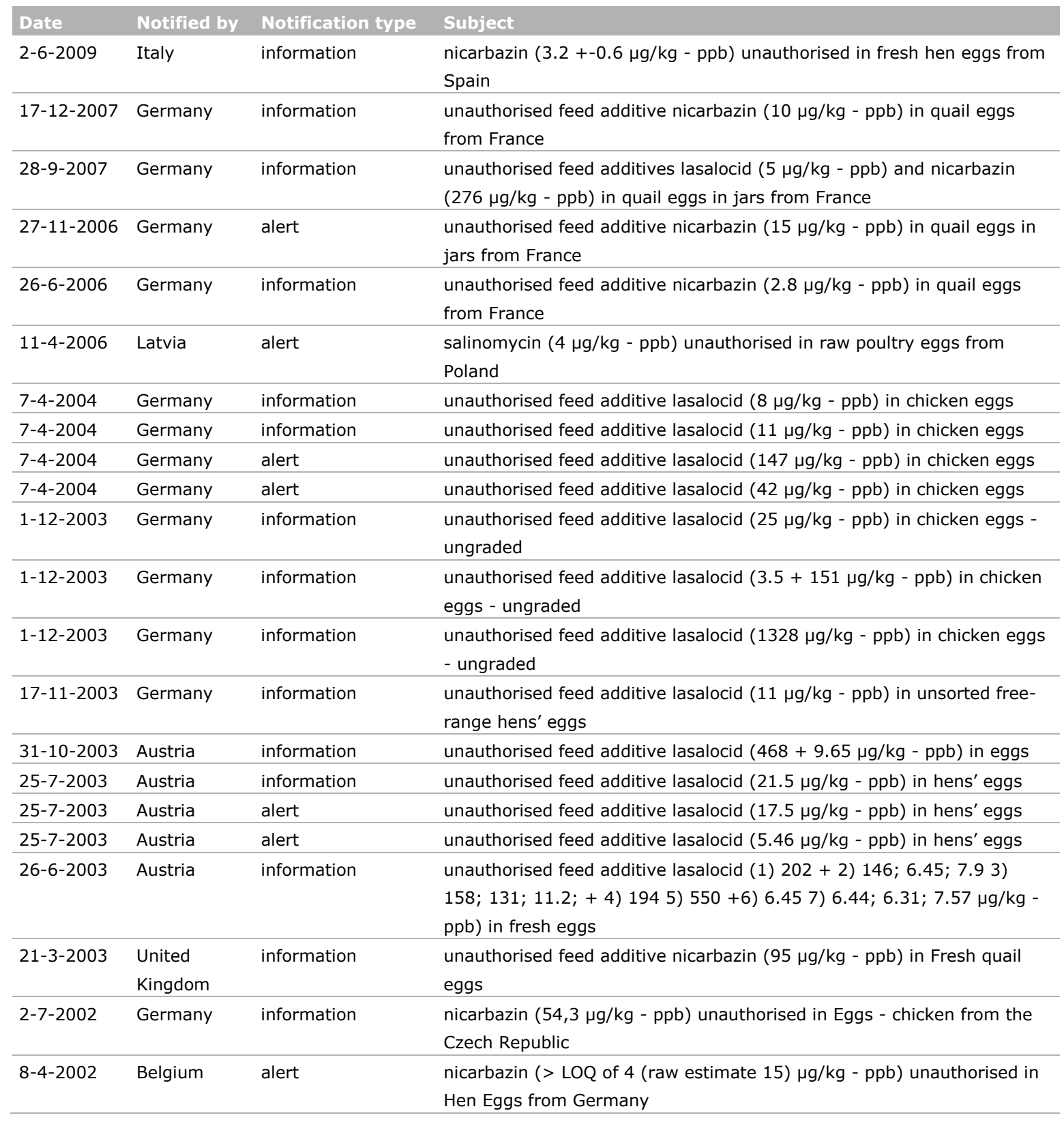


Table 6c Alert and information notifications of banned VMP residues (class A6 compounds), reported as chemical hazards in the RASFF system, between 2002-2015.

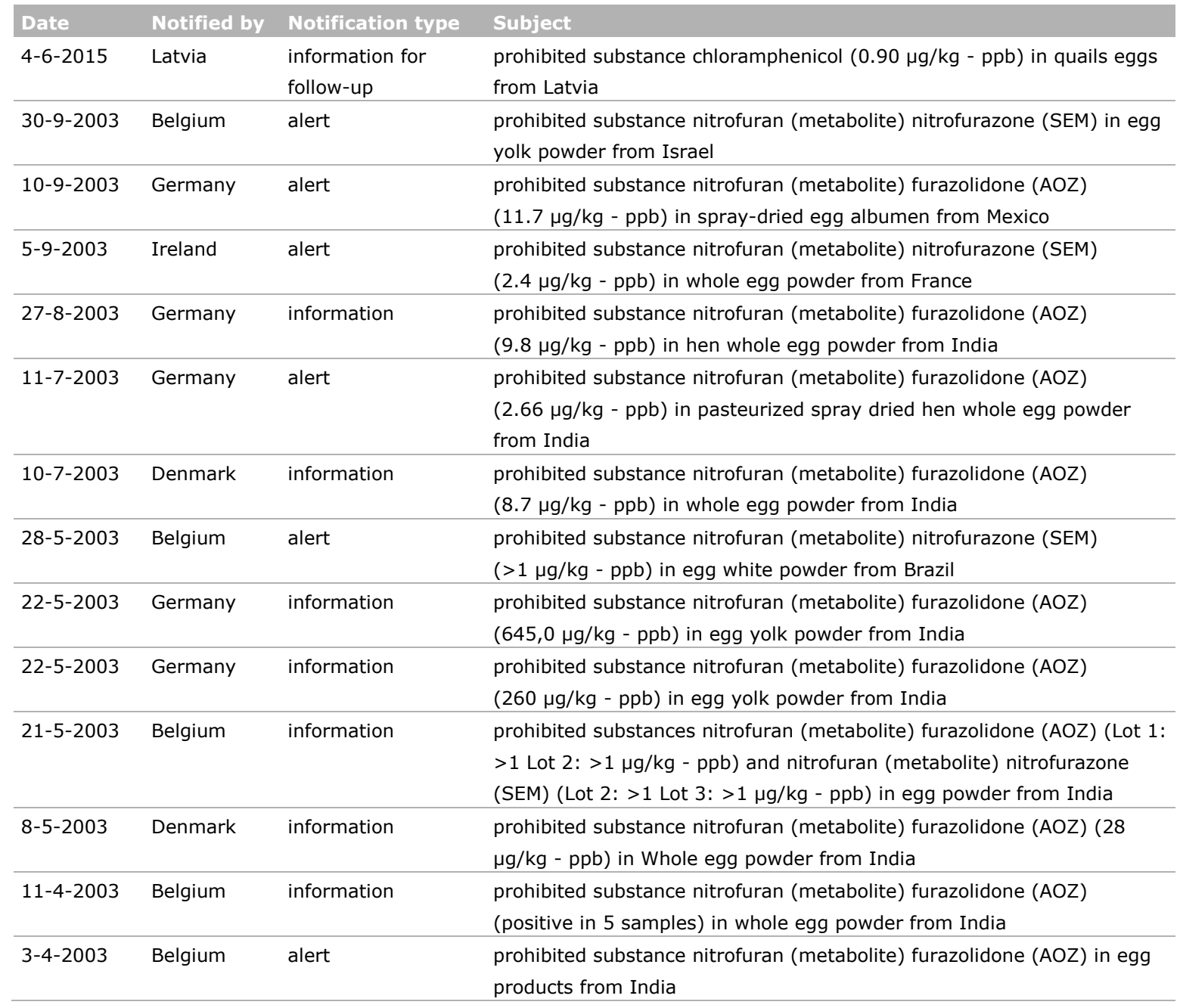

Below, the various groups of veterinary drugs are described that have an MRL (see Table 4) as well as drugs that have been found in eggs (see for example Table 6), are frequently used in eggs or were reported in literature as relevant for eggs are described.

\section{Quinolones}

Quinolones include, for example, enrofloxacin and difloxacin, which have been reported in RASFF (Table 6). They are considered critically important for human medicine, and the use for veterinary purposes is strongly discouraged. Enrofloxacin is used in veterinary medicine for the treatment of infections of the respiratory and alimentary tract in cattle, pigs, turkeys and chickens (EMA, 1998a). Difloxacin acts against a broad spectrum of bacteria including aerobic and anaerobic Gram-positive and Gram-negative organisms (EMA, 1995).

For (fluoro)quinolones, several residue depletion studies in eggs are available. Data have been published for enrofloxacin, sarafloxacin, ciprofloxacin, danofloxacin, pefloxacin, flumequine, norfloxacin and oxolinic acid (see Goetting 2011 for references). Enrofloxacin is studied most extensively, whereas for difloxacin no published data were found. Animal experiments showed that enrofloxacin could be detected in eggs up to around 15 days after treatment (Lolo, 2005; Cornejo, 2012; Bogialli, 2009b). For flumequine, another relatively frequently applied fluoroquinolone antibiotic, depletion takes longer than for enrofloxacin (Cornejo et al., 2012). The Committee for Veterinary Medicinal Products (CVMP) of EMA recommended MRLs for enrofloxacin excluding the use in poultry from which eggs are produced for human consumption (EMA, 2002a). Nevertheless, this quinolone has been found in egg samples, which is most likely caused by prescription through the Cascade (EC, 
2001). In 2002, the CVMP recommended MRLs for difloxacin in bovine/ovine/caprine, porcine, poultry and all other food producing species, but not for eggs (EMA, 2002b).

\section{Macrolides}

Macrolides are broad-spectrum antibacterial substances used in both human and veterinary medicine. Their basic structure consists of a central lactone ring. Eight macrolides had been authorized for veterinary use within the EU by 2011: erythromycin, tildipirosin, tylosin, tylvalosin, spiramycin, tilmicosin, tulathromycin, and gamithromycin (EMA, 2011). CVMP has established MRLs for eggs intended for human consumption for two of the eight macrolides: erythromycin and tylosin.

For erythromycin, it was estimated that, based on their proposed MRL values, "the daily intake will represent about $90 \%$ of the ADI" (EMA, 2000a; EMA, 2000b). JECFA compared their proposed ADI with the LOEL for non-tumorigenic effects in a 2-year dietary study in rats, which lead to a 300,000fold margin of exposure. JECFA concluded that, "although based on a LOEL, this margin of exposure is such that residues of erythromycin are unlikely to pose a risk of systemic toxicity to humans" (JECFA, 2006). In 2000, EMA extended MRLs for tylosin to eggs and estimated that, based on the MRLs, "the daily intake would represent about $80 \%$ of the ADI", which was established at $360 \mu \mathrm{g}$ per person (EMA, 2000c).

For tilmicosin, CVMP has set MRL levels in several animal-based products, including products from poultry. However, the provisions state that tilmicosin is "not for use in animals from which eggs are produced for human consumption" (EMA, 2002c). It can however still be prescribed by the veterinarian through the Cascade. This compound has been reported in an alert to be present in eggs in the RASFF database (Table 6a).

For macrolides, several residue depletion studies in eggs are available in scientific literature. Data have been published for tylosin, spiramycin, erythromycin, josamycin, kitasamycin and oleandomycin (see Goetting 2011 for references). Almost all these studies, however, are based on bioassay analyses, which have relatively high detection limits, making it difficult to determine days to complete depletion. In general, for some macrolides, such as tilmicosin, residues could be detected in eggs for a long period of time (up to 20 days) after treatment (FAO 1998). For other macrolides, such as tylosin, residue levels rapidly decreased and dropped below the limit of detection on day 14 of the study (Hamscher, 2006).

\section{Tetracyclines}

All tetracyclines have a broad spectrum of activity, which includes gram-positive and gram-negative bacteria, chlamydias, rickettsias, mycoplasmas and spirochaetes (EMA, 1996). Tetracyclines include, amongst othersdoxycycline and oxytetracycline. Most data concerning tetracycline residues in eggs focus on oxytetracycline. Doxycycline hyclate is indicated for use in cattle, pigs, poultry, turkeys, rabbits, dogs and cats, but it is not for use in animals from which milk or eggs are produced for human consumption (EPMAR Doxycycline, 2015). Nevertheless, doxycycline has been found in egg samples (Table 5). From the data available in literature (Yoshimura, 1991; Gajda \& Posyniak, 2015; Vandenberge, 2012a), it is clear that doxycycline readily transfers to eggs. Considering the extensive use of this compound in broilers, and potential prescription for laying hens under the Cascade, occurrence in eggs can also be expected. From a food safety and enforcement point of view it would be desirable to have an MRL established for this tetracycline as well.

\section{Polyether ionophores}

There are several ionophores, such as lasalocid, narasin and salinomycin. "Lasalocid is authorized as a feed additive under Regulation (EC) No 1831/2003 for the prevention of coccidiosis in chickens and turkeys. As a feed additive, lasalocid is given continuously to chickens and turkeys from day 0 up to 16 weeks, at doses of $75-125 \mathrm{mg} / \mathrm{kg}$ feed with a withdrawal period of 5 days" (EPMAR Lasalocid, 2015). Narasin is used to prevent coccidiosis in poultry; it "is authorized according to Regulation (EC) No $1464 / 2004$ as a coccidiostat for use in chickens for fattening with a maximum content of the active substance in feed of $70 \mathrm{mg} / \mathrm{kg}^{\prime \prime}$ (EFSA CONTAM, 2007). Salinomycin is presently approved as feed additive for chickens for fattening and for chickens reared for laying (EFSA Feedap, 2004). Several studies analysed the deposition and residue depletion of ionophores in eggs. 
The available residue studies on ionophores all show a strong correlation between the concentration in the feed and the plateau concentrations observed in the eggs, but there is a marked difference in their ability to accumulate (Kennedy, 1996; Vandenberge, 2012b; Rokka et al., 2005; Akhtar et al., 1996). Kennedy et al. (1998) determined the relative ability of monensin, salinomycin and lasalocid to accumulate in eggs and found results of, respectively, $0.12,3.3$ and $63 \mu \mathrm{g} / \mathrm{kg}$ egg per $\mathrm{mg} / \mathrm{kg}$ feed, indicating that lasalocid is much more readily transferable into eggs than salinomycin and monensin. Finally, it should be noted that data for lasalocid primarily refer to exposure from cross-contamination, so concentrations studied represented a maximum of $10 \%$ of the authorized concentration. In practice, occasional exposure to much higher concentrations might occur in case of erroneous administration of broiler feed to laying hens.

In February 2015, the CVMP established an ADI for lasolocid of $5 \mu \mathrm{g} / \mathrm{kg}$ bw (i.e. $300 \mu \mathrm{g} /$ person). This ADI was "based on the NOEL of $0.5 \mathrm{mg} / \mathrm{kg}$ bw/day from the 2-year chronic oral toxicity study in rats and the maternal toxicity study in rabbits, applying an uncertainty factor of 100" (EPMAR Lasalocid, 2015). The CVMP calculated theoretical maximum daily intakes of lasalocid residues for consumers, with the worst case assumption that all chicken derived foods contain the maximum residue levels of lasalocid. The theoretical maximum daily intake of lasalocid residues would be $265.2 \mu \mathrm{g} /$ person, representing approximately $88.4 \%$ of the ADI (EPMAR Lasalocid, 2015).

In 2004, the EFSA FEEDAP panel established an ADI for narasin of $0.005 \mathrm{mg} \mathrm{kg} / \mathrm{bw}$ (equal to $300 \mu \mathrm{g}$ person/day for a person of $60 \mathrm{~kg}$ bodyweight), based on the lowest toxicological NOEL of $0.5 \mathrm{mg} / \mathrm{kg}$ bw per day for neuropathy seen in a one-year dog toxicity study (EFSA FEEDAP, 2004). Although narasin is only authorised within the EU for use as feed additive in chickens for fattening, crosscontamination may lead to the occurrence of narasin in non-target feeding stuffs. In 2007, EFSA estimated human exposure to narasin from cross-contaminated feed. The relevant food items for this calculation are (non-chicken) liver and eggs. Liver consumption was calculated to lead to exposure of $23 \mu \mathrm{g}$ narasin equivalents per person per day (corresponding to $0.38 \mu \mathrm{g} / \mathrm{kg} \mathrm{bw}$ for a $60 \mathrm{~kg}$ adult or $7.6 \%$ of the ADI). Eggs were calculated to lead to a maximum intake of $1.5 \mu \mathrm{g}$ narasin per person per day, corresponding to $0.025 \mu \mathrm{g} / \mathrm{kg}$ bw per day for a $60 \mathrm{~kg}$ adult $(0.5 \%$ of the ADI) (EFSA CONTAM, 2007).

The ADI for salinomycin was established at $0.005 \mathrm{mg} / \mathrm{kg}$ bw per day, based on the lowest NOEL of $0.5 \mathrm{mg} / \mathrm{kg}$ bw per day and a safety factor of 100 (EFSA FEEDAP, 2004).

\section{Nicarbazin}

Nicarbazin is a synthetic complex composed of an equimolar amount of 4,4'-dinitrocarbanilide (DNC) and 2-hydroxy-4,6-dimethylpyrimidine (HDP). Since the HDP fraction is absorbed and excreted more rapidly than the DNC fraction, DNC is considered the appropriate marker residue (EFSA CONTAM, 2008). Nicarbazin has been used for several decades as an aid in the prevention of faecal and intestinal coccidosis in broiler chickens. Nicarbazin is authorized in the EU as a coccidiostat feed additive for use in chickens for fattening only (JECFA, 1998; EFSA CONTAM, 2008; EFSA Feedap, 2010).

The data available on nicarbazin (DNC) deposition in eggs (Cannavan et al, 20; Furusawa, 2001; Mortier et al., 2005) indicate that residues accumulate effectively in egg (yolk) and are relatively persistent, explaining the frequent occurrence in RASFF alerts before 2010. However, with the establishment of an MRL anticipating the unavoidable carry-over of this compound in feed (Regulation (EC) No 124/2009), non-compliances (exceeding $300 \mu \mathrm{g} / \mathrm{kg}$ ) are less likely to occur.

In 2010, EFSA stated that only DNC should be considered for consumer safety assessment, "as the consumer will not be exposed to nicarbazin but to DNC (HDP residues are negligible, the level of consumer exposure is expected to be several orders of magnitude less than the levels showing toxicity in animals). The lowest NOAEL for DNC derived from a two-year dog study was $154 \mathrm{mg} \mathrm{DNC/kg} \mathrm{bw}$ per day. (...) An uncertainty factor of 200 is applied in deriving an ADI from the NOAEL. (...) This corresponds to an ADI of $770 \mu \mathrm{g}$ DNC/kg bw (corresponding to $46 \mathrm{mg}$ DNC per $60 \mathrm{~kg}$ person)." Consumer exposure to DNC-related residues was calculated according to daily consumption values of animal products set in Regulation (EC) No 429/2008, and the calculated DNC total residues measured 
in the different tissues. The results indicate that consumer exposure to the whole DNC-derived residues present in chicken tissues at one-day withdrawal is $5.453 \mathrm{mg}$ DNC per person per day, corresponding to $12 \%$ of the ADI (EFSA Feedap, 2010).

\section{Nitrofurans}

Nitrofurans are synthetic antimicrobials identified by their common 5-nitrofuran ring. In most countries including the EU, nitrofurans are banned from use in food producing animals because of their carcinogenic and genotoxic properties. Nitrofurans are to some extent transferred to eggs (McCracken, 2007). Metabolism of nitrofurans results in the formation of protein-bound residues with a relatively long half-life in the animal. The rapid metabolism of nitrofurans has made screening for parent drugs difficult in food products, so methods able to detect tissue bound side-chain metabolites which is released upon acid hydrolysis, have been developed as an alternative (furazolidone -> 3-amino-2oxazolidinone (AOZ), nitrofurazone -> semicarbazide (SEM), furaltadone -> 1-aminohydantoin (AHD) and nitrofurantoin -> 3-amino-5-morpholinomethyl-1,3-oxazolidin-2-one (AMOZ). Several studies with these compounds showed that, depending on the compound, they could be detected in eggs after a prolonged withdrawal period (McCracken, 2001; McCracken, 2007). For official control, a minimum required performance level (MRPL) of $1 \mu \mathrm{g} / \mathrm{kg}$ was established for the marker metabolites (2002/657/EC) (EC, 2002b). This MRPL should be considered as the reference point of action (RPA) (Regulation (EC) No 34/2005). Because most of the nitrofurans and potentially also their marker metabolites are genotoxic and/or carcinogenic, derivation of health-based guidance values (HBGVs) including an acceptable daily intake (ADI) or tolerable daily intake (TDI) is not appropriate (EFSA CONTAM, 2015). The CONTAM Panel of EFSA calculated human dietary exposure "for a scenario in which a single nitrofuran marker metabolite is present at the RPA of $1.0 \mu \mathrm{g} / \mathrm{kg}$ in foods of animal origin, excluding milk and dairy products. The mean chronic dietary exposure for this worst-case scenario would range from 3.3 to 8.0 and 1.9 to $4.3 \mathrm{ng} / \mathrm{kg}$ bw per day for toddlers and adults, respectively. Margins of exposure (MOEs) were calculated at $2.0 \times 10^{5}$ or greater for carcinogenicity and at $2.5 \times 10^{3}$ or greater for non-neoplastic effects. The CONTAM panel concluded therefore that it is unlikely that exposure to food contaminated with nitrofuran marker metabolites at or below the RPA of $1.0 \mu \mathrm{g} / \mathrm{kg}$ is a health concern" (EFSA CONTAM, 2015). Interestingly, Mc Cracken et al. (2001) found that in particular SEM appeared to accumulate considerably in the egg shell $(1.8 \mathrm{mg} / \mathrm{kg})$, but also the other nitrofurans (nitrofurazone, furaltadone and nitrofurantion) were found in egg shells. Since egg shells are used as animal feed ingredient, they could occur as an unexpected source of contamination in the food and feed chain.

Egg processing has a negative effect on the presence of SEM. Pasteurization and spray drying was reported to cause considerable loss of SEM: $51 \%$ in whole egg, $17 \%$ in yolk and $72 \%$ in albumen (Cooper et al., 2008).

In general, it can be concluded that residues of both authorized and unauthorized veterinary pharmaceutical compounds may occur in eggs. In particular coccidiostats (compounds administered through feed) are likely to be present, due to cross contamination, but also because feed formulated for target animal species may accidentally be given to a non-target species (in this case laying hens). With respect to antibiotics, the limited availability of products registered for use in laying hens is provoking Cascade prescription of drugs for which no MRL has been set in eggs. This creates a significant probability of residues occurring in eggs as a result of unsubstantiated withdrawal periods.

\section{Situation in countries exporting eggs/egg products to Europe}

For decades, antimicrobials have also been administered at sub-therapeutical levels in feed, for the sole purpose of improving growth rate and feed conversion efficiency (as antimicrobial growth promoter). However, concerns about development of antimicrobial resistance and subsequent risk of transfer to humans, led to withdrawal of the approval for use of antibiotics as growth promoters in the European Union since January 1, 2006 (Regulation (EC) No 1831/2003). Outside Europe however, supplementing animal feed with antimicrobial agents to enhance growth is still common practice. Only a limited number of countries hold so-called Third Country establishments for exporting eggs and egg products to the EU (Regulation (EC) No 854/2004): Albania, Argentina, Canada, China, India, Israel, Mexico, Russian Federation, Serbia, Turkey, Ukraine, United States. The US, Argentina, India and potentially Ukraine are the most important exporters of egg powder to the EU (van Horne, 2012). 
The extent of their ability to comply with EU food safety and veterinary requirements has been derived from Food \& Veterinary Office (FVO) audit and inspection reports. Key elements assessed during these audits are design and implementation of residue control programs, legislation on maximum allowed residue levels and the authorisation of veterinary medicinal products, as well as appropriate (analytical) capacity to sustain enforcement. The evaluation of various countries (USA, India, Argentina and Ukraine) showed that either weaknesses in legislation or control plans preclude the residue monitoring from being considered fully equivalent to EU requirements (FVO, 2010a, 2010b, 2011a, 2011b, 2014, 2015). Also, in some countries, like India, there is a difference in tolerated antibiotics for domestic and export production. The safety of egg products imported from such countries relies heavily on a strict separation of production systems intended for export and the domestic market. It should be noted that there are some products used as antimicrobial additive/growth promoter that are not (and never have been) on the market in Europe, and are not included in scope of EU methods and surveillance. In particular compounds like zoalene and enramycin are used in some parts of the world, primarily in the United States and Asia. For these compounds, little or no information on pharmacodynamics and kinetics is available, precluding any founded conclusion with respect to the potential presence of residues when occurring in eggs.

\subsubsection{Pesticides}

Pesticides are agents used to control or kill undesired insects, weeds, rodents and other organisms such as bacteria and fungi. Herbicides, insecticides, fungicides, rodenticides, and disinfectants are classified under the name pesticides. The main route for pesticide residues to enter the egg production chain is through laying hens that are fed on crops treated with pesticides. Pesticides that are persistent are of potential concern to human health because they have the ability to bio-accumulate (EC, 2004). Pesticide residues are accumulated to higher concentrations in eggs as compared to poultry meat (Aulakh et al., 2006). As with antibiotics, the potential health and environmental risks associated with pesticides are assessed before they are allowed for use in Europe. MRLs have been set by the EC for authorized pesticides via Regulation (EC) No 396/2005 (EC, 2005).

As a result of their persistence and risk for human and animal health, certain pesticides are banned from use worldwide. One known example is dichloro-diphenyl-trichloroethane or DDT, which has been widely used to control insect pests in agriculture and to control the spreading of malaria. In several European countries, the use of DDT as an insecticide has been restricted since the late 1960s and its use was finally banned in the early 1970s. Since 1986, it has been completely banned as a pesticide in the European Union but it is still in use for vector control in those countries with endemic malaria (EFSA, 2006).

Due to its widespread use in the past and its persistent characteristics, DDT and especially its break down product (DDE) are still widely found in the environment. As a result, DDT can still be found in feed and food. DDT and its metabolites are lipophilic compounds that bioaccumulate in the body. (EFSA, 2006). DDT is rapidly metabolized in chickens into dichlorodiphenyldichloroethane (DDD) and dichlorodiphenyldichloroethylene (DDE), where DDD is only found in the liver and DDE is excreted in the egg (Furusawa, 2002). Most species, including humans, store DDE more efficiently than DDT (EFSA, 2006).

There is limited background monitoring data available on DDTs in eggs. Although the use of DDTs as a pesticide is prohibited, an MRL still exists at a level of $50 \mathrm{ng} / \mathrm{g}$ fat. A study from Belgium in home produced eggs from 58 locations showed median concentration of DDTs in eggs of $63 \mathrm{ng} / \mathrm{g}$ fat, and a mean is $457 \mathrm{ng} / \mathrm{g}$ fat. Seventeen percent of the samples contained DDT concentrations above the MRL (500 $500 \mathrm{ng} / \mathrm{g}$ fat) and one sample had an extremely high concentration of $12170 \mathrm{ng} / \mathrm{g}$ fat. p, $\mathrm{p}^{\prime}$-DDE dominated the profile in most cases. No correlation was found between the residues found in eggs with feed or soil levels (Windal et al., 2009). Although home produced eggs are not considered in the current production chain study, similar elevated contamination with DDTs may occur in free-range produced chicken eggs that are exposed to contaminated soil. To what degree soils at free-range chicken farms are contaminated, and as a result also the eggs, is currently unclear (Windal et al., 2009. Authors reported the levels found in the Belgium study were extreme high. In commercial eggs produced in Spain, Belgium and Sweden, DDT is usually not detected or only at trace levels (Windal et al., 2009). 
KAP data from the years 2005-2014 showed that 7 out of 524 egg samples contained DDE (ranging from 11 to $20 \mathrm{ng} / \mathrm{g} \mathrm{egg).} \mathrm{Furthermore,} \mathrm{two} \mathrm{samples} \mathrm{contained} \mathrm{HCB} \mathrm{(10} \mathrm{and} 30 \mathrm{ng} / \mathrm{g}$ egg) and two samples dieldrin ( 72 and $91 \mathrm{ng} / \mathrm{g}$ egg). According to the results of the control activities related to pesticide residues in food carried out in 2012 in the EU Member States, 727 samples of chicken eggs were analyzed. No pesticide residues were detected in 688 samples, while 39 contained one or several pesticide residues in measurable concentrations. DDT was the most frequently detected residue in chicken eggs, with $5.8 \%$ of the samples having levels above the LOQ (EFSA, 2014a).

RASFF alert and notifications for pesticide residues in eggs and egg products in the period 2002 2015 showed only 7 reports, covering nitrofen, nicotine and cotinine (data not shown). It actually shows two different incidents, one in Germany in 2002 with nitrofen, and one with nicotine that was occasionally used as treatment against blood lice. Nitrofen (2,4-dichloro-1-(4-nitrophenoxy)benzene) is a contact herbicide that has been banned from use since 1 January 1988 under Directive $79 / 117 /$ EEC. It is classified as a probable human carcinogen and probable reproductive toxin due to its teratogenicity. The MRL for eggs has been set at the default, which is $0.01 \mathrm{mg} / \mathrm{kg}$ (EU pesticides database). Although its use is banned, nitrofen was found in organic poultry meat, eggs, pork and in organic feed in Germany in 2002 (EC, 2002a) as a result of the use of contaminated wheat in chicken feed (Hooper, 2002). The wheat had been stored in a depot previously used for the storage of herbicides, such as nitrofen. Apparently, the warehouse had not been properly cleaned, causing a contamination of the animal feed subsequently stored (Tuffs, 2002). Nicotine has also been used as an insecticide, falling under the legislation for pesticides. Cotinine is the major metabolite of nicotine. In 2009, the European Commission concluded that a safe use of nicotine as a plant protection product was not sufficiently demonstrated. Since June 2009, all plant protection products containing nicotine as active substance were withdrawn (EFSA, 2011a). Nicotine is sometimes illegally used in poultry as a treatment against Dermanyssus gallinae (red poultry mite or chicken mite). A batch of nicotine presumably intended for the treatment of Dermanyssus gallinae was found in the Netherlands in 2005. In 2006, RIKILT performed an experiment with nicotine in laying hens and measured nicotine and its residues in the eggs and meat of the animals (Traag 2005). Eggs were collected one day after exposure of the laying hens to nicotine. The eggs did not contain nicotine (levels below the LOD of $25 \mathrm{ng} / \mathrm{g})$, but did contain cotinine $(18 \mathrm{ng} / \mathrm{g})$ and $30 \mathrm{H}$-cotinine $(129 \mathrm{ng} / \mathrm{g})$.

Based on these levels, it was estimated that this would lead to a total intake of nicotine, cotinine and $30 \mathrm{H}$-cotinine of $0.15 \mu \mathrm{g} / \mathrm{kg}$ bw for an adult (bw $60 \mathrm{~kg}$ ) consuming one nicotine-contaminated egg (of $60 \mathrm{~g}$ ) (Frontoffice beoordeling 2006), which is below the established ArfD and ADI for nicotine of $0.8 \mu \mathrm{g} / \mathrm{kg}$ bw/day (EFSA, 2009a). For cotinine, no health based guidance levels are available.

The BfR has performed a scenario study assuming nicotine levels in eggs at 3, 30 and $300 \mathrm{ng} / \mathrm{g}$ egg. BfR concluded that at these hypothetical levels, no adverse effects are to be expected from egg consumption. The highest exposure levels resulted in an estimated daily intake of 0.31 and $0.39 \mu \mathrm{g} / \mathrm{kg}$ bw for children and adults respectively (BfR, 2006).

\subsubsection{Mycotoxins}

The main route of exposure of animals to mycotoxins is via feed (Pettersson, 2012). Mycotoxins of potential concern in feed for production animals include: aflatoxins, ochratoxin $A$, and Fusarium toxins including trichothecenes like deoxynivalenol (DON), diacetoxyscirpenol, nivalenol, T2-toxin/HT2-toxin, and zearalenone and fumonisins (EFSA, 2009c). Mycotoxins present in feed could be transferred into eggs (Sypecka et al., 2004). However, contamination of eggs with mycotoxins is generally low. RASFF does not contain any notifications of mycotoxins in eggs and egg products in the period 2002-2015. Mycotoxins are currently not tested in eggs in the Dutch monitoring program. In a study performed in Belgium, low levels of deoxynivalenol (DON)(2.6-17.9 ng/g) and its metabolite de-epoxy-DON (2.4-23.7 $\mathrm{ng} / \mathrm{g}$ ) were found in home-produced egg samples (Tangni et al., 2009). None of the egg samples collected from Belgium had quantifiable levels of zearalenone, a-zearalenol, $\beta$-zearalenol, ochratoxin A, and citrinin (Tangni et al., 2009).

The diet of laying hens is to a large extent composed of cereals grains, which are vulnerable to DON and other mycotoxin contamination. In Europe, guidance limits have been set for the presence of DON and other mycotoxins in a wide variety of feed ingredients and complete feeds, including those used 
for laying hens. Exposure of hens to DON, also below the legal limits, may results into lower (re)productivity. Human exposure via food consumption is, however, low. DON is metabolised in livestock resulting in only trace elements in eggs. Indeed, a feeding trial with laying hens that were fed with up to $83 \mathrm{mg} \mathrm{DON} / \mathrm{kg}$ feed for 27 days did not result in DON residues in chicken tissues (MacLachlan, 2011). In 2013, a mycotoxin-dedicated total human diet study was performed in the Netherlands showing that the main contributors to DON exposure were bread and cookies and biscuits in in children aged 2-6 years and adults aged 7-69 years. In the latter group, beer and pasta also contribute to the exposure to DON (Sprong et al, 2016; Lopez et al, 2016). Eggs are, therefore, not seen as a major contributor to human DON intake.

\subsubsection{Melamine}

Melamine is a metabolite and degradation product of the pesticide and veterinary drug, cyromazine. It is also used in the synthesis of melamine formaldehyde resins for manufacture of laminates, plastics, coatings, commercial filters, glues and adhesives, and some dishes and kitchenware. It is a chemical that is produced from urea. In the manufacturing process of melamine, ammeline, ammelide and cyanuric acid can be formed by hydrolysis under acidic conditions (http://www.chemistrymag.org/cji/2009/118037re.htm). Impure melamine may, therefore, contain cyanuric acid, ammeline and ammelide, which are structurally related. Cyanuric acid can occur in food due to the use of certain disinfection agents. In addition, urea-based animal feed might contain impurities like melamine and cyanuric acid (EFSA, 2010).

Melamine received considerable public attention after the pet food contamination scandal in North America in 2007, and the melamine-tainted milk powder and eggs incident in China in 2008 (Gossner et al., 2009). Melamine is not approved for use as a feed or food additive. However, it has been illegally used as a nitrogen source in animal nutrition to increase feed protein content. When melamine is present in feed, it can be transferred into eggs, at a carry-over rate of approx. 0.5-1.5\% (Gallo, Bertuzzi et al. 2012, Novak, Suchy et al. 2012, Lorenz, Fry et al. 2014). Melamine might also enter the egg production chain at the egg processing stage as a result of its illegal addition to food products in order to boost their protein content or as a contact material. Melamine is converted to cyanuric acid, which is deposited in eggs at a similar concentration as melamine (Novak, Suchy et al. 2012).

In the Netherlands, there is currently no background level monitoring on this compound in eggs. EFSA reported a median level of melamine in eggs of $0.01 \mathrm{mg} / \mathrm{kg}$, based on 315 results, with a P95 of $0.1 \mathrm{mg} / \mathrm{kg}$. The levels of cyanuric acid in eggs were $0.01 \mathrm{mg} / \mathrm{kg}$ (median) and $0.05 \mathrm{mg} / \mathrm{kg}$ (P95), based on 209 results (EFSA, 2010). The consumption of eggs seems to have a minor contribution to the total dietary melamine exposure; for high consumers, the melamine intake via eggs is estimated to range from 0.06 to $0.21 \mu \mathrm{g} / \mathrm{kg}$ bw per day, whereas the total dietary exposure to melamine, based in the upper bound melamine concentrations, was estimated to range between $2.66-6.16 \mu \mathrm{g} / \mathrm{kg}$ bw per day for average (mean) consumers and $6.21-10.58 \mu \mathrm{g} / \mathrm{kg}$ bw per day for high consumers (P95) for the adult European population (EFSA, 2010).

Both melamine and cyanuric acid alone have a low toxicity. Simultaneous exposure to both melamine and cyanuric acid leads to synergistic effects compared to individual exposure to the compounds, due to the increased formation of urinary crystals. However, a factor for this increased toxicity due to coexposure could not be derived and no TDI has been established (EFSA, 2010; WHO, 2008). The TDI established for melamine is not appropriate when co-exposure with cyanuric acid, ammeline or ammelide occurs (EFSA, 2010).

\subsubsection{Plant Toxins}

Plant toxins are naturally occurring components in plants that have adverse effects on human health. There are different groups of plant toxins, such as glycoalkaloids, which occur in some species of the nightshade family, glucosinolates, which mainly occur in vegetables form the Brassica genus, cyanogens, occurring for example in cassava, almonds and bamboo, hydrazins, ocurring in mushrooms and pyrrolizidine alkaloids (PAs), occurring in herbs and other plants. PAs comprise around 200 different compounds, some of which have been shown to be hepatotixic and carcinogenic (Speijers and van Egmond, 1999). These PAs may be present in feed and can subsequently be ingested by poultry. An incident in South Australia in 1987 showed that plant toxins present in feed 
can be transferred to eggs. A reduced egg production at the poultry farm could be traced back to the feed, which contained heliotrope alkaloids and PAs. These plant toxins were subsequently found in the eggs up to $9.7 \mu \mathrm{g}$ of PAs per egg (Colegate et al. 2003). PAs can thus transfer to eggs (Edgar et al., 2011), but there is currently limited information on the actual transfer rates.

Due to the limited availability of organic feed for organic poultry, alternative feed sources, e.g., clover grass or luzerne, are used due to their good amino acid composition (Hermansen, 2015). Such feed materials may, however, be susceptible for plant toxins and should be monitored to prevent possible transfer to the egg.

\subsubsection{Per- and polyfluorinated alkyl substances}

Per- and polyfluorinated alkyl substances (PFASs) are a group of industrial compounds that are widely used in consumer and industrial products, including Teflon, carpet stain repellents, aqueous fire fighting foams (AFFFs) and mist suppressants in metal plating industry. Their extensive usage over the last 50-60 years resulted in a wide distribution of these chemicals in the environment. Most known examples are the surfactant type chemicals perfluorooctane sulfonate (PFOS) and perfluorooctanoic acid (PFOA) (Halldorsson et al., 2008). Other PFASs vary by chain length, functional group or degree of fluorination. These chemicals received attention since the early 2000s (Buck et al., 2011). In 2008, EFSA produced a scientific opinion on PFOS and PFOA, and TDIs were set at $1500 \mathrm{ng} / \mathrm{kg}$ bw per day for PFOA and $150 \mathrm{ng} / \mathrm{kg}$ bw per day for PFOS (EFSA, 2008). In 2012, EFSA performed an additional exposure assessment, based on new data that was obtained since the opinion was published (EFSA, 2012f). The average levels of PFOS and PFOA in fresh eggs were 0.76 and $0.70 \mathrm{ng} / \mathrm{g}$, respectively. Egg products contributed less than $5 \%$ to the dietary exposure to PFOS across the age groups. For PFOA, the average contribution of eggs to the total dietary intake ranged from $10-15 \%$ depending on the age group. Based on dietary exposure assessment, EFSA concluded that the current exposure to PFASs poses no risk for the consumer (i.e. sufficient margin of exposure) (EFSA, 2012f). However, EFSA recently (12 April 2016) installed a new working group on PFASs in Food

(http://www.efsa.europa.eu/en/chemical-contaminants/working-groups), which may lead to a revision of the TDIs for PFOS and PFOA. This may have consequences for the MOE.

Noorlander et al (2011) established the dietary intake of PFOS and PFOA in the Netherlands showing that eggs contributed $2.4 \%$ to the total dietary exposure of PFOS. There was no contribution of eggs to the PFOA intake, because the PFOA concentration was below the limit of quantification, and set at 0 (lower bound) in the exposure assessment. In a recent study, Zafeiraki et al. (2016) determined levels of various PFASs in commercially and home produced eggs. The level of PFOS in 22 sampled commercial eggs ( 8 battery, 8 free range and 6 organic egg producers) from the Netherlands were always $<0.5 \mathrm{ng} / \mathrm{g}$, except for 1 free range egg sample where the PFOS level was $1.1 \mathrm{ng} / \mathrm{g}$. Other PFASs were always $<0.5 \mathrm{ng} / \mathrm{g}$. Home produced eggs $(n=73)$ frequently contained PFOA, perfluorononanoic acid (PFNA), perfluorodecanoic acid (PFDA), perfluoroundecanoic acid (PFUnA), perfluorohexane sulfonate (PFHXS) and PFOS (detection frequency 7-81\%). Positive samples for these compounds contained between $0.5-2.7,0.5-2.0,0.5-3.0,0.5-2.3,0.6-5.2$ and $0.5-25 \mathrm{ng} / \mathrm{g}$, respectively. It is likely that the consumption of these eggs will lead to a higher exposure compared to EFSA's findings (EFSA, 2012f), but it is expected that it will remain below the TDIs (Zafeiraki et al., 2016).

\subsubsection{Primary processing}

The primary processing stage refers to collection, handling, cleaning, storage and transport of eggs from farm to wholesalers/retailers and/or egg processing industry. The egg shell protects the egg from contamination with chemical hazards during this stage. However, contamination of the eggs might occur if the eggshell is broken and not sorted-out/detected during the candling process. Chemical contamination of eggs might also occur during washing/cleaning of eggs when an improper cleaning procedure is applied.

Egg washing is widely used in many countries including the US and Japan. However, according to Regulation (EC) No 589/2008, the washing of table eggs marketed as class A is generally not permitted in EU countries. Following this Regulation, class A eggs should not be washed or cleaned 
because such practices can cause damage to the egg shell. Some practices, such as treatment of eggs with ultra-violet rays, are not considered as a cleaning process. Washing of class A eggs could be allowed when performed in authorized packing centers, and fulfilling certain criteria (Regulation (EC) No 589/2008). Class A eggs also shall not be treated for preservation.

Dirty eggs (B grade) could be washed with sanitizing agents to reduce the microbiological contamination of the egg shell. Besides for reducing the bacterial load on the egg surface, the sanitizing agents are also used to prevent potential accumulation of microorganisms in the rinse water. The sanitizers and disinfectants that are used should be approved for their use within the EC.

\subsubsection{Egg processing}

Sources of potential chemical contamination during egg processing include: residues of cleaning and disinfection products, ink and glue for packaging and labels, fluids, such as cooling liquid, steam, and warm water, compressed air, food additives, and processing aids.

Food additives and processing aids during the production process of egg products might result in a risk to public health if they are misused. There are currently over 3,000 food additives that are used for preservation, colouring or sweetening of a product (USDA, 2015). Within Europe, food additives are assessed for authorization previously by the Scientific Committee on Food (SCF) and now by the European Food Safety Authority (EFSA). Only authorized food additives obtain an E number and can be used in food products. Regulation (EC) No 1333/2008 sets the rules for food additives including the definitions of food additives and their conditions for use.

A list of approved food additives to be used in food products can be found in the Annex of Commission Regulation (EU) 1129/2011. Several food additives are permitted in all food products, whereas others are only regulated for specific food products. For egg products, for example, food colours are mentioned that can be used for decorative colouring or stamping of egg shells. Some food additives that are mentioned to be used with regard to egg processing are additives for adjusting the $\mathrm{pH}$ of egg products, such as E 501 (potassium carbonate), E 524 (sodium hydroxide) and E 525 (potassium hydroxide) or phosphates to improve the processing and functional properties of eggs, for example for colouring purposes or to improve the whipping of egg white and increase foam stability (FSIS, 2015). A full list of authorised food additives in processed egg products (except for colourants) is given in Table 7.

Processing aids include for example filtration aids, antifoaming agents or catalysts. They are defined as "any substance which: (i) is not consumed as a food by itself; (ii) is intentionally used in the processing of raw materials, foods or their ingredients, to fulfil a certain technological purpose during treatment or processing; and (iii) may result in the unintentional but technically unavoidable presence in the final product of residues of the substance or its derivatives provided they do not present any health risk and do not have any technological effect on the final product" (Regulation (EC) $1333 / 2008)$. Due to the latter criterion, there are no human health effects expected from the use of processing aids and they are, therefore, exempted from Regulation (EC) 1333/2008 (EC, 2008b). There is no approval process for processing aids in Europe and they are not harmonized at EU level, with the exception of enzymes and extraction solvents used as processing aids (Magnuson et al., 2013).

No data are available on the presence of residues of any food additives and processing aids in egg or egg products. In the history of the RASFF database, there is only one notification regarding the presence of unauthorised food additives. This notification regards the presence of $E 211$ (sodium benzoate) and E 451 (pentapotassium triphosphate) in boiled eggs from the Netherlands in 2005. According to Regulation (EU) No 1130/2011, these additives are only allowed in liquid eggs (white, yolk or whole egg). 
Table 7 Food additives other than food colourants that are allowed for use in processed eggs and egg products according to Regulation (EU) 1129/2011.

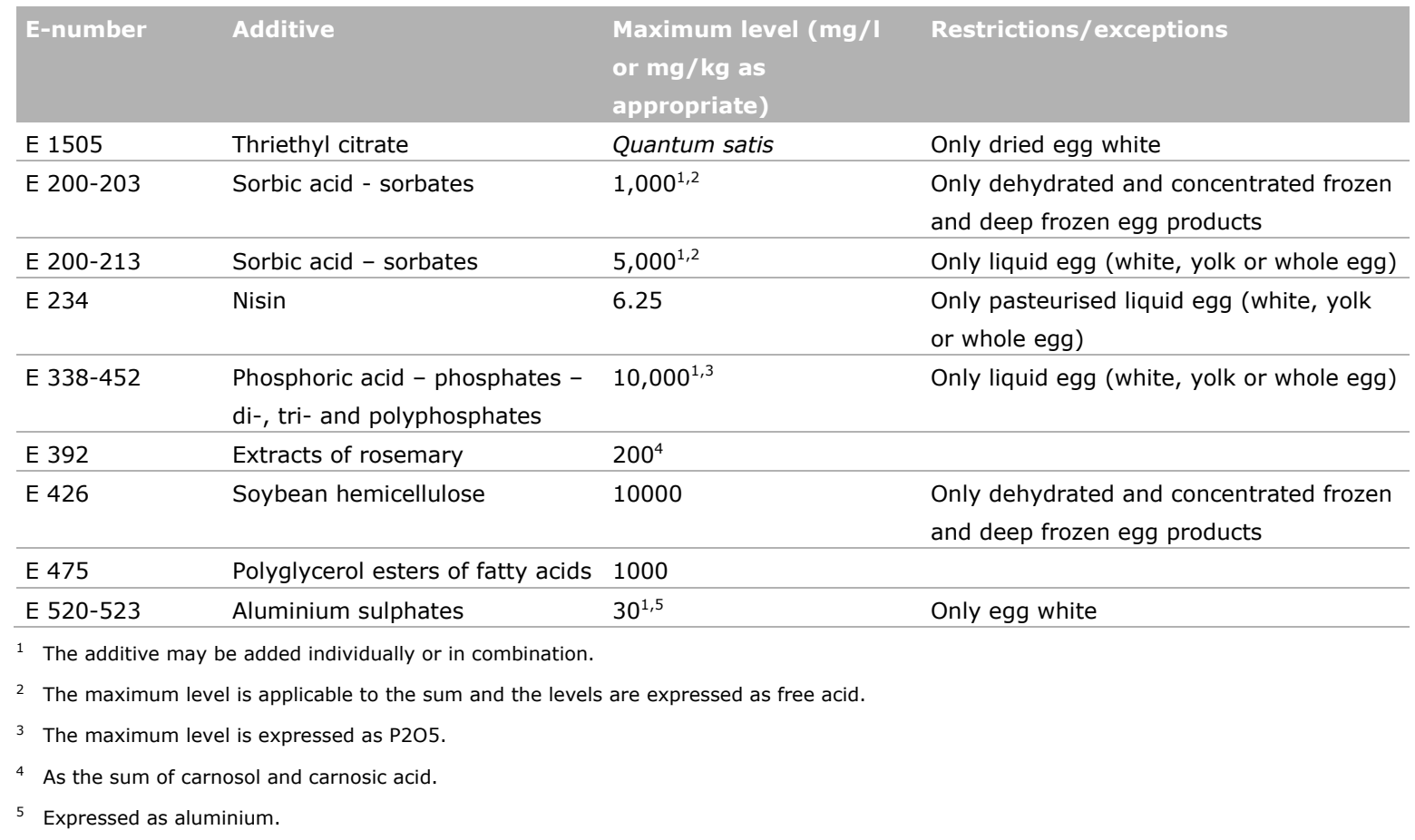

\subsection{Physical hazards}

Physical contaminants associated with egg and egg products include on-farm (intrinsic) contaminants introduced through broken/dirty eggshells, and improper candling and grading activities - and extrinsic contaminants - introduced through improper processing activities (EEPA, 2011). As a result of the protection of the egg by the shell, the probability of intrinsic physical contaminants affecting eggs at the layer farm stage is limited, except for blood spots. During primary processing, foreign bodies such as feathers and droppings can enter the egg, when the eggshell is broken.

Extrinsic contaminants might be introduced at any stage of the processing chain via raw materials, poorly maintained facilities and equipment, packaging materials, and poor food safety practices. Examples of extrinsic contaminants are eggshell, metal, glass, wood and plastic. RASFF contains 1 notification between 2002 and 2015 regarding physical hazards in eggs and egg products. This notification comprised the presence of glass particles in mayonnaise.

\subsection{Most relevant chemical and physical hazards}

Based on the evaluation of possible chemical and physical hazards in the egg production chain in the Netherlands, presented in sections 4.1-4.2, it can be concluded that the most important chemical hazards in the egg production chain are the potential presence of dioxins and dl-PCBs in feed material and in eggs and egg products, of veterinary drug residues in imported egg and derived products, and of veterinary drugs in national produced eggs as a result of the Cascade regulation or from the production of medicated feeds for other target animals.

The presence of dioxins and dl-PCB is primarily important for organic and free range eggs as the hens from these housing systems may come into contact with contaminated soil. The use of veterinary drugs as growth-promoting agents is allowed in non-European countries, therefore, eggs imported from those countries are more likely to contain residues from such agents than European eggs. In case no suitable veterinary product is available for laying hens, the Cascade allow the prescription of products authorized for other animals, and a standard waiting period has to be taken into account. Unintended use of feed supplemented with coccidiostats for laying hens, or carry-over of these 
compounds to feed for laying hens during compound feed production might results in residues in eggs; in particular lasolocid is of concern.

The most important physical hazard is the presence of foreign bodies in egg products, introduced at egg processing.

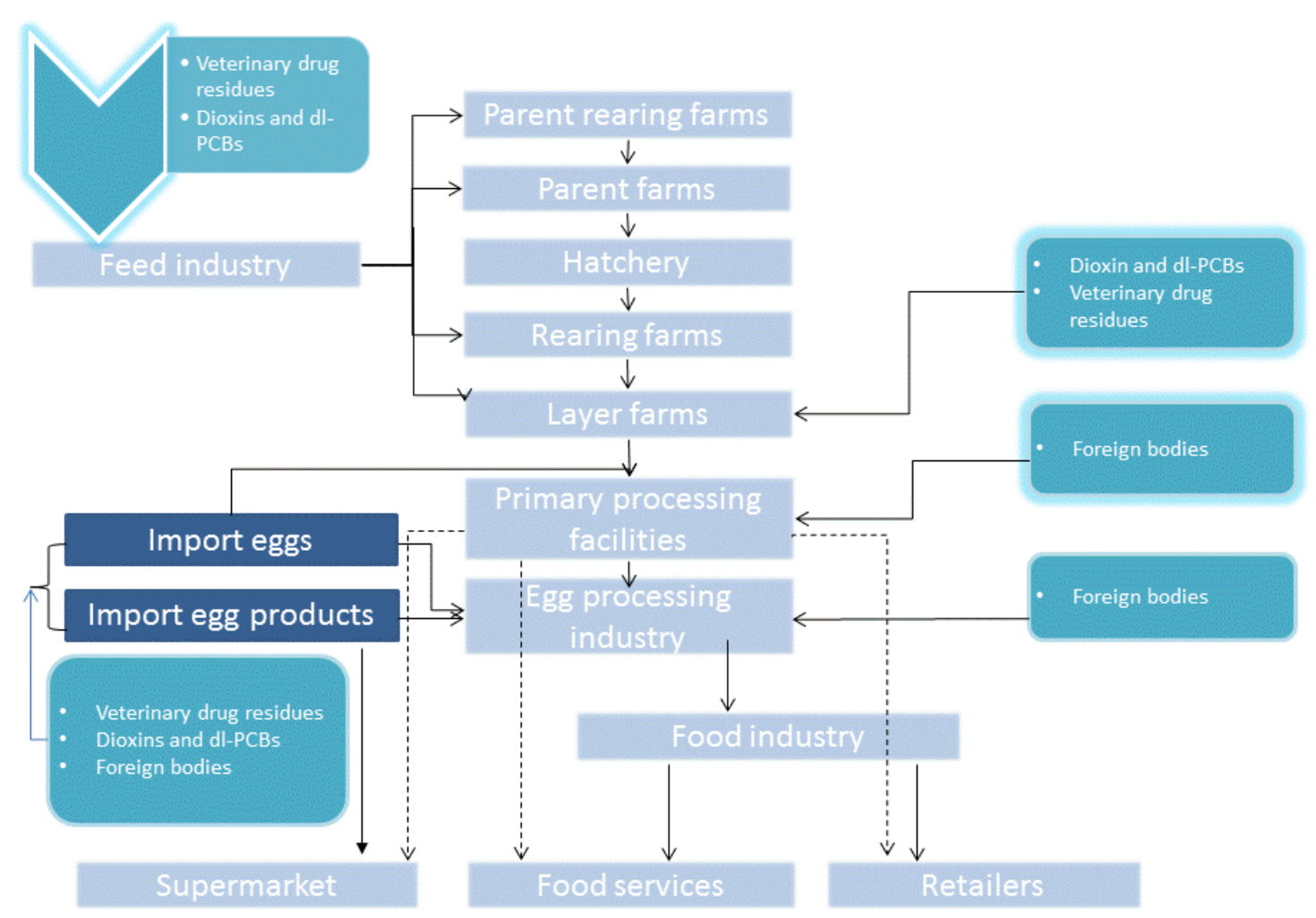

Figure 3 Summary of the most relevant chemical and physical hazards in the egg production chain in the Netherlands. 


\section{$5 \quad$ Human health implications}

In section 4, dioxins and dl-PCBs were identified as the most important hazards in Dutch eggs and egg products. Due to the fact that these compounds occur in food products containing animal fat (milk, eggs, meat and fish) and, to a lesser extent, in food products containing vegetable oil, consumers are exposed to dioxins and dl-PCBs frequently via food, almost on a daily basis (depending on the diet). Therefore, the 'normal' exposure is characterized by a chronic exposure. The consumer may be additionally exposed when, due to an incident, levels in eggs or egg products are elevated. In 2004, a preliminary estimate of the burden of disease related to dioxins was performed (van Kreijl et al., 2004).

In the following sections the toxicity, exposure (both chronic and occasional) and the burden of disease of dioxins are described.

\subsection{Toxicity of dioxins}

\subsubsection{Acute/short-term toxicity}

Dioxins cause acute toxicity in various experimental animals. Several LD $50^{1}$ values have been reported for the most potent congener within the group of dioxins, namely 2,3,7,8-tetrachlorodibenzop-dioxin (2,3,7,8-TCDD): mice: $180-2600 \mu \mathrm{g} / \mathrm{kg}$ bw; rat: $25-3000 \mu \mathrm{g} / \mathrm{kg}$ bw; rhesus monkey: $50-70 \mu \mathrm{g} / \mathrm{kg}$ bw; guinea pig: $0.6-2.1 \mu \mathrm{g} / \mathrm{kg}$ bw (JECFA/FAO/WHO, 2002).

The following semi-chronic effects have been observed after the short-term exposure of 13 weeks to 2,3,7,8-TCDD (JECFA/FAO/WHO, 2002):

- Hepatic porphyria (mouse): lowest-observed-adverse-effect level (LOAEL) of $45 \mathrm{ng} / \mathrm{kg}$ bw per day;

- Decreased body organ weight (rat): no-observed-adverse-effect level (NOAEL) of $10 \mathrm{ng} / \mathrm{kg}$ bw per week;

- Hepatic EROD induction (rat): NOAEL of $0.35 \mathrm{ng} / \mathrm{kg}$ bw per day.

\subsubsection{Chronic toxicity and health based guidance values}

In 2001, EFSA's predecessor the Scientific Committee on Food (SCF) determined a Tolerable Weekly Intake (TWI) of $14 \mathrm{pg} \mathrm{TEQ/kg} \mathrm{bw} \mathrm{per} \mathrm{week} \mathrm{(SCF,} \mathrm{2011)} \mathrm{for} \mathrm{dioxins} \mathrm{and} \mathrm{dl-PCBs.} \mathrm{This} \mathrm{TWI} \mathrm{was} \mathrm{derived}$ on the basis of reproductive toxicity observed in male offspring of rats, i.e. the disturbance of the development of the male reproductive system, in particular sperm formation. In deriving the TWI, this toxicity was extrapolated to man.

In the derivation of the TWI, a "body burden approach" was used. Intake below this TWI ensures that the chronic daily exposure to dioxins and dl-PCBs from food does not lead to an 'internal' (body burden) level that might induce the above-mentioned reproductive toxicity, in particular in pregnant women. Finally, the TWI is deliberately defined on a weekly basis. Within this time frame, the TWI corresponds with an average daily exposure of $2 \mathrm{pg}$ TEQ/kg bw per day. The EFSA CONTAM panel could not establish health based guidance values for ndl-PCBs due to the potential simultaneous exposure to dioxins, dl-PCBs, and ndl-PCBs. It is expected that many, if not all, effects can be attributed to dioxins and dl-PCBs (TEQ-driven) (EFSA CONTAM, 2005).

\footnotetext{
1 LD50 (Lethal Dose, 50\%): represents the dose of a substance required to kill 50 percent of a population of test animals (e.g. fish, mice, rats) after a specified test duration.
} 
Recently, the Environmental Protection Agency (EPA) in the US (2012) derived a "Reference Dose" (RfD) of $0.7 \mathrm{pg} \mathrm{TEQ/kg} \mathrm{bw} \mathrm{per} \mathrm{day} \mathrm{(US} \mathrm{EPA,} \mathrm{2012).} \mathrm{This} \mathrm{health} \mathrm{based} \mathrm{guidance} \mathrm{value} \mathrm{is} \mathrm{based} \mathrm{on} \mathrm{two}$ epidemiological studies performed in people exposed during the Seveso incident. In concordance with SCF's derivation of the TWI, the epidemiological studies indicated reproductive toxicity and thyroid toxicity as the most sensitive non-carcinogenic effects in humans.

\subsection{Exposure to dioxins}

In 2014, the chronic dietary exposure to dioxins and dl-PCBs was estimated for two Dutch populations: young children aged 2 to 6 years and persons aged 7 to 69 years (Boon et al., 2014). These two populations were addressed because two separate food consumption databases were available for these population groups. To assess the chronic dietary exposure to dioxins, consumption data were linked to dioxin concentrations analysed within the Dutch monitoring programme on dioxins, dioxin-like PCBs, indicator PCBs and flame retardants in primary agricultural products, as well as the one on contaminants in Dutch fish and fishery products. These concentration data are stored within the KAP database.

According to this exposure assessment, egg (fat) contributed less than $5 \%$ to the chronic dietary exposure of the average consumer to dioxins and dl-PCBs in both populations. Because the contribution was below 5\%, exact percentages were not reported. When assuming that the contribution was $5 \%$ (worst case), this percentage can be used to assess the exposure to dioxins and dl-PCBs due to the consumption of egg (fat) based on the reported exposure estimates for the whole diet (including also the consumption of e.g. milk, meat and fish). The estimated median exposure to dioxins and dl-PCBs via the consumption of egg (fat) would then range in young children from $0.04 \mathrm{pg}$ $\mathrm{TEQ} / \mathrm{kg}$ bw per day in 6-year olds to $0.05 \mathrm{pg}$ TEQ/kg bw per day in 2-year olds. Since the exposure declined with age and the exposure in the young children at the highest estimated level $\left(99^{\text {th }}\right.$ percentile (P99)) did not exceed the daily equivalent of the TWI (see section 5.1), the exposure in persons aged 7 to 69 years was not estimated per age, but an overall exposure estimate for the whole age range was calculated. The estimated median exposure to dioxins and dl-PCBs for this age group via the consumption of egg (fat) could be calculated to equal $0.025 \mathrm{pg}$ TEQ/kg bw per day. Corresponding dioxin exposure estimates via the consumption of egg (fat) for the P9g level of exposure were $0.08 \mathrm{pg}$ TEQ/kg bw per day for 6-year olds, $0.10 \mathrm{pg}$ TEQ/kg bw per day for 2-year olds and $0.07 \mathrm{pg}$ TEQ/kg bw per day for persons aged 7 to 69 years. The exposure estimates of dioxins via egg (fat) included both the exposure via the consumption of table eggs and eggs used as an ingredient in processed foods.

It should be noted that the estimated contribution of egg (fat) to the dioxin exposure via the whole diet was based on the total exposure distribution. At the upper tail of the exposure distribution, the contribution of food products to the exposure may be different. The contribution to the upper tail of the exposure distribution was however not reported in Boon et al. (2014), making a more precise estimation of the P99 level of exposure via the consumption of egg (fat) not possible.

In 2010, 2013 and 2014, (incidental) exposure to dioxins in eggs was assessed by the Front Office upon request of the NVWA. In 2010, the NVWA sampled eggs that contained dioxin levels (excluding dioxin-like PCBs) above the maximum limit of $3 \mathrm{pg}$ TEQ/g (egg) fat. The NVWA requested the Front Office to calculate the wash-out period that was necessary to achieve dioxin levels in eggs below the maximum limit. No dietary risk assessment was performed. In 2013, eggs were sampled in the municipality of Harlingen with elevated levels of dioxins. The highest concentration was $10.9 \mathrm{pg}$ TEQ/g fat. The NVWA requested a health risk assessment and more specifically, considering the current dioxin background exposure levels of consumers, how many eggs could be eaten per week by an individual without exceeding the TWI of $14 \mathrm{pg}$ TEQ/kg bw per week (section 5.1) or the Reference Dose (RfD) established by the US EPA of $0.7 \mathrm{pg}$ TEQ/kg bw per day. In 2013, the dioxin background exposure levels were based on food consumption data of 1997/1998 and on dioxin background levels available in 2004 (de Mul et al., 2008). The situation in Harlingen led to a national survey in which 60 farms, spread all over the Netherlands, were sampled. Based on the results of this survey and the fact that background exposure in the Netherlands had been updated (Boon et al., 2014), the NVWA 
requested another risk assessment. In 2014, the long-term background exposure for the persons aged 7 to 69 years was estimated to be $0.5 \mathrm{pg}$ TEQ/kg bw per day (P50) and $1.0 \mathrm{pg}$ TEQ/kg bw per day (P95) (Boon et al., 2014). The long-term exposure for young children aged 2 to 6 years was $0.9 \mathrm{pg}$ TEQ/kg bw per day (P50) and $1.5 \mathrm{pg}$ TEQ/kg bw per day (P95), as reported in the assessment performed by the Front Office in 2014. If eggs from private owners with an average concentration of $6.1 \mathrm{pg} \mathrm{TEQ} / \mathrm{g}$ fat (this was the average level found in the national survey) would have been consumed instead of regular retail eggs, the exposure of the above-mentioned populations would have been clearly increased by $20-30 \%$. The long-term dioxin background exposure for the persons aged 7 to 69 years would be $0.6 \mathrm{pg}$ TEQ/kg bw per day (P50) and $1.3 \mathrm{pg}$ TEQ/kg bw per day (P95). The longterm exposure for young children aged 2 to 6 years would be $1.2 \mathrm{pg}$ TEQ/kg bw per day (P50) and $1.9 \mathrm{pg}$ TEQ/kg bw/ per day (P95). In this risk assessment, it was also calculated how many contaminated eggs per week could be consumed without exceeding the TWI. In particular for young children with a background exposure at the P95, eating eggs with the highest observed level (18.9 pg $\mathrm{TEQ} / \mathrm{g}$ fat), this could be less than one egg were week. It should be pointed out that private owners will most likely consume only eggs from their own hens. For commercial eggs this is less likely, although their might be a preference to buy eggs from a nearby farm, selling eggs locally. In general, however, the levels observed in eggs from private owners are much higher than those observed nowadays from commercial farms.

\subsection{Burden of disease}

With respect to the carcinogenicity of dioxins, Hänninen et al. (2014) mentions an Environmental Burden of Disease (EBD) of 10794 DALYs per 1.000 .000 people. Given a current population size of 16.9 million in the Netherlands, this results in $16.9 \times 10794=182419$ DALYs. Hänninen et al. (2014) estimated that approximately $2.1 \%$ of the EBD results from dioxin exposure, i.e. 227 DALYs per million, or a total of 3831 DALYs.

This calculation is based on the dietary dioxin exposure in the Netherlands in 2004 . This could be adjusted for the Dutch dietary exposure in 2014, but it cannot be deduced from this publication if this means that the total of 3831 DALYs can be interpreted as 3831 DALYs/year. Part of the problem is the fact that dioxins accumulate in the human body over time and it is not clear whether this EBD is based on an acute or chronic carcinogenic effect of dioxins.

In 2004, a preliminary burden of disease assessment on dioxins was performed. At that time, no burden of disease was attributed to non-cancer effects of dioxins (van Kreijl et al., 2004). Currently, within WHO's Foodborne Disease Burden Epidemiology Reference Group (FERG), a DALY approach has been developed for the non-cancer effects of dioxins (Zeilmaker et al., in preparation). In short, deducing the current (world-wide) body burden of dioxins from breast milk data, the corresponding non-cancer toxicity (reproductive and thyroid) was quantified and translated via morbidity (impaired fertility and thyroid functioning) into DALYs. 


\section{Prevention and control}

The potential for chemical contamination in the egg production chain is highest during primary production at the layer farms (section 4.1.1), followed by primary processing (section 4.1.2) and egg processing (section 4.1.3). The potential for contamination with a physical hazard is greatest during egg processing (section 4.3). As a result, intervention measures to prevent or to reduce the presence of chemical and physical hazards in the egg production chain are outlined below for each of the three stages: layer farms, primary processing and egg processing, as well as for the entire chain.

\subsection{Entire egg production chain}

In the Netherlands, an integrated quality assurance system "IKB Ei" is used to guarantee to consumers that requirements concerning the production, quality, and origin of eggs are met (www.ikbei/overikbei). This system applies to all stages involved in the production or consumption of eggs, from the farmer up to sale. It also includes the feed industry, transport companies and veterinarians. Participation in the "IKB Ei" program is voluntary. To participate in the IKB EI program, the farms/companies need to fulfill a large amount of requirements. IKB ei also incorporates a certain amount of legal restrictions.

In brief, IKB EI regulations include requirements for traceability, transparency, feed, hygiene, use of drugs on animals, transport and animal welfare. All previous stages in the production chain of eggs need to be IKB certified. So, all animals and (breeding) eggs bought by the company need to fulfill the IKB requirements. Suppliers of feed, veterinarians and service companies need to have the proper certifications (IKB PSB certified). Feed producers have to comply with Good Manufacturing Practices (GMPs) and the veterinarians have to work according to Good Veterinarian Practices (GVPs). Regarding transparency, companies need to register information on e.g. amounts of animals, animal health, quality but also safety aspects. This information is exchanged within stages of the chain.

The number of IKB EI participants per 31-12-2015 is: 52 farms for cage eggs, 497 organic farms and 370 free-range farms. In total 26 egg packaging stations were IKB Ei certified, in total representing $90-95 \%$ of the total production by packaging stations.

In order to improve the quality of information retrieved from the IKB EI system, there are collaborations with other systems used internationally such as the Belgium Belplume, the German KAT, QS and Global-GAP systems.

A high awareness of farmers, veterinarians, workers and other personnel for potential chemical contamination is of utmost importance for minimizing the presence of chemical hazards in eggs and egg products. Increasing awareness and better understanding can be achieved through continuous training and education related to, amongst others, rules and regulations concerning agricultural hygiene and processing practices, and new technologies.

\subsection{Layer farms}

The most important routes of chemical contamination at the layer farm are via contaminated diet from feed crops grown on contaminated soil, direct ingestion of contaminated soil and medication (section 4.2.1).

When animals fall ill, permitted drugs (with set MRLs or which do not require an MRL) should be used. When prescriptions are required, the drugs should be ordered by a licensed veterinarian and should have an accurate label. Veterinary drugs must be dispensed in quantities required for the treatment of 
the animals for which they are needed, and extra deliveries must be restricted to avoid misuse. Farmers and veterinarians need to take appropriate measures to ensure that the withdrawal times are met and adhered to and no drug residues above the MRLs occur in eggs.

The presence of environmental contaminants, like dioxins and heavy metals, may result from deposition in the soil due to industrial contamination, application of contaminated sewage sludge to agricultural land, the use of synthetic products (e.g. paints), local waste burning, and mining (in case of heavy metals). To prevent the presence of such contaminants in eggs, layer farms must not be located in areas where contamination with dioxins and heavy metals is anticipated. This especially applies to organic and free-range systems at which laying hens can consume (contaminated) soil. Exposure may be limited by providing feed in feeders, which is usually common practice in commercial layer farms. Private owners, however, have the tendency to spread the feed on the ground, which may lead to increased exposure to environmental contaminants. Building materials used at the layer farms (e.g. pentachlorophenol-treated wood) and bedding materials might also be sources of contamination with dioxins and heavy metals. For animal welfare reasons, there may be an increased use of bedding materials. It is important to include these in quality control.

Recent incidents in the Netherlands show that farmers should also be aware of the use of PCBcontaminated building debris in the courtyard and of old asbestos roof plates covered with PCB containing paint (used in the early seventies). These cases show that it is very important to follow-up incidents, disclose the sources and communicate on them to avoid repetition.

Feed for laying hens can be a major source of contamination. To assure high quality of feed used, the feed should be bought only from certified producers.

\subsection{Processing}

At the primary egg processing stage, the use of inappropriate disinfectants, improper cleaning procedures, ineffective candling and sorting procedures are the main sources of contamination of eggs and egg products (section 4.4.2). Good hygienic and processing practices are needed for proper candling, sorting and cleaning. Eggs with inclusions or with hairline cracked shells should be sortedout. Furthermore, during cleaning, the use of authorized cleaning and disinfection products at recommended dosages, and efficient rinsing after cleaning operations should be applied to prevent chemical contamination. These procedures are part of GMP and GHP.

At the egg processing industries, the main sources of contaminations are improper processing practices; ill-maintained equipment, inappropriate packaging materials, improper cleaning procedures, improper waste management, and adulteration (section 4.2.3). The measures related to hygiene and cleaning mentioned during primary processing also apply to this stage. Packaging materials should minimize possible chemical contamination. The application of a proper waste management program is necessary in order to reduce environmental contamination. Furthermore, a critical control and monitoring program is required in order to prevent adulteration.

Measures to prevent the presence of physical hazards include good processing practices such as frequent control and timely maintenance of equipment, and visual examinations of products. Moreover, specific measures such as using filters, the use of a metal detector or magnet and strainers to monitor physical hazards during processing should be applied as part of GMP. 


\section{$7 \quad$ Trends and forecasts}

In this section, trends and forecasts (till the year 2025) for the egg production chain in the Netherland, which may impact the presence of chemical and physical hazards, are described. Changes within the egg production chain are influenced by, amongst others, consumer demand, sustainability concerns, legislations, economical factors, global trade, education, and knowledge and technology development. To date, consumers evaluate their food choices critically taking into consideration the origin of their food, the way it was produced, its safety and reliability, its overall healthfulness, and its costs. Accordingly, food needs to be produced sustainably implying its production is optimized using resources efficiently and minimizing waste. In order to fulfill these requirements, rules and regulations are adapted continuously at the national and EU level. On the basis of the above mentioned drivers, changes that could be expected within the egg production chain in the Netherlands include changes in animal husbandry/housing systems, feeding management, egg consumption, export of eggs and egg products as well as the import of raw materials, feed and feed ingredients, eggs and egg products. In the following section, these five expected changes will be addressed in more detail in relation to their effect on the egg production chain.

\subsection{Animal husbandry systems}

In the Netherlands, the number of layer farms decreases annually. The number of layer farms was 2076 in the year 2000, against 1031 layer farms in 2014. On the other hand, the number of laying hens per farm increases annually. In 2000, the average number of laying hens per farm was 15,690 against 33,734 in 2014. Thus, there is a trend towards larger laying farms. Figure 4 shows the trend in the number of farms and the average number of laying hens per farm per year between 2000 and 2014.

Housing systems are also changing in the Netherlands, mainly as a result of Directive 1999/74/EC, which banned conventional battery cages in the EU from January 2012 for welfare reasons. This led to a rapid decrease of the number of farms with battery cages in the EU. In the Netherlands, the share of farms with cage systems (based on total number of laying hens) decreased significantly from $47 \%$ in 2006 to $16 \%$ in 2013 because of a shift from cage systems to other systems. Increases were observed in both the proportion of laying hens held at organic farms (from 1.9\% in 2006 to $5 \%$ in 2013) and the proportion held at free-range farms (from $13 \%$ in 2006 to $16 \%$ in 2013), while the proportion of laying hens kept in barn systems increased from 37\% in 2006 to $62 \%$ in 2013 . Figure 5 shows the trend in housing systems at the layer farm, expressed as percentage of hens per farm system, in the Netherlands between 2006 and 2013 (KIP database).

During the last few years, almost all layer farms in the Netherlands have made an investment in new housing systems. As a result, no major change is expected in the housing systems for the upcoming 10 years. However, a further ban on enriched cages is implied in 2021 according to the 'Legkippenbesluit' (2004). The total number of laying hens kept annually, which is related to the number of eggs produced, is kept constant in the Netherlands due to the system of production rights. The total number of poultry in the Netherlands is controlled by a system of rights to keep poultry ("pluimveerechten"). As a result, the proportion of laying hens housed in cage systems is expected to remain stable at $15-20 \%$. However, as a result of the increasing consumer demand for eggs produced at organic and free-range systems, a slight increase is expected in eggs produced at these farming systems. This slight increase will be compensated with a decrease in the proportion of laying hens housed in barn systems. The switch to free-range is a critical step for farmers, since it may reveal the presence of contaminants like dioxins and dl-PCBs in the courtyard, which was not noticed before. This also applies to farms where laying hens are bred during the first 20 weeks, since dioxins and dl-PCBs are stored in the body fat and will slowly be released to the eggs, once they start laying. 
Recent changes in legislation require that also at this stage animals should be allowed to forage outside.

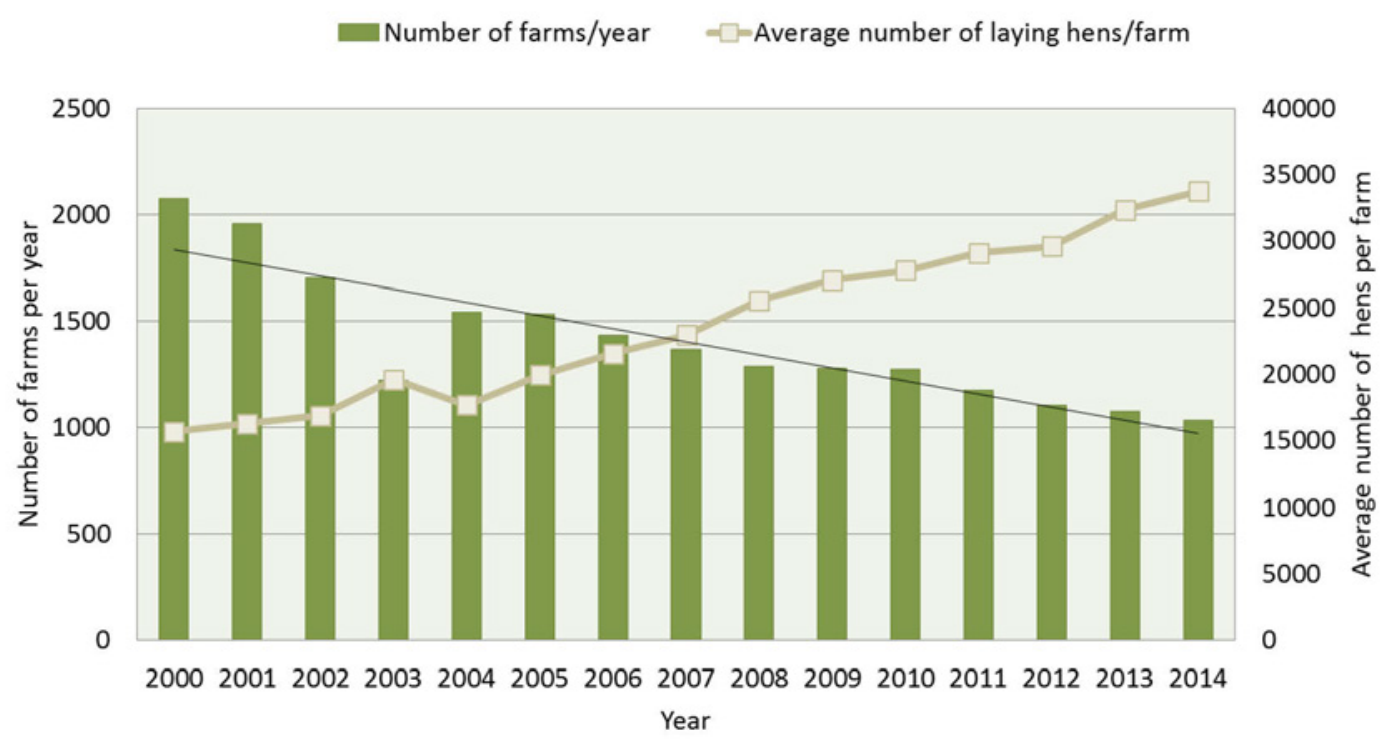

Figure 4 Number of farms and average number of laying hens per farm in the Netherlands (2000-2014), based on LEI data.

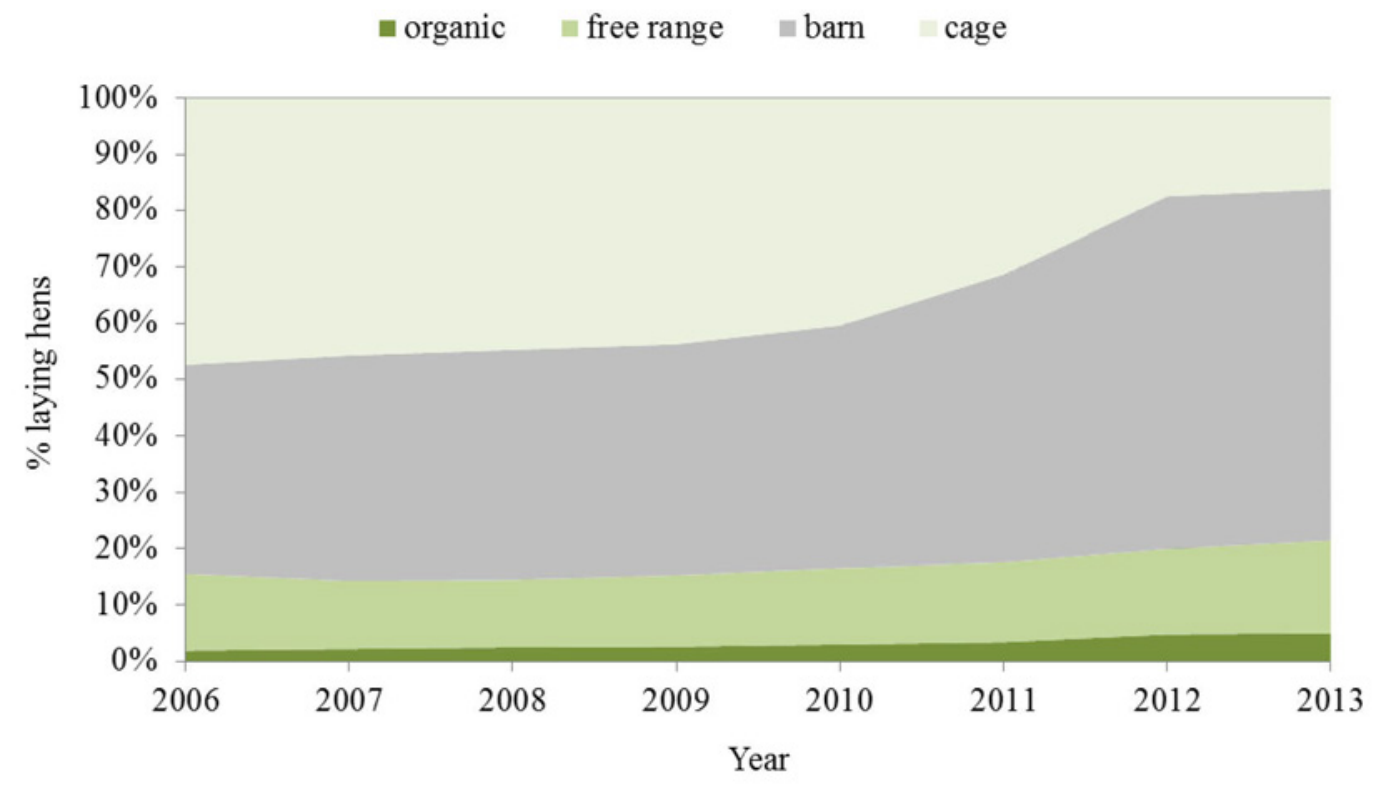

Figure 5 The use of housing systems, expressed as percentage of laying hens from the total number of laying hens, in the Netherlands between 2006 to 2013.

\subsection{Feed management and import}

Regulation (EC) no $889 / 2008$ on organic livestock systems, including systems for laying hens, requires that animals/hens should be given feed derived from organic origin. At least $20 \%$ of the feed should originate from the farm unit or - in case this is not possible - from the same region. Fresh roughage, dried fodder, or silage should be added to the daily ration for poultry (EC, 2008a). Feed management of layer hens held in organic systems will be adapted accordingly. The increased demand for 
organically produced feed may lead to shortages and, possibly, a higher chance of using batches that are contaminated with, e.g. mycotoxins.

Due to welfare issues, there will be a ban on routine beak trimming of laying hens in the near future. However, banning beak trimming causes an increased risk of feather pecking and cannibalism in laying hens. To tackle these problems, farm management will need to be adapted, among others, with alternative feeding management such as providing additional roughage like alfalfa. Severe feather pecking has been demonstrated in birds that were fed with a too low level of minerals, protein and/or amino acids in their diets. In addition, more feather pecking may occur when the hens were fed restrictedly, fed coarsely ground, or fed as pellets. On the other hand, feeding high-fiber and low energy diets, or roughages reduces feather pecking (van Krimpen et al., 2005). As a result, a decreasing trend of feeding pellets and an increasing trend of using green feed/roughages at the layer farms is expected.

Feed and feed ingredients are imported into the Netherlands from abroad. Maize is imported from Germany and France, wheat from Germany, France and the UK, and rapeseed from Germany and Belgium. The oil seeds soya and sunflower are imported from Argentina, Brazil, China and Ukraine. Only $10 \%$ of the wheat and $30 \%$ of the rapeseed used in feed are produced in the Netherlands (Wageningen UR, 2015).

Global trade (price competition) and safety issues (Genetically Modified Organisms (GMOs) free crops) may result in fluctuations of the origin of imported feed and feed ingredients in the coming years. For example, due to less strict rules about using and producing GMO products in the USA, South America and Asian countries, the feed companies in the Netherlands might prefer to import feed and feed ingredients from EU countries where higher priority is given to safety issues (PVE, 2008).

\subsection{Egg consumption}

The consumption of eggs and egg products is increasing annually in the Netherlands, because eggs have become an attractive source of protein and a versatile food source. The total number of eggs consumed in 2013 was 195 eggs per head of the population out of which 150 as table/shell egg and 45 in egg products. Ten years ago, these numbers were 177, 136 and 41, respectively. Figure 6 shows the trend in egg consumption in the Netherlands between 2003 and 2013 (PPE, 2013).

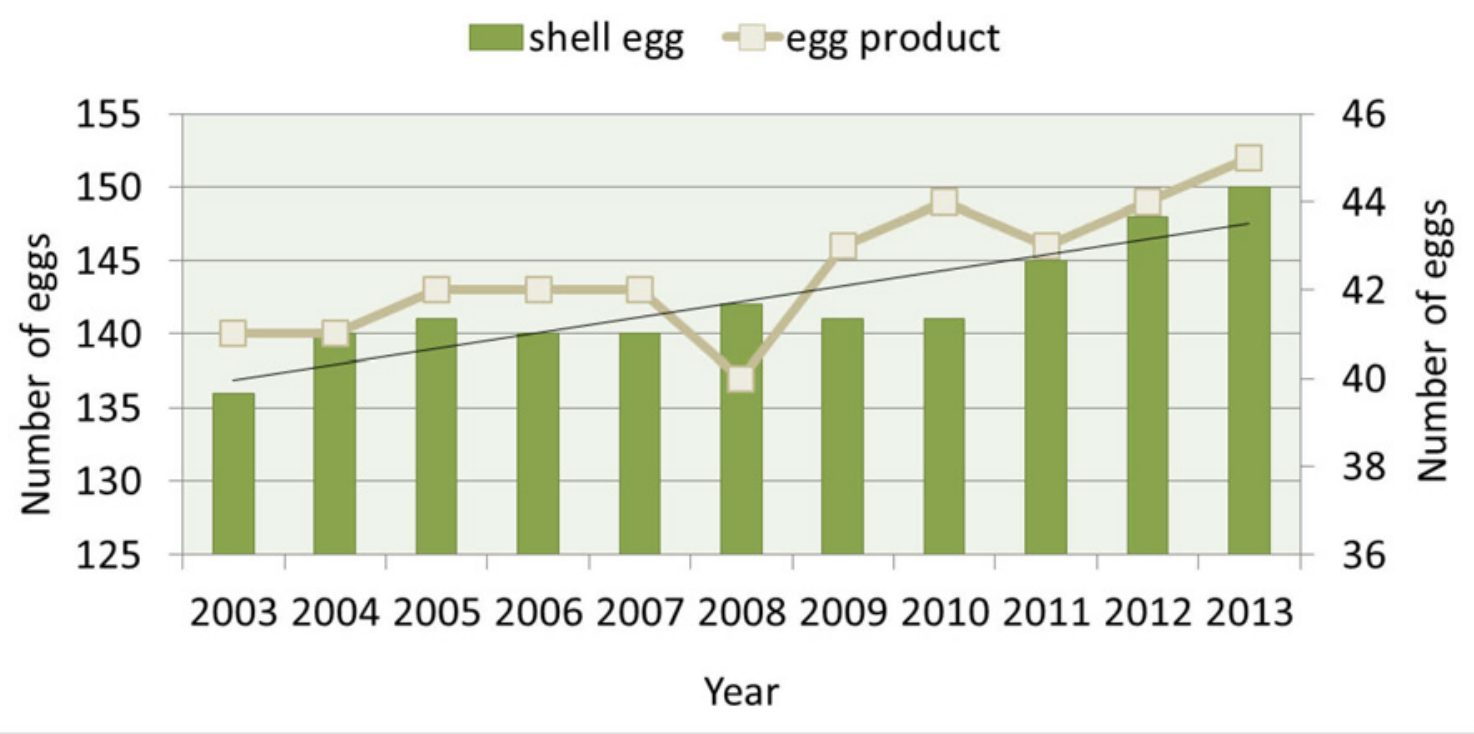

Figure 6 Consumption of eggs and egg products in the Netherland (2003-2013). 
The total share of eggs from the barn system has increased significantly during the last years. In $1995,57 \%$ of the eggs consumed were from cage systems, $40 \%$ from barn systems and $3 \%$ from free-range and organic systems. In 2013, the corresponding figures were $6 \%, 78 \%$ and $16 \%$, respectively. Since 2003, eggs from the cage system are still sold at the layer farms or small retails, but not at supermarkets anymore. It is expected that the share of eggs from free-range and organic systems will increase from $16 \%$ to about $20-25 \%$ in the coming years. Additionally, it is expected that the share of eggs from the cage system will further decrease. Figure 7 shows the trend in eggs consumed per housing system in the Netherlands between 1995 and 2013.

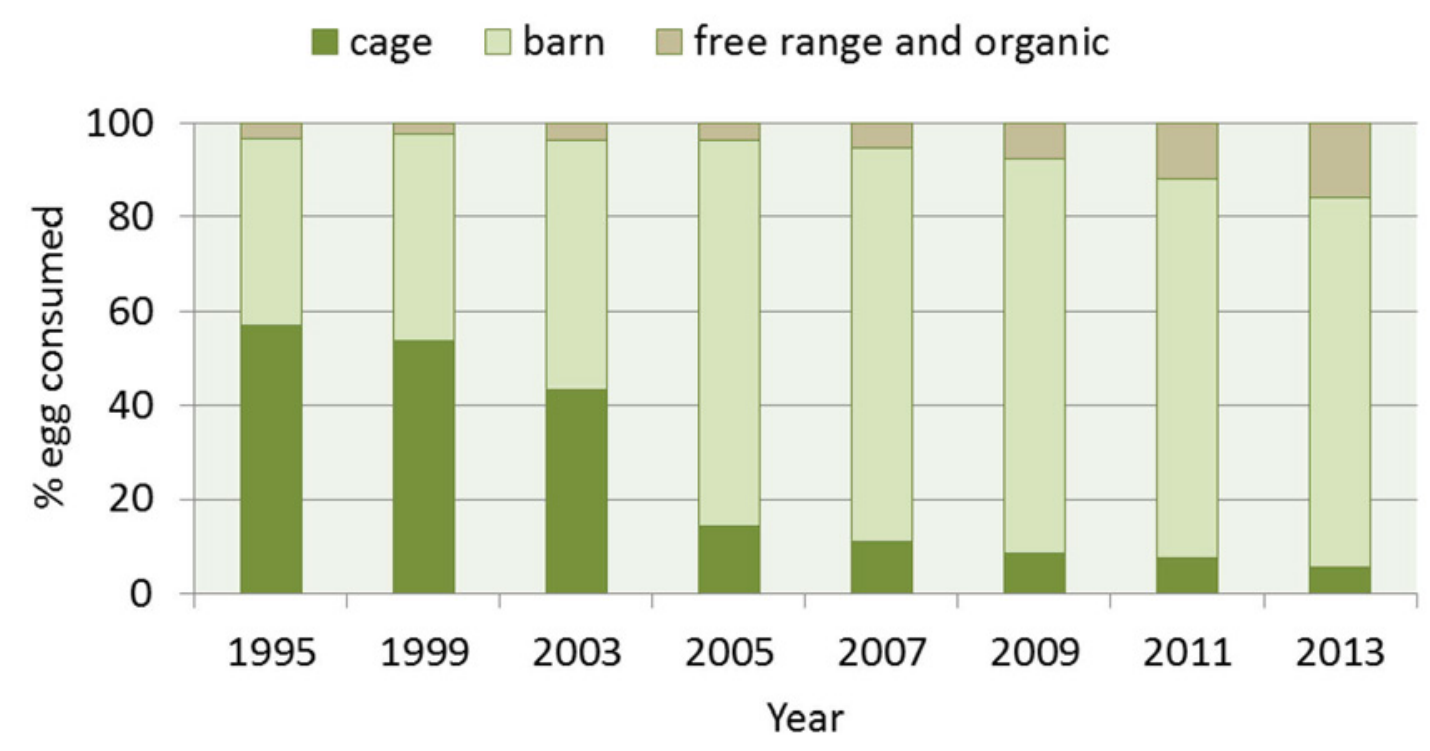

Figure 7 Consumption of eggs per housing system in the Netherlands (1995-2013).

\subsection{Export and import of eggs and egg products}

\subsubsection{Export of egg and egg products}

Countries in North-West Europa, especially Germany and the UK, are the main export destinations for eggs and egg products from the Netherlands, followed by Switzerland, Japan and Angola. There is a decreasing trend in the export of eggs and egg products from the Netherland since 2011. In 2012, about 9.4 milliard eggs (as eggs and egg products) were exported, a decrease of almost 5\% compared to 2011. In 2013, the export of eggs and egg products decreased further to about 83,000 ton of eggs, amongst others due to and increased egg production in Germany. Figures $8.1-8.3$ present the trend and destinations of exported eggs and egg products from the Netherlands (PPE data). 
Eggs $\sim$ Egg products

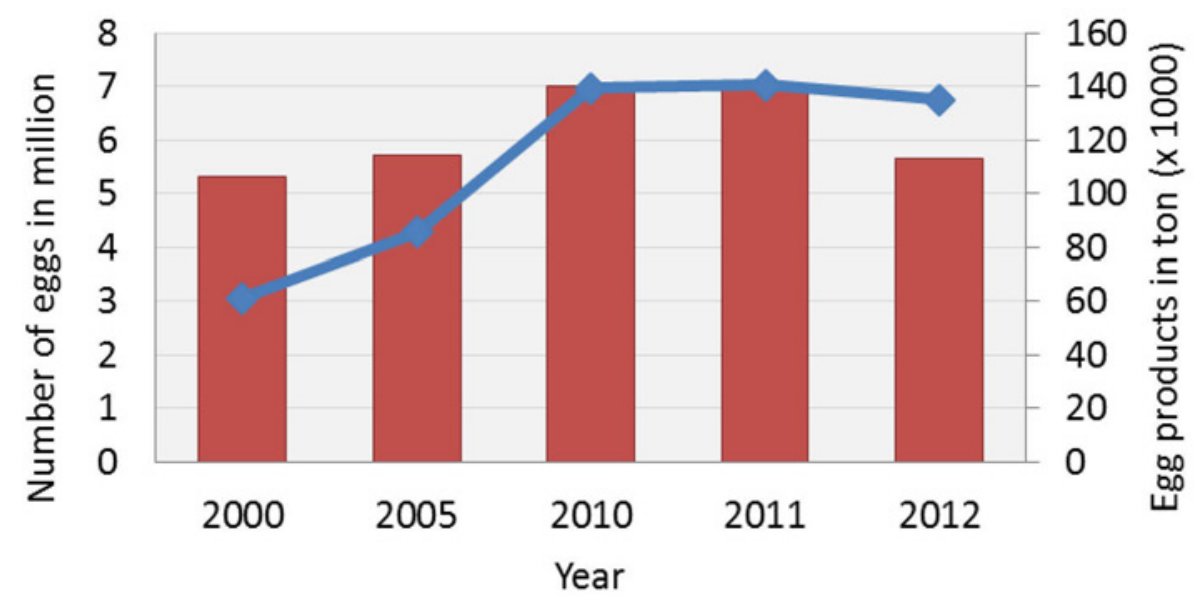

Figure 8.1 Trend in export of eggs and egg products from the Netherlands.

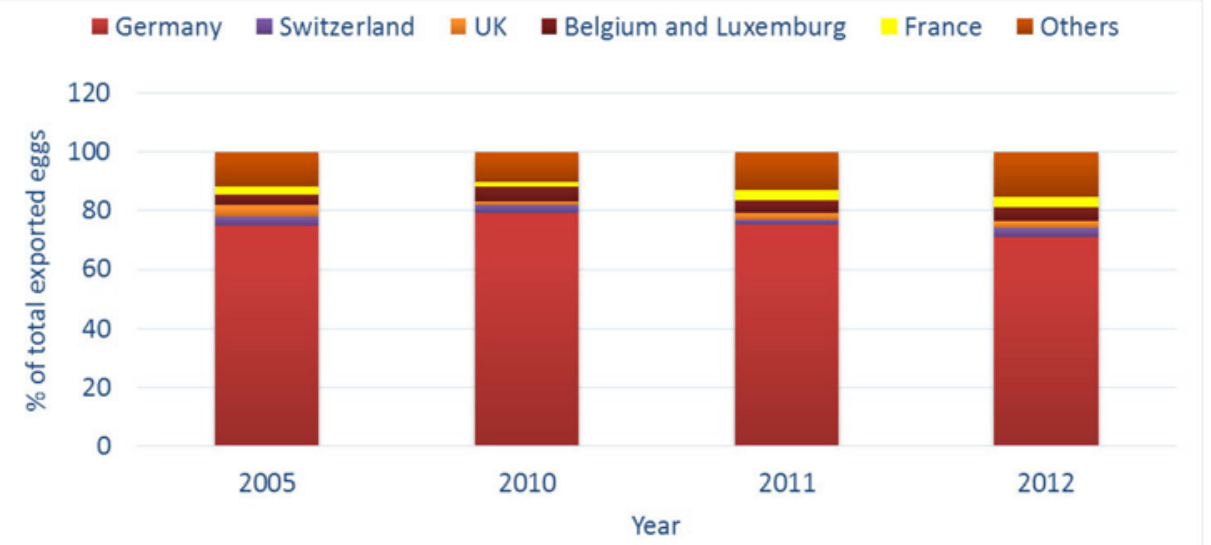

Figure 8.2 Trend and destination of exported eggs from the Netherlands.

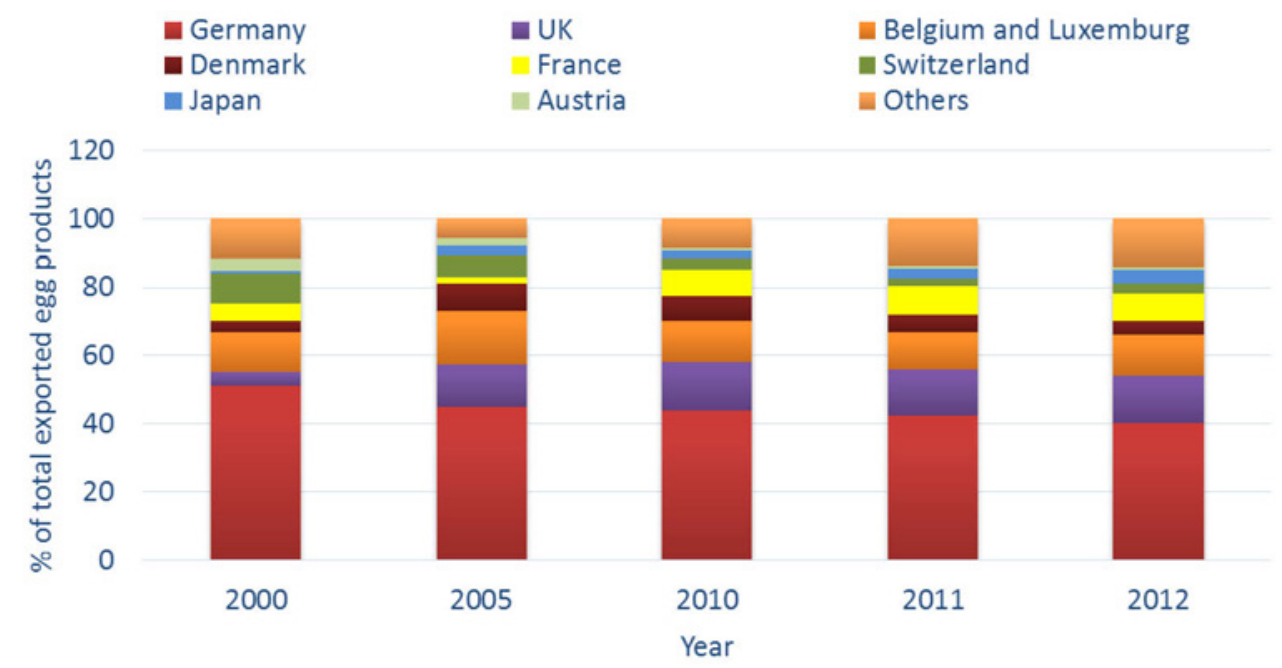

Figure 8.3 Trend and destination of exported egg products from the Netherlands. 


\subsubsection{Import of egg and egg products}

The Netherlands imports liquid egg products mainly from European countries. For example, in 2012, the majority of the egg products were imported from Belgium and Germany, while a small portion was imported from Spain, France and Poland. Egg powder is mainly imported from non-European countries, of which the majority comes from India, followed by the USA and Argentina, and a small portion is imported from China (PPE, 2013).

There is a decreasing trend in the import of eggs and egg products, not only for the Netherlands but for the whole of the EU. In 2013, the EU imported 20,000 ton of eggs and egg products. This was almost 50\% less than in 2012. In 2012, the Netherlands imported about 250 ton ( 2.5 milliard eggs) from countries outside the EU. The import of eggs and egg products in 2012 decreased with $2 \%$ compared with 2011. This decreasing trend was a result of an increased egg price following the decreased egg production in the EU countries. Currently, the EU is negotiating with other countries to liberalize trade in agricultural products, including eggs and egg products. These agreements are designed to further liberalize trade by either reducing or removing import tariffs. In a scenario with lower import tariffs, countries outside the EU will offer a lower price for egg powder. In this respect, an increased import of egg products from countries outside the EU, like USA, India and Argentina, can be expected (Van Horne, 2014). 


\section{Conclusion}

This study evaluated possible chemical and physical hazards in the egg production chain in the Netherlands, using both literature and monitoring data. From the results, we conclude not much specific information is available for the Netherlands. The main physical hazard is pieces of egg shells that may end up in the egg product during the egg breaking process. The major potential chemical hazards in eggs and egg products include the possible presence of dioxins and dl-PCBs in eggs produced in the Netherlands, of veterinary drugs in egg products imported from outside the EU, and of veterinary drugs used within the Netherlands, following the Cascade or resulting from the production of medicated feed. The latter groups concerns either the unintended use of feed supplemented with coccidiostats for laying hens, or carry-over of these compounds to feed for laying hens during feed production, which might results in residues in eggs.

The probability of contamination of eggs with dioxins and dl-PCBs is mainly related to the housing system at the layer farms and to feed materials, both imported and produced in the Netherlands. Higher concentrations of dioxins and dl-PCBs may be observed in eggs from free-range and organic systems compared to other housing systems. As there is a trend towards more production and consumption of free-range and organic eggs, monitoring for dioxins and dl-PCBs in eggs is important. Poultry that has outdoor access is also more vulnerable for other environmental contaminants, such as flame retardants and PFASs. Therefore, more data are needed on eggs from these housing systems. Furthermore, there is limited knowledge on the toxicological effects of ndl-PCBs, compounds that are also frequently found in eggs. Dioxin intake through food can cause adverse human health effects. However, a recent exposure assessment showed that eggs contributed less than $5 \%$ to the overall intake of dioxins and dl-PCBs via food in the Netherlands.

There is an increase of eggs and egg products imported from countries outside the EU. Since egg and egg products imported from other countries may contain veterinary drug residues, it is important to monitor for veterinary drugs in these products. For this purpose, the current scope should be expended to include both approved and non-approved veterinary drugs in the EU. Furthermore, since only a few veterinary drugs are regulated for laying hens, it is relevant to include residues from authorized drugs for poultry in general in the current monitoring programs for eggs.

Measures to prevent and/or reduce the presence of contaminants and egg shell fragments in eggs and their products are related to generally accepted good agricultural practices, good veterinary practices, good hygienic practices, good processing practices, and quality management systems, as well as ensuring that the awareness and knowledge of actors within the entire chain is at a high level and up to date. In addition, the collection and exchange of relevant, good quality data is a prerequisite to enhance traceability within the egg production chain.

It is recommended to monitor feed, eggs and egg products for the presence of chemical contaminants; in particular dioxins and dl-PCBs and veterinary drug residues. Also, the concentrations of these contaminants in eggs produced in the various housing systems should be investigated more in-depth, as well as the required withdrawal period of veterinary drug residues used under the Cascade. 


\section{References}

Akhtar, M. H., El-Sooud, K.A., Shehata, M.A.A. 1996. Concentrations of Salinomycin in Eggs and Tissues of Laying Chickens Fed Medicated Feed for 14 Days Followed by Withdrawal for 3 Days. Food Additives \& Contaminants, 13, 897-707.

Aulakh, R.S., Gill, J.P., Bedi, J., Sharma, J.K. Joia, B.S., Ockerman, H.W. 2006. Organochlorine pesticide residues in poultry feed, chicken muscle and eggs at a poultry farm in Punjab, India. J. Sci. Food Agric. 86, 741-744.

Beran, G.W., Baum, D.H. 1997. Food safety begins at the farm. Iowa State University (ISU), Swine research report on health, document ASL-R1512. ISU, Ames.

BfR. 2006. Keine Gesundheitsgefahr durch Nikotinspuren im Hühnerei - Aktualisierte Gesundheitliche Bewertung* Nr. 006/2008. 8 p. Available at: http://www.bfr.bund.de/cm/343/keine_gesundheitsgefahr_durch_nikotinspuren_im_huehnerei.pdf

Bogialli, S., D'Ascenzo, G., Di Corcia, A., Lagana, A., Tramontana, G. 2009. Simple assay for monitoring seven quinolone antibacterials in eggs: extraction with hot water and liquid chromatography coupled to tandem mass spectrometry Laboratory validation in line with the European Union Commission Decision 657/2002/EC. Journal of Chromatography A, 1216, 794-800.

Boon, P.E., Te Biesebeek, J.D., Sioen, I., Huybrechts, I., Moschandreas, J., Ruprich, J., Turrini, A., Azpiri, M., Busk, L., Christensen, T., Kersting, M., Lafay, L., Liukkonen, K-H., Papoutsou, S., Serra-Majem, L., Traczyk, I., De Henauw, S., van Klaveren, J.D. 2012. Long-term dietary exposure to lead in young European children: comparing a pan-European approach with a national exposure assessment. Food Additives \& Contaminants Part A, volume 29: p1701-1715.

Boon, P.E., Te Biesebeek, J.T., de Wit-Bos, L., van Donkersgoed, G. 2014. Dietary exposure to dioxins in the Netherlands. Report nr: 2014-0001. National Institute for Public Health and the Environment (RIVM), Bilthoven, the Netherlands, 42 pp. Available online: www.rivm.nl.

Boon, P.E., Te Biesebeek, J.D., van Leeuwen, S.P.J., Hoogenboom, L.A.P. 2016. Dietary exposure to polybrominated diphenyl ethers in the Netherlands. RIVM Letter report 2016-0037. National Institute for Public Health and the Environment (RIVM), Bilthoven, the Netherlands, $54 \mathrm{pp}$. Available online: www.rivm.nl.

Buck, R.C., Franklin, J., Berger, U., Conder, J.M., Cousins, I.T., de Voogt, P., Jensen, A.A., Kannan, K., Mabury, S.A., van Leeuwen, S.P.J. 2011. Perfluoroalkyl and Polyfluoroalkyl Substances in the Environment: Terminology, Classification, and Origins. Integrated Environmental Assessment and Management. 7(4), 513-541.

Cannavan, A., Ball, G., Kennedy, D.G. 2000. Nicarbazin contamination in feeds as a cause of residues in eggs. Food Additives \& Contaminants, 17:10, 829-836.

Codex. 1995. CODEX general standards for contaminants and toxins in food and feed (CODEX STAN 193-1995), pp: 1-44.

Colegate, S.M., Edgar, J.A., Stegelmeier, B.L. 2003. Plant-associated Toxins in the Human Food Supply. In Rose, J. (eds). Environmental Toxicology, Gordon and Breach Science Publishers: Amsterdam, the Netherlands, 317-344

Cornejo, J., Lapierre, L., Iragüen, D., Cornejo, S., Cassus, G., Richter, P., San Martín, B. 2012. Study of enrofloxacin and flumequine residues depletion in eggs of laying hens after oral administration. J. vet. Pharmacol. Therap. 35, 67-72.

Cooper, K.M., Le, J., Kane, C., Kennedy, D.G. 2008. Kinetics of semicarbazide and nitrofurazone in chicken eggs and egg powders, Food Additives \& Contaminants: Part A, 25:6, 684-692.

De Mul, A., Bakker, M.I., Zeilmaker, M.J., Traag, W.A., van Leeuwen, S.P.J., Hoogenboom, L.A.P., Boon, P.E., van Klaveren, J.D. 2008. Dietary exposure to dioxins and dioxin-like PCBs in the Netherlands anno 2004. Regulatory Toxicology and Pharmacology 51: 278-287.

De Vries, M., Kwakkel, R.P., Kijlstra, A. 2006. Dioxins in organic eggs: a review. NJAS - Wageningen Journal of Life Sciences 54, 207-221. 
Edgar, J.A., Colegate, S.M., Boppré, M., Molyneux, R.J. 2011. Pyrrolizidine alkaloids in food: a spectrum of potential health consequences. Food Additives \& Contaminants: Part A. 28 (3), 308-324.

European Commission regulation (EC). 1991. Commission Regulation (EC) No 1274/91. "Introducing detailed rules for implementing Regulation (EC) No 1907/90 on certain marketing standards for eggs. Official Journal of the EU.

European Commission regulation (EC). 1996. Council Directive 96/23/EC on measures to monitor certain substances and residues thereof in live animals and animal products and repealing Directives 85/358/EEC and 86/469/EEC and Decisions 89/187/EEC and 91/664/EEC. Official Journal of the EU L125/10.

European Commission regulation (EC). 2001. Directive 2001/82/EC of the European Parliament and of the Council on the Community code relating to veterinary medicinal products. Official Journal of the EU L311/1.

European Commission regulation (EC). 2002a. Directive 2002/32/EC of the European parliament and of the council of on undesirable substances in animal feed. Official Journal of the EU 140, pp. 10.

European Commission Decision (EC). 2002b. Commission Decision No 2002/657 implementing Council Directive 96/23/EC concerning the performance of analytical methods and the interpretation of results. Official Journal of the EU L221/8.

European Commission regulation (EC). 2003. Commission regulation (EC) No 1831/2003 on additives for use in animal nutrition. Official Journal of the EU, L268/29.

European Commission regulation (EC). 2004. Commission Regulation (EC) No 850/2004 on persistent organic pollutants and amending Directive 79/117/EEC. Official Journal of the EU, L158/7.

European Commission regulation (EC). 2005. Regulation (EC) No 396/2005 of the European Parliament and of the Council of 23 February 2005 on maximum residue levels of pesticides in or on food and feed of plant and animal origin and amending Council Directive 91/414/EEC

European Commission regulation (EC). 2006. Commission Regulation (EC) No 1881/2006 setting maximum levels for certain contaminants in foodstuffs. Official Journal of the EU, L364/5.

European Commission regulation (EC). 2008a. Regulation (EC) No 889/2008 laying down detailed rules for the implementation of Council Regulation (EC) No 834/2007 inorganic production and labelling of organic products with regard to organic production, labelling and control. Official Journal of the EU, L250/1.

European Commission regulation (EC). 2008b. Regulation (EC) No 1333/2008 on food additives. Official Journal of the EU, L354/16.

European Commission regulation (EC). 2009. Commission Regulation (EC) No 124/2009 setting maximum levels for the presence of coccidiostats or histomonostats in food resulting from the unavoidable carry-over of these substances in non-target feed. Official Journal of the EU L40/7.

European Commission regulation (EC). 2010. Commission Regulation (EC) No 37/2010 on pharmacologically active substances and their classification regarding maximum residue limits in foodstuffs of animal origin. Official Journal of the EU, L15/1.

European Commission regulation (EC). 2011. Commission Regulation (EC) No. 1259/2011 of 2 December 2011 amending Regulation (EC) No 1881/2006 as regards maximum levels for dioxins, dioxin-like PCBs and non-dioxin-like PCBs in foodstuffs. Official Journal of the EU, L320/3.

European Commission regulation (EC). 2014. Commission Regulation (EU) No 488/2014 of 12 May 2014 amending Regulation (EC) No 1881/2006 as regards maximum levels of cadmium in foodstuffs. Official Journal of the EU, L138/75.

European Egg Processors Association (EEPA). 2011. Guide good manufacturing practice for "Liquid, concentrated, frozen and dried egg products" used as food ingredients. www.eepa.info retrieved on 13-01-2015.

EFSA Feedap. 2004. Opinion of the Scientific Panel on Additives and Products or Substances used in Animal Feed on a request from the Commission on the safety and the efficacy of product "BIOCOX 120G" as feed additive in accordance with Council Directive 70/524/EEC.

EFSA Feedap. 2010. Scientific opinion on the safety and efficacy of Koffogran (nicarbazin) as a feed additive for chickens for fattening. EFSA Journal 2010; 8(3):1551 http://www.efsa.europa.eu/sites/default/files/scientific_output/files/main_documents/1551.pdf

European Food Safety Authority (EFSA). 2005. Opinion of the Scientific Panel on Animal Health and Welfare on a request from the Commission related to the welfare aspects of various systems of keeping laying hens. The EFSA Journal, 197:1-23. 
European Food Safety Authority (EFSA). 2008. Perfluorooctane sulfonate (PFOS), perfluorooctanoic acid (PFOA) and their salts. Scientific Opinion of the Panel on Contaminants in the Food chain. The EFSA Journal (2008) 653, 1-131.

European Food Safety Authority (EFSA). 2009a. Potential risks for public health due to the presence of nicotine in wild Mushrooms. The EFSA Journal, RN-286, 1-47.

http://www.efsa.europa.eu/sites/default/files/scientific_output/files/main_documents/286r.pdf

European Food Safety Authority (EFSA). 2009b. Scientific Opinion of the Panel on Contaminants in the Food Chain (Cadmium). The EFSA Journal, 980: 1-139.

European Food Safety Authority (EFSA). 2009c. Review of mycotoxins-detoxifying agents used as feed additives: mode of action, efficacy and feed/food safety. CFP/EFSA/FEEDAP/2009/01.

European Food Safety Authority (EFSA). 2010. Scientific Opinion on Melamine in Food and Feed. EFSA Journal 2010; 8(4):1573. http://www.efsa.europa.eu/sites/default/files/scientific_output/files/main_documents/1573.pdf

European Food Safety Authority (EFSA). 2011a. Setting of temporary MRLs for nicotine in tea, herbal infusions, spices, rose hips and fresh herbs. The EFSA Journal, 9(3), 2098. http://www.efsa.europa.eu/sites/default/files/scientific_output/files/main_documents/2098.pdf

European Food Safety Authority (EFSA). 2011b. Scientific Opinion on Polybrominated Diphenyl Ethers (PBDEs) in Food1. EFSA Panel on contaminants in the Food Chain (CONTAM). The EFSA Journal, $9(5): 2156$.

European Food Safety Authority (EFSA). 2012a. Update of the monitoring of levels of dioxins and PCBs in food and feed. The EFSA Journal, 10(7):2832.

European Food Safety Authority (EFSA). 2012b. Cadmium dietary exposure in the European population. The EFSA Journal, 10 (1):2551.

European Food Safety Authority (EFSA). 2012c. Lead dietary exposure in the European population. The EFSA Journal, 10 (7):2831.

European Food Safety Authority (EFSA). 2012d. Cadmium dietary exposure in the European population. The EFSA Journal, 10 (1):2551.

European Food Safety Authority (EFSA). 2012e. Scientific Opinion on the risk for public health related to the presence of mercury and methylmercury in food. The EFSA Journal, 10(12):2985.

European Food Safety Authority (EFSA). 2012f. Perfluoroalkylated substances in food: occurrence and dietary exposure. The EFSA Journal 2012; 10(6):2743. [55 pp.] doi:10.2903/j.efsa.2012.2743.

European Food Safety Authority (EFSA). 2014a. The 2011 European Union Report on Pesticide Residues in Food. The EFSA Journal, 12(5):3694-511.

European Food Safety Authority (EFSA). 2014b. Dietary exposure to inorganic arsenic in the European population. The EFSA Journal, 12(3):3597.

EFSA CONTAM. 2005. Opinion of the Scientific Panel on Contaminants in the Food Chain on a Request from the Commission related to the Presence of Non Dioxin-like Polychlorinated Biphenyls (PCB) in Feed and Feed. The EFSA journal, 281, 1-137.

http://www.efsa.europa.eu/sites/default/files/scientific_output/files/main_documents/284.pdf

EFSA CONTAM. 2007. Cross-contamination of non-target feedingstuffs by narasin authorized for use as a feed additive. The EFSA journal, 552, 1-35.

http://www.efsa.europa.eu/sites/default/files/scientific_output/files/main_documents/CONTAM_ej 552_narasin_en\%2C3.pdf

EFSA CONTAM. 2008. Cross-contamination of non-target feedingstuffs by nicarbazin authorized for use as a feed additive. Scientific opinion of the Panel on Contaminants in the Food Chain. The EFSA Journal, 690, 1-34.

http://www.efsa.europa.eu/sites/default/files/scientific_output/files/main_documents/contam_op_ ej690_nicarbazin_en\%2C3.pdf

EFSA CONTAM. 2009. Scientific Opinion on Arsenic in Food. EFSA Journal 2009;7(10):1351, 199 pp. doi:10.2903/j.efsa.2009.1351. The EFSA Journal 2012;10(12):2985 http://www.efsa.europa.eu/sites/default/files/scientific_output/files/main_documents/2985.pdf

EFSA CONTAM. 2015. Scientific Opinion on nitrofurans and their metabolites in food. EFSA Panel on Contaminants in the Food Chain (CONTAM). The EFSA Journal 2015;13(6):4140 http://www.efsa.europa.eu/sites/default/files/scientific_output/files/main_documents/4140.pdf

EMA. 1995. Committee for Veterinary Medicinal Products, Difloxacin, Summary Report EMEA/MRL/029/95-Rev5. 
http://www.ema.europa.eu/docs/en_GB/document_library/Maximum_Residue_Limits_-

_Report/2009/11/WC500013811.pdf

EMA. 1996. Committee for Veterinary Medicinal Products, Doxyxycline Hyclate Summary Report (1)

EMEA/MRL/101/96-FINAL.

http://www.ema.europa.eu/docs/en_GB/document_library/Maximum_Residue_Limits_-

_Report/2009/11/WC500013940.pdf

EMA. 1997. Tylosin: Summary Report (3) - Committee for Veterinary Medicinal Products

EMEA/MRL/205/97-FINAL.

http://www.ema.europa.eu/ema/index.jsp?curl=pages/includes/document/document_detail.jsp?w ebContentId=WC500015764\&mid=WC0b01ac058008d7ad

EMA. 1998a. Committee for Veterinary Medicinal Products, Enrofloxacin (modification for bovine, porcine and poultry, Summary Report (2).

http://www.ema.europa.eu/ema/index.jsp?curl=pages/includes/document/document_detail.jsp?w ebContentId $=$ WC500014142\&mid $=$ WCOb01ac058008d7ad

EMA. 2000a. Erythromycin, Erythromycin thiocyante, Erythromycin stearate: Summary report (1) Committee for Veterinary Medicinal Products.

http://www.ema.europa.eu/ema/index.jsp?curl=pages/includes/document/document_detail.jsp?w ebContentId $=$ WC500014182\&mid $=$ WCOb01ac058008d7ad

EMA. 2000b. Erythromycin: Summary report (2) - Committee for Veterinary Medicinal Products EMEA/MRL/720/99-FINAL.

http://www.ema.europa.eu/ema/index.jsp?curl=pages/includes/document/document_detail.jsp?w ebContentId=WC500014184\&mid=WC0b01ac058008d7ad

EMA. 2000c. Tylosin (extension to eggs): Summary Report (4) - Committee for Veterinary Medicinal Products EMEA/MRL/732/00-FINAL.

http://www.ema.europa.eu/ema/index.jsp?curl=pages/includes/document/document_detail.jsp?w ebContentId =WC500015766\&mid =WC0b01ac058008d7ad

EMA. 2002a. Committee for Veterinary Medicinal Products, Enrofloxacin (extension to all food producing species) Summary Report (5) EMEA/MRL/820/02-final.

http://www.ema.europa.eu/docs/en_GB/document_library/Maximum_Residue_Limits__Report/2009/11/WC500014151.pdf

EMA, 2002b. Committee for Veterinary Medicinal Products, Difloxacin, extension to all food producing species, Summary report (5) EMEA/MRL/819/02-FINAL.

http://www.ema.europa.eu/docs/en_GB/document_library/Maximum_Residue_Limits_-

_Report/2009/11/WC500013849.pdf

EMA. 2002c. Committee for Veterinary Medicinal Products, Tilmicosin, Extension to all food producing species, Summary Report (7) EMEA/MRL/827/02-FINAL.

http://www.ema.europa.eu/docs/en_GB/document_library/Maximum_Residue_Limits_-

_Report/2009/11/WC500015599.pdf

EMA. 2011. Committee for Medicinal Products for Veterinary Use (CVMP), Reflection paper on the use of macrolides, lincosamides and streptogramins (MLS) in food-producing animals in the European Union: development of resistance and impact on human and animal health. EMA/CVMP/SAGAM/741087/2009.

http://www.ema.europa.eu/docs/en_GB/document_library/Scientific_guideline/2011/11/WC50011 8230.pdf

EPMAR Doxycycline. 23 February 2015. European Public MRL Assessment Report Doxycycline (all food producing species). EMA/CVMP/347870/2014.

http://www.ema.europa.eu/docs/en_GB/document_library/Maximum_Residue_Limits__Report/2015/02/WC500183123.pdf

EPMAR Lasalocid. 10 February 2015.

European public MRL assessment report (EPMAR) Lasalocid (modification of the ADI and MRLs in poultry). EMA/CVMP/769137/2014.

http://www.ema.europa.eu/docs/en_GB/document_library/Maximum_Residue_Limits__Report/2015/02/WC500182165.pdf

FAO. 1998. Tilmicosin - Addendum to the monographs prepared by the 47 th meeting of the Committee and published in the FAO Food and Nutrition Paper 41/9. $\mathrm{ftp}$ ://ftp.fao.org/ag/agn/jecfa/vetdrug/6-2009-tilmicosin.pdf 
FSIS. 2015b. FSIS Directive 7120.1 Safe and Suitable Ingredients used in the Production of Meat, Poultry and Egg Products. Available at: http://www.fsis.usda.gov/wps/wcm/connect/bab10e09aefa-483b-8be8-809a1f051d4c/7120.1.pdf?MOD=AJPERES.

Furusawa, N. 2001. Transference of dietary veterinary drugs into eggs. Veterinary Research Communications, 25(8), 651-662.

Furusawa, N. 2002. Transferring and distributing profiles of $p, p^{\prime}-(D D T)$ in egg-forming tissues and eggs of laying hens following a single oral administration. J Vet Med Ser A, 49, pp. 334-336.

FVO. 2010a. Final report of a mission carried out in the United States from 18-29 October 2010 In order to evaluate the control of residues and contaminants in live animals and animal products, including controls on veterinary medicinal products.

http://ec.europa.eu/food/fvo/audit_reports/details.cfm?rep_id=2891

FVO. 2010b. Final report of a mission carried out in Ukraine from 12-22 October 2010 in order to evaluate the control of residues and contaminants in live animals and animal products, including controls on veterinary medicinal products. http://ec.europa.eu/food/fvo/act_getPDF.cfm?PDF_ID $=8825$

FVO. 2011a. Final report of an audit carried out in Argentina from 13 to 23 September 2011 in order to evaluate the monitoring of residues and contaminants in live animals and animal products, including controls on veterinary medicinal products. http://ec.europa.eu/food/fvo/act_getPDF.cfm?PDF_ID $=9355$

FVO. 2011b. Final report of an audit carried out in Ukraine from 15 to 24 November 2011 in order to evaluate the implementation of requirements for feed additives and premixtures. http://ec.europa.eu/food/fvo/act_getPDF.cfm?PDF_ID $=9500$

FVO. 2014. Final report of a mission carried out in India from 03 to 14 March 2014 In order to evaluate the control of residues and contaminants $n$ live animals and animal products, including controls on veterinary medicinal products.

http://ec.europa.eu/food/fvo/audit_reports/details.cfm?rep_id=3325

FVO. 2015. Final report of an audit carried out in India from 27 January to 06 February 20115 in order to evaluate the control systems in place governing the production if egg products intended for export to the European Union. http://ec.europa.eu/food/fvo/audit_reports/details.cfm?rep_id=3450

Gajda, A., Posyniak,A. 2015. Doxycycline depletion and residues in eggs after oral administration to laying hens, Food Additives \& Contaminants: Part A, 32:7, 1116-1123.

Gallo, A., Bertuzzi, T., Battaglia, M., Masoero, F., Piva, G., Moschini, M. 2012. Melamine in eggs, plasma and tissues of hens fed contaminated diets. Animal, 6(7), 1163-1169.

Goetting, V., Lee, K.A., Tell, L.A. 2011. Pharmacokinetics of veterinary drugs in laying hens and residues in eggs: a review of the literature. J. of Vet. Pharma. and Thera., 34 (6), 521-556.

Gossner, C.M-E., Schlundt, J., Embarek, P.B., Hird, S., Lo-Fo-Wong, D., Beltran, J.J.O., Teoh, K.N., Tritscher, A. 2009. The Melamine Incident: Implications for International Food and Feed Safety. World Health Organization. Environ Health Perspect 117:1803-1808.

Halldorsson, T.I., Fei, C., Olsen, J., Lipworth, L., McLaughlin, J. ., Olsen, S. . 2008. Dietary Predictors of Perfluorinated Chemicals: A Study from the Danish National Birth Cohort. Environmental Science \& Technology 42(23), 8971-8977.

Hänninen, O., Knol, A.B., Jantunen, M., Lim, T.-A., Conrad, A., Rappolder, M., Carrer, P., Fanetti, A.-C., Kim, R., Buekers, J., Torfs, R., Iavarone, I., Classen, T., Hornberg, C., Mekel, O.C.L. The EBoDE Working Group, 2014. Environmental Burden of Disease in Europe: Assessing Nine Risk Factors in Six Countries. Environ Health Perspect 122, 439-446.

Hamscher, G., Limsuwan, S., Tansakul, N. \& Kietzmann, M. 2006. Quantitative analysis of tylosin in eggs by high performance liquid chromatography with electrospray ionization tandem mass spectrometry: residue depletion kinetics after administration via feed and drinking water in laying hens. Journal of Agricultural and Food Chemistry, 54, 9017-9023.

Harnly, M.E., Petreas, M.X., Flattery, J., Goldman, L.R. 2000. Polychlorinated dibenzo-p-dioxin and polychlorinated dibenzofuran contamination in soil and home-produced chicken eggs near pentachlorophenol sources. Environmental Science and Technology, 34:1143-1149.

Hermansen, J.E. 2015. Improved Contribution of Local Feed to support 100\% Organic Feed Supply to Pigs and Poultry - Overall assessment report. Aarhus University, Denmark, 6 p. 
Hoogenboom, L.A., Kan, C.A., Zeilmaker, M.J., Van Eijkeren, J., Traag, W.A. 2006. Carry-over of dioxins and PCBs from feed and soil to eggs at low contamination levels-- influence of mycotoxin binders on the carry-over from feed to eggs. Food Additives \& Contaminants: Part A, 23(5): 518-27.

Hoogenboom, R.L.A.P., ten Dam, G., van Bruggen, M., Jeurissen, S.M.F., van Leeuwen, S.P.J., Theelen, R.M.C., \& Zeilmaker, M.J. 2016. Polychlorinated dibenzo-p-dioxins and dibenzofurans (PCDD/Fs) and biphenyls (PCBs) in home-produced eggs. Chemosphere, 150, 311-319.

Hooper, J. 2002. Organic farms in scandal of illegal herbicide. The Guardian (Tuesday 28 May 2002). Hoste, R. 2014. Sojaverbruik in de Nederlandse diervoederindustrie 2011-2013. Report no. 14-098. LEI Wageningen UR: Wageningen, The Netherlands. 26 p.

JECFA. 1998. Monograph Nicarbazin in Toxicological Evaluation of Certain Residues in Food Prepared by the 50th meeting of the Joint FAO/WHO Expert Committee on Food Additives (JECFA) WHO Food Additives Series 41. http://www.inchem.org/documents/jecfa/jecmono/v041je10.htm.

JECFA. 2006. Evaluation of Certain Veterinary Drug Residues in Food; Sixty-sixth report of the Joint FAO/WHO Expert Committee on Food Additives WHO Technical Report Series 939. Available at: http://apps.who.int/iris/bitstream/10665/43464/1/9241209399_eng.pdf.

JECFA. 2011. Evaluation of certain contaminants in food: seventy-second report of the Joint FAO/WHO Expert Committee on Food Additives. WHO technical report series no. 959.

JECFA. 2002. Fifty-seventh meeting of the Joint FAO/WHO Expert Committee on Food Additives. Geneva, Switzerland.

Kan, C.A. 2003. Residues of veterinary drugs in eggs and possible explanations for their distribution between egg white and yolk. Dissertation, Bergische Universität Wuppertal, Germany.

Kan, C.A., Meijer, G.A.L. 2007. The risk of contamination of food with toxic substances present in animal feed. Animal Feed Science and Technology, 133(1-2): 84-108.

Kennedy, D.G., Blanchflower, W.J., Hughes, P.J., McCaughey, W.J. 1996. The incidence and cause of lasalocid residues in eggs in Northern Ireland. Food Additives and Contaminants, 13, 787-794.

Kennedy, D.G., Hughes, P.J. and Blanchflower, W.J. 1998. Ionophore residues in eggs in Northern Ireland: incidence and cause. Food Additives and Contaminants, 15, 535-41.

Kijlstra, A. 2004. The role of organic and free poultry production systems on the dioxin levels in eggs. Proceedings of the 3rd SAFO Workshop, 16-18 September 2004, Falenty. University of Reading, Reading, pp. 83-90.

Kijlstra, A., Traag, W.A., Hoogenboom, L.A.P. 2007. Effect of flock size on dioxin levels in eggs from chickens kept outside. Poultry Science, 86:2042-2048.

Leenstra, F., Maurer, V., Galea, F., Bestman, M., Amsler-Kepalaite, Z., Visscher, J., Vermeij, I., van Krimpen, M. 2014. Laying hen performance in different production systems; why do they differ and how to close the gap? Results of discussions with groups of farmers in The Netherlands, Switzerland and France, benchmarking and model calculations. Europ. Poult.Sci. 78. ISSN 1612-9199.

Legkippenbesluit. 2004. Besluit van 27 mei 2003, houdende regels voor de huisvestiging en verzorging van legkippen. Staatsblad, 40, 1-20.

LEI/CBS Landbouwtelling 2014.

Lolo, M., Pedreira, S., Fente, C., Vazquez, B.I., Franco, C.M., Cepeda, A. 2005. Study of enrofloxacin depletion in the eggs of laying hens using diphasic dialysis extraction / purification and determinative HPLC-MS analysis. Journal of Agricultural and Food Chemistry, 53, 2849-2852.

Lopez, P., de Rijk, T., Sprong, R.C., Mengelers, M.J.B., Castenmiller, J.J.M., Alewijn, M. 2016. A mycotoxin-dedicated total diet study in the Netherlands in 2013: Part II - occurrence. World Mycotoxin Journal, 9(1), 89-108.

Lorenz, N., Fry, H., Deventer, A., Dinse, D., Lochotzke, H.-M., Hiller, A., Mietle, K., Preiss-Weigert, A., Schafft, H., Lahrssen-Wiederholt, M. (2014). Transfer of Melamine from Fodder into the Egg of the Laying Hen. Journal Fur Verbraucherschutz Und Lebensmittelsicherheit-Journal of Consumer Protection and Food Safety, 9(4), 345-357.

Magnuson, B., Munro, I., Abbot, P., Baldwin, N., Lopez-Garcia, R., Ly, K., McGirr, L., Roberts, A., Socolovsky, S. 2013. Review of the regulation and safety assessment of food substances in various countries and jurisdictions. Food Additives \& Contaminants: Part A, 30(7), 1147-1220.

McCracken, R.J., Spence, D.E., Floyd, S.D., Kennedy, D.G. 2001. Evaluation of the residues of furazolidone and its metabolite, 3-amino-2-oxazolidinone (AOZ), in eggs. Food Additives and Contaminants, 18, 954-959. 
McCracken, R.J., Kennedy, D.G. 2007. Detection, accumulation and distribution of nitrofuran residues in egg yolk, albumen and shell, Food Additives \& Contaminants, 24:1, 26-33,

MacLachlan, D.J. 2011. Estimating the transfer of contaminants in animal feedstuffs to livestock tissues, milk and eggs: a review. Animal Production Science, 51 (12): 1067-1078

Mortier, L., Huet, A.C., Daeseleire, E., Huyghebaert, G., Fodey, T., Elliott, C., Delahaut, P., Van Peteghem, C. 2005. Deposition and depletion of five anticoccidials in eggs. Journal of Agricultural and Food Chemistry, 53, 7142-7149.

Noorlander, C.W., van Leeuwen, S.P.J., te Biesebeek, J.D., Mengelers, M.J.B., Zeilmaker, M.J. 2011. Levels of Perfluorinated Compounds in Food and Dietary Intake of PFOS and PFOA in The Netherlands. J. Agric. Food Chem. 59, 7496-7505.

Novak, P., Suchy, P., Strakova, E., Vlcakova, M., Germuska, R. 2012. The assessment of melamine and cyanuric acid residues in eggs from laying hens exposed to contaminated feed. Acta Veterinaria Brno, 81(2), 163-167.

Pettersson, H. 2012. Mycotoxin contamination of animal feed. In: Fink-Gremmels, J. (ed). Animal feed contamination - Effects on livestock and food safety. Woodhead Publishing Limited: Oxford, UK, 233-285.

Pirard, C., Eppe, G., Massart, A., Fierens, S., De Pauw, E., Focant, J. 2005. Environmental and human impact of an old-timer incinerator in terms of dioxin and PCB level: A case study. Environmental Science and Technology, 39:4721-4728.

Productschap Pluimvee en Eieren (PPE). 2013. Vee Vlees en Eieren in Nederland: Kengetallen 2012.

United States Department of Agriculture (USDA). 1997. Meat and poultry products hazards and control guide. Food Safety Inspection Services, HACCP-2.

Productschappen Vee, Vlees en Eieren (PVE). 2008. Toekomstvisie Pluimveehouderij 2015-2020.

Rawn, D.F.K., Sadler, A., Quade, S.C., Sun, W.-F., Lau, B.P.-Y., Kosarac, I., Hayward, S., Ryan, J.J. 2011. Brominated flame retardants in Canadian chicken egg Yolks. Food Additives and Contaminants, part A, 28(6): 807-815.

Front Office Food And Consumer Product Safety. 2015. Intake of methylmercury in children aged 2 to 15 in the Netherlands. Front Office Food And Consumer Product Safety, National Institute for Public Health and the Environment (RIVM), RIKILT Wageningen UR, Bilthoven, Wageningen.

Rokka, M., Eerola, S., Perttilä, U., Rossow, L., Venäläinen, E., Valkonen, E., Valaja, J., Peltonen, K. 2005. The residue levels of narasin in eggs of laying hens fed with unmedicated and medicated feed. Mol Nutr Food Res 49: 38-42.

Schoeters, G., Hoogenboom, R. 2006. Contamination of freerange chicken eggs with dioxins and dioxin-like polychlorinated biphenyls. Mol. Nutr. Food Res. 50:908-914.

SCF, 2011. Opinion of the Scientific Committee on Food in the risk assessment of dioxins and dioxinlike PCBs in food European Commission, Brussels, Belgium, 29 p.

SCOOP report of experts participating in Task 3.2.11. 2004. Assessment of the dietary exposure to arsenic, cadmium, lead and mercury of the population of the EU Member States. DirectorateGeneral Health and Consumer Protection.

Speijers, G.J.A., van Egmond, H.P. 1999. Natural Toxins III. Inherent Plant Toxins. In: Van der Heijden, K., Younes, M., Fishbein, L. and Miller, S. (eds.). International Food Safety handbook. Marcel Dekker, Inc: New York, USA. 369-380.

Sprong, R.C., Boon, P.E. 2015. Dietary exposure to cadmium in the Netherlands. RIVM Letter report 2015-0085. National Institute for Public Health and the Environment (RIVM), Bilthoven. Available online: www.rivm.nl

Sprong, R.C., de Wit-Bos, L., te Biesebeek, J.D., Alewijn, M., Lopez, P., Mengelers, M.J.B. 2016. A mycotoxin-dedicated total diet study in the Netherlands in 2013: Part III - exposure and risk assessment. World Mycotoxin Journal, 9(1), 109-128.

Sypecka, Z., Kelly, M., Brereton, P. 2004. Deoxynivalenol and zearalenone residues in eggs of laying hens fed with a naturally contaminated diet: effects on egg production and estimation of transmission rates from feed to eggs. J. Agric. Food Chem. 52(17):5463-5471.

Tahvonen, R., Kumpulainen, J. 1995. Lead and cadmium contents in milk, cheese and eggs on the Finnish market. Food Additives and Contaminants, part A, 12(6):789-98.

Tangni, E.K., Waegeneers, N., Van Overmeire, I., Goeyens, L., Pussemier, L. 2009. Mycotoxin analyses in some home produced eggs in Belgium reveal small contribution to the total daily intake. Sci. of The Tot. Environ. 407(15):4411-4418. 
Traag, W.A., Portier, L., Bovee, T.F.H., Van der Weg, G., Onstenk, C., Elghouch, N., Coors, R., Van de Kraats, C., Hoogenboom, L.A.P. 2002. Residues of dioxins and coplanar PCBs in eggs of free range chickens. Organohalogen Compounds 57:245-248.

Traag, W.A., de Rijk, T.C., Zomer, P., Vos Van Avezathe, A., Kan, C.A., Zeilmaker, M., Hoogenboom, L.A.P. 2005. Opname van Nicotine door kippen en overdracht naar eieren bij toepassing van Nicotine tegen bloedluis. Report No. 2005.013. RIKILT: Wageningen, The Netherlands. 20 p.

Traag, W.A., Kotz, A., Van der Weg, G., Malisch, R., and R. Hoogenboom. 2009. Bioassay directed detection of brominated dioxins in the feed additive choline chloride. Organohal. Comp. 71: 2210-2213.

Tuffs, A. 2002. Organic meat products contaminated with carcinogenic herbicide. The British Medical Journal, 324(1416), 15 June 2002.

USDA, 2015. Additives in Meat and Poultry Products. Available at: http://www.fsis.usda.gov/wps/portal/fsis/topics/food-safety-education/get-answers/food-safetyfact-sheets/food-labeling/additives-in-meat-and-poultry-products/additives-in-meat-and-poultryproducts

US EPA, 2012. EPA's reanalysis of key issues related to dioxin toxicity and responses to NAS comments. U.S. Environmental Protection Agency, Washington DC, USA, 344 p.

Vandenberge, V., Delezie, E., Huyghebaert, G., Delahaut, P., De Backer, P., Daeseleire, E., Croubels, S. 2012a. Residues of sulfadiazine and doxycycline in egg matrices due to cross-contamination in the feed of laying hens and the possible correlation with physicochemical, pharmacokinetic and physiological parameters, Food Additives \& Contaminants: Part A, 29:6, 908-917.

Vandenberge, V., Delezie, E., Huyghebaert, G., Delahaut, P., Pierret, G., De Backer, P., Croubels, S., Daeseleire, E. 2012b. Transfer of the coccidiostats monensin and lasalocid from feed at crosscontamination levels to whole egg, egg white and egg yolk, Food Additives \& Contaminants: Part A, 29:12, 1881-1892.

van Horne, P.L.M. 2012. Concurrentiekracht van de Nederlandse eiersector. LEI-rapport 2012-079.

van Horne, P.L.M. 2014. Competitiveness in the EU egg sector. LEI-rapport 2014-041.

van Kreijl, C.F., Knaap, A.G.A.C. 2004. Ons eten gemeten - gezonde voeding en veilig voedsel in Nederland. National Institute for Public Health and the Environment (RIVM), Bilthoven, the Netherlands, $364 \mathrm{p}$.

van Krimpen, M.M., Kwakkel, R.P., Reuvekamp, B.F.J., van Der Peet-Schwering, C.M.C., Den Hartog, L.A., Verstegen, M.W.A. 2005. Impact of feeding management on feather pecking in laying hens. World's Poul. Sci. J. 61: 663-686.

van Overmeire, I., Pussemier, L., Hanot, V., de Temmerman, L., Hoenig, M., Goeyens, L. 2006. Chemical contamination of free-range eggs from Belgium. Food Addit. Contam. 23:1109-1122.

Waegeneers, N., Hoenig, M., Goeyens, L., De Temmerman, L. 2009. Trace elements in homeproduced eggs in Belgium: Levels and spatiotemporal distribution. Sc. Tot. Env. 407: 4397-4402.

Wageningen UR, 2015. Feedprint: Calculate CO2 per kilogram meat, milk or eggs. Available at: //http://www.wageningenur.nl/en/show/FeedPrint-Calculate-CO2-per-kilogram-meat-melk-oreggs.htm, accessed 21 August 2015.

WHO. 2012a. Arsenic. Fact sheet N³72. Rretrieved on 27-01-2015 from http://www.who.int/mediacentre/factsheets/fs372/en/

WHO. 2012b. Prevention and Reduction of Food and Feed contamination first edition. ISSN 0259-2916.

WHO. 2014. Dioxins and their effects on human health. Fact sheet $N^{\circ} 225$. Accessed from http://www.who.int/mediacentre/factsheets/fs225/en/ on 21-01-2015.

Windal, I., Hanota, V., Marchia, J., Huysmansa, G., Van Overmeirea, I., Waegeneers, N., Goeyensa, L. 2009. PCB and organochlorine pesticides in home-produced eggs in Belgium. Sc. Tot. Env. 407: $4430-4437$.

Yoshimura, H., Osawa, N., Rasa, F.S.C., Hermawati, D., Werdiningsih, S., Isriyanthi, N.M.R., Sugimori, T. 1991. Residues of doxycycline and oxytetracycline in eggs after medication via drinking water to laying hens. Food Additives and Contaminants, 8, 65-69.

Zafeiraki, E., Costopoulou, D., Vassiliadou, I., Leondiadis, L., Dassenakis, E., Hoogenboom, L.A.P., van Leeuwen, S.P.J. 2016. Perfluoroalkylated substances (PFASs) in home and commercially produced chicken eggs from the Netherlands and Greece. Chemosphere 144, 2106-2112.

Zeilmaker, M., Bokkers, B.G.H., Mengelers, M.J.B. In preparation. Health impact assessment of dioxin toxicity: A global perspective. 


\section{Annex 1}

Table 1.1 RASFF reports within the egg and egg products product category between 01/01/2002 and $31 / 12 / 2014$.

\begin{tabular}{lll} 
Category & Number of reports & Percentage \\
\cline { 2 - 3 } Total & Frequency & 100 \\
\hline & & 185 \\
\hline Notification type & & 43 \\
\hline Alert & 80 & 40 \\
\hline Border rejection & 74 & 4 \\
\hline Information & 8 & 8 \\
\hline Information for attention & 15 & 8 \\
\hline Information for follow-up & 8 & 4 \\
\hline
\end{tabular}

\begin{tabular}{|c|c|c|}
\hline \multicolumn{3}{|l|}{ Hazard categories } \\
\hline Pathogenic micro-organisms & 87 & 47 \\
\hline Veterinary drugs & $22^{(1)}+21^{(2)}$ & $12+11$ \\
\hline Adulteration/Fraud & 15 & 8 \\
\hline Labelling absent/incomplete/incorrect & 7 & 4 \\
\hline Poor or insufficient controls & 2 & 1 \\
\hline Organoleptic aspects & 2 & 1 \\
\hline Non-pathogenic micro-organisms & 2 & 1 \\
\hline Foreign bodies (e.g., physical hazards like glass) & 1 & 1 \\
\hline Allergens & 0 & 0 \\
\hline Packaging defective/incorrect & 0 & 0 \\
\hline Heavy metals & 0 & 0 \\
\hline Biotoxins (other) & 0 & 0 \\
\hline Biocontaminants & 0 & 0 \\
\hline Chemical contamination (other) & 0 & 0 \\
\hline GMO/novel food & 0 & 0 \\
\hline Migration & 0 & 0 \\
\hline Mycotoxins & 0 & 0 \\
\hline
\end{tabular}

1) In RASFF, the hazard category is Feed additives.

2) In RASFF, the hazard category is Residues of Veterinary Medicinal Products (VMPs). 
RIKILT Wageningen University \& Research P.O. Box 230

6700 AE Wageningen

The Netherlands

$\mathrm{T}+31(0) 317480256$

www.wur.eu/rikilt

RIKILT report 2016.005
The mission of Wageningen University and Research is "To explore the potential of nature to improve the quality of life". Under the banner Wageningen University \& Research, Wageningen University and the specialised research institutes of the Wageningen Research Foundation have joined forces in contributing to finding solutions to important questions in the domain of healthy food and living environment. With its roughly 30 branches, 5,000 employees and 10,000 students, Wageningen University \& Research is one of the leading organisations in its domain. The unique Wageningen approach lies in its integrated approach to issues and the collaboration between different disciplines. 



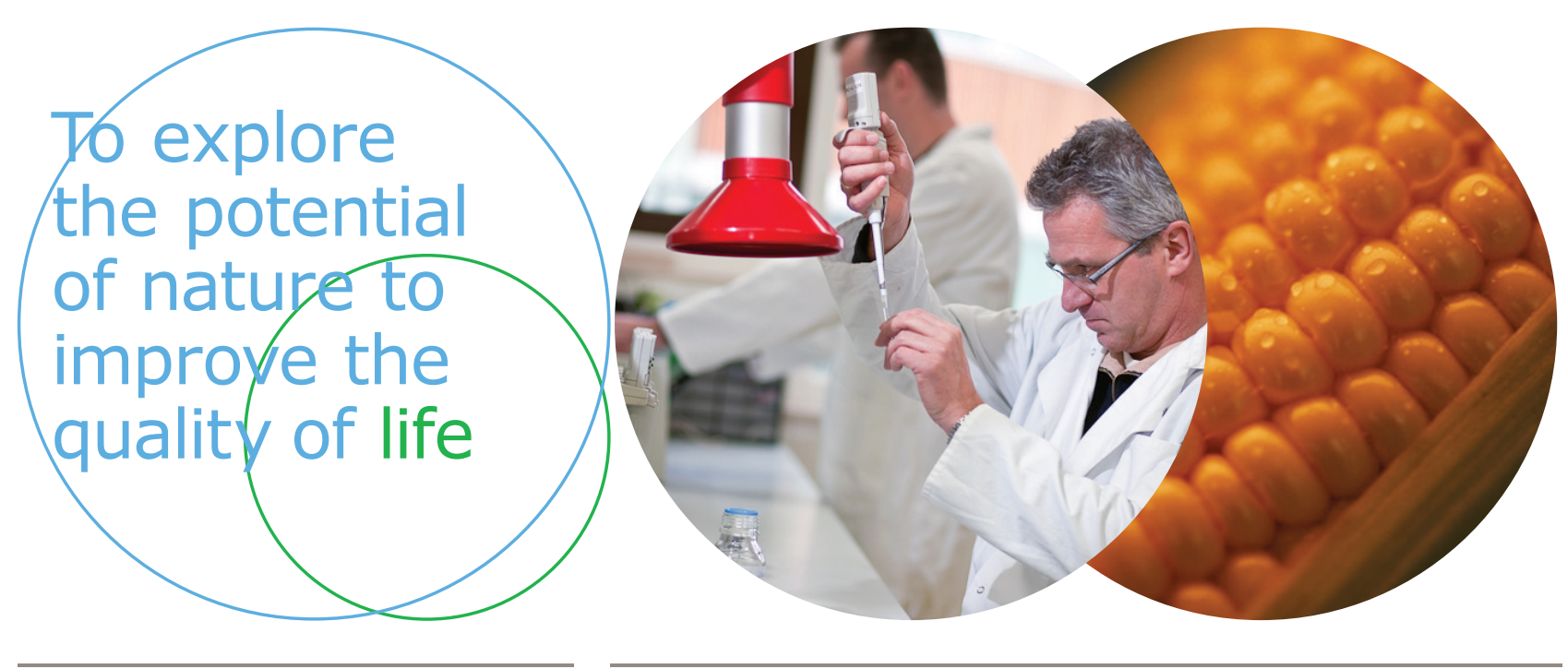

RIKILT Wageningen University \& Research P.O. Box 230

6700 AE Wageningen

The Netherlands

T +31 (0)317480256

www.wur.eu/rikilt

Report 2016.005
The mission of Wageningen University and Research is "To explore the potential of nature to improve the quality of life". Under the banner Wageningen University \& Research, Wageningen University and the specialised research institutes of the Wageningen Research Foundation have joined forces in contributing to inding solutions to important questions in the domain of healthy food and living environment. With its roughly 30 branches, 5,000 employees and 10,000 students, Wageningen University \& Research is one of the leading organisations in its domain. The unique Wageningen approach lies in its integrated approach to issues and the collaboration between different disciplines. 